\title{
Deep Eutectics and analogues as electrolytes in batteries
}

\author{
Maria Enrica Di Pietro, ${ }^{a *}$ and Andrea Mele ${ }^{a, b}$ \\ a Department of Chemistry, Materials and Chemical Engineering "G. Natta", Politecnico di Milano, Piazza L. \\ da Vinci 32, 20133 Milano, Italy. E-mail: mariaenrica.dipietro@polimi.it \\ ${ }^{b}$ CNR-SCITEC Istituto di Scienze e Tecnologie Chimiche, Via A. Corti 12, 20133 Milano, Italy.
}

\begin{abstract}
Deep eutectic Solvents (DESs) are an emerging class of materials showing a marked depression in melting points compared to those of the neat constituents and characterized by a number of beneficial properties. DES research currently prospers and out of the multiple current applications, the electrochemistry field is likely the most flourishing. This detailed review emphasizes recent research efforts in order to apply type III and type IV DESs and their analogues as electrolytes for rechargeable cationic batteries. The recent developments in the last decade are outlined, framing outstanding achievements and open questions, and identifying future optimisation directions to overcome the existing challenges.
\end{abstract}

\section{CONTENTS}

1. Introduction

2. Lithium batteries

2.1. Type IV DESs composed of lithium salts and HBDs

2.1.1. Lithium salts and amides

2.1.2. Lithium salts and sulfonamides or sulfones

2.1.3. Lithium salts and nitriles

2.1.4. Lithium salts and alcohols

2.1.5. Lithium salts and glymes

2.1.6. Lithium salts and ketoesters

2.2. Lithium salt-added type III DESS

3. Sodium and Potassium batteries

3.1. Type IV DESs composed of sodium/potassium salts and HBDs

4. Aluminium batteries

4.1. Type IV DESs composed of aluminium salt and HBDs

4.1.1. Aluminium ion batteries

4.1.2. Aluminium-air batteries

4.1.3. Aluminium sulfur batteries

4.1.4. Aluminium selenium batteries

5. Zinc batteries

5.1.Zinc salt-added type III DESS

5.2. Type IV DESs composed of zinc salts and HBDs

6. Outlook and future perspectives

7. Appendix

8. Declaration of competing interest

9. Acknowledgement

10. References 


\section{Keywords}

Energy storage systems, cationic shuttle, viscosity, conductivity, electrochemistry

\section{Graphical abstract}

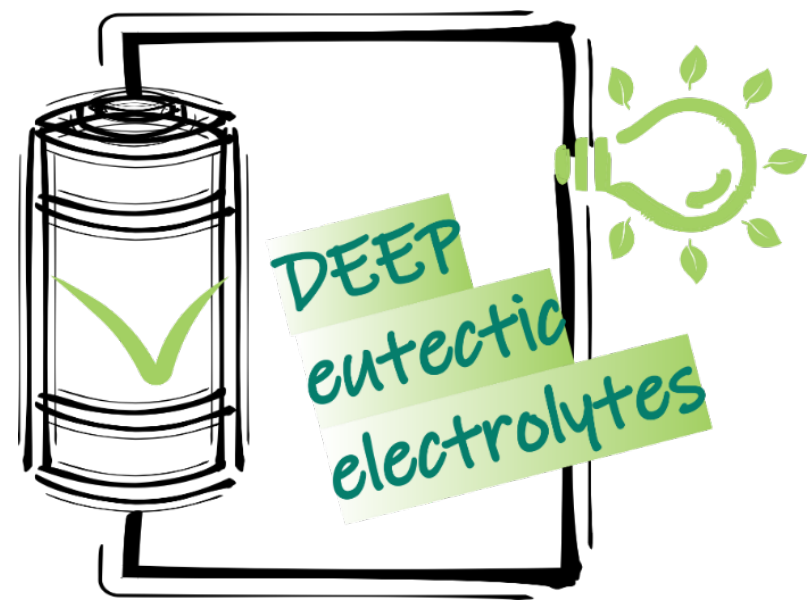




\section{Introduction}

Eutectic mixtures of salts have been known for a long time and used to decrease the temperature for molten salt applications. Eutectic mixtures of urea with alkali metal halide and other metal salts date back to the 50 ' $\mathrm{s}, 1,2$ but it is with the inaugural work identifying "reline", a mixture of choline chloride $(\mathrm{ChCl})$ and urea (U) in 2003 by Abbott and coworkers that the term "deep eutectic solvents" (DESs) appeared, ${ }^{3}$ and started arousing great interest in the scientific community. From then on, eutectic mixtures had a revival. The concept was soon extended from amides to a wide variety of other small molecules such as acids, amines and alcohols. ${ }^{4}$ A charge delocalization achieved through strong hydrogen bonding between the species of the mixture (Hydrogen Bond Acceptor HBA and Hydrogen Bond Donor HBD) is postulated as the root cause of the large melting point depressions and unusual physicochemical properties of these choline chloride-based mixtures. ${ }^{5}$ Particularly relevant are their exceptionally high solvent properties which are similar to ambient temperature Ionic Liquids (ILs), with a wide variety of solutes exhibiting high solubilities. ${ }^{3,4,6}$ Furthermore, the high conductivity of these materials was clear since their discovery, with values comparable to those for most imidazolium based ILs (in the range 0.1 to $10 \mathrm{mS} \mathrm{cm}^{-1}$ at $30^{\circ} \mathrm{C}$ ). ${ }^{3,4,7}$

Eutectics are mixtures of two components $A$ and $B$ at a given molar ratio, showing a melting point well below that of A and B. For a eutectic mixture to be labelled as "deep", a eutectic temperature much lower than that predicted by assuming a thermodynamic ideal behaviour of the liquid phase has to be observed as a result of stronger interactions between the DES precursors than those present in the pure compounds. ${ }^{8}$ From a quick look at the literature it is clear that there is an overgeneralization of the definition of DES, resulting in several misconceptions. As a result, an extremely high number of mixtures have been presented as DESs without any strict characterization of their phase behaviour. On the other hand, a number of works report on systems which correspond to the general formula of a DES but are referred to with a different name. A likely non-exhaustive list of terms - used sometimes for the same system - includes Deep Eutectic Solvents (DESs), ${ }^{5}$ Deep Eutectic Systems (DESs), ${ }^{9}$ Deep Eutectic Mixtures (DEMs), ${ }^{10}$ Deep Eutectics (DEs), ${ }^{11}$ Deep Eutectic Electrolytes (DEEs), ${ }^{12}$ Ionic Liquid Analogs (ILAs), ${ }^{13}$ quasi-ILs, ${ }^{14}$ eutectic-based ILs, ${ }^{15,16}$ Room Temperature Molten Salts (RTMSs), ${ }^{17}$ Low-Transition-Temperature Mixtures (LTTMs), ${ }^{18}$ Liquid Coordination Complexes (LCCS). ${ }^{19}$ Also, it occurs that the same system has been labelled in the literature as IL or DES according to the authors, and even the same authors did use different definitions (one for all the overlap between the classifications of eutectic based ILs, ${ }^{16}$ and DESs, ${ }^{20}$ by Abbott's group). DES literature also witnesses several subcategories, such as NAtural DESs (NADESs), ${ }^{21}$ Acidic DESs (ADESs), ${ }^{22}$ Brønsted Acidic DESs (BADESs), ${ }^{22}$ Lewis Acidic DESs (LADESs), ${ }^{22}$ and so forth. A debate about the strict definition of a DES or a proper classification is outside the scope of this review. Here we will adopt the term "Deep Eutectic Solvents" (DESs) as the catch-all term for this class of materials, and we discuss and compare all systems presented in the literature that comply with the classification adopted by Abbott et al., ${ }^{20}$ and reported in Table 1 . Under this notation, DESs are defined by the general formula $\mathrm{Cat}^{+} X^{-} \mathrm{Z} Y$, with $\mathrm{X}^{-}$a Lewis base and $Y$ a $B r ø n s t e d t$ base, and are classified in 4 categories.

It should be mentioned that a relatively new family of DESs, dubbed type $\mathrm{V}$, has been proposed as composed of only non-ionic, molecular HBAs and HBDs, ${ }^{23}$ and also other mixtures of Brønsted-Lowry acids and bases that do not exactly fit into this classifications show yet deep eutectic depressions. ${ }^{5}$ This review focuses primarily on type III and type IV DESs, which are the materials used in the overwhelming majority of the research of interest here (see Fig. 1 for a graphic summary of the components of the systems investigated here and the Appendix for a list of abbreviations). 
Table 1. The main types of DESs (adapted from Abbott et al. ${ }^{20}$ ). A list of abbreviation is provided in the Appendix.

\begin{tabular}{|c|c|c|c|}
\hline Type & General composition & Formula & Example \\
\hline 1 & Metal salt + organic salt & $\begin{array}{l}\text { Cat }^{+} X^{-} z M C l_{x} \\
M=Z n, S n, F e, A l, ~ G a, ~ I n\end{array}$ & $\mathrm{ZnCl}_{2}+\mathrm{ChCl}$ \\
\hline II & $\begin{array}{l}\text { Metal salt hydrate + } \\
\text { organic salt }\end{array}$ & $\begin{array}{l}\mathrm{Cat}^{+} \mathrm{X}^{-} \mathrm{zMCl} \mathrm{M}_{\mathrm{x}} \cdot \mathrm{yH}_{2} \mathrm{O} \\
\mathrm{M}=\mathrm{Cr}, \mathrm{Co}, \mathrm{Cu}, \mathrm{Ni}, \mathrm{Fe}\end{array}$ & $\mathrm{CoCl}_{2} \cdot 6 \mathrm{H}_{2} \mathrm{O}+\mathrm{ChCl}$ \\
\hline III & Organic salt + HDB & $\begin{array}{l}\operatorname{Cat}^{+} X^{-} z R Z \\
Z=\mathrm{CONH}_{2}, \mathrm{COOH}, \mathrm{OH}\end{array}$ & $\mathrm{ChCl}+\mathrm{U}$ \\
\hline IV & Metal salt (hydrate) + HBD & $\begin{array}{l}\mathrm{MCl}_{\mathrm{x}}+\mathrm{RZ}=\mathrm{MCl}_{\mathrm{x}-1}{ }^{+} \cdot \mathrm{RZ}+\mathrm{MCl}_{\mathrm{x}+1} \\
\mathrm{M}=\mathrm{Al}, \mathrm{Zn} \\
\mathrm{Z}=\mathrm{CONH}_{2}, \mathrm{OH}\end{array}$ & $\mathrm{ZnCl}_{2}+\mathrm{U}$ \\
\hline
\end{tabular}

$\mathrm{Cat}^{+}=$any ammonium, phosphonium, or sulfonium cation $\mathrm{X}^{-}=$Lewis base, generally a halide anion 


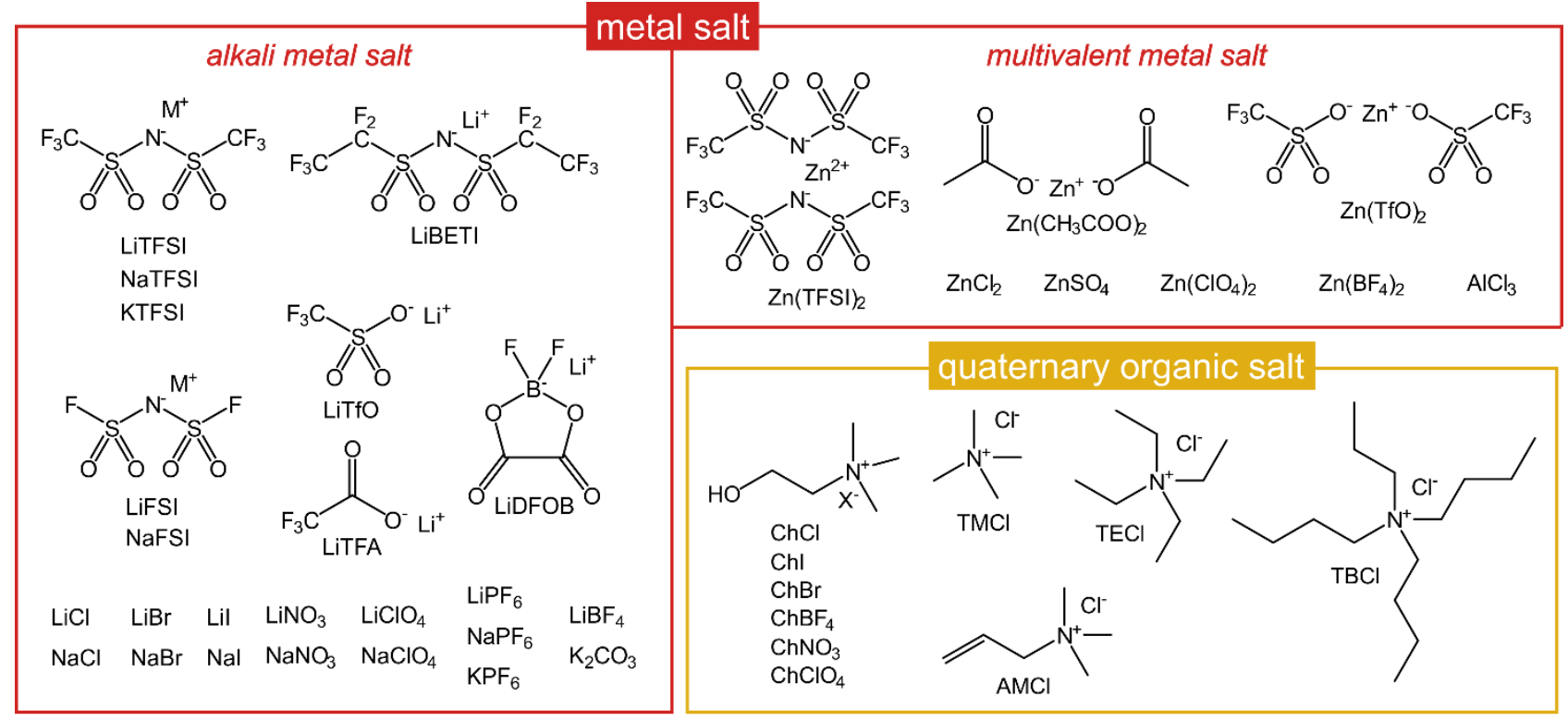

(n)

\section{metal salt $+\mathrm{HDB}=$ type IV DES \\ quaternary organic salt $+\mathrm{HDB}=$ type III DES}

Figure 1. Constituents (metal salt, quaternary organic salt and HDB) of the type III and type IV DESs discussed in this review. A list of abbreviation is provided in the Appendix.

Historically, DESs gained a lot of attention as IL analogues, as they share many of the advantageous properties of ILs, namely negligible vapour pressure, good thermal and chemical stability, high polarity, nonflammability, and potential as tunable solvents. ${ }^{5,24,25}$ Also, like ILs, DESs have relatively high conductivities, 
viscosities, and surface tensions. A point to be stressed here is that, although related to ILs, the molecular level interactions and structural organization in DESs are quite different. Notably, DESs are multicomponent systems originating from the combination of ionic and molecular species, and their liquid state relies on a more structurally complex network with contributions from dominant hydrogen bonding plus electrostatic or van der Waals forces, rather than only electrostatic forces between anion and cation as in the case of conventional ILs. ${ }^{24,26}$

Being the electrochemical field one of the most trodden paths for IL application, it is easy to understand that, soon after they apparition on the scientific scene, DESs were suggested as alternative electrolytes in energy storage systems and this sector is now progressing at a rapid pace. The remarkable increase in the level of interest in DES electrolytes for batteries is illustrated by the rapid growth in the number of publications on the topic over the period 2012 to 2021 (Fig. 2). Actually DESs are somehow replacing - or pretending to - ILs in electrochemical applications. The keywords analysis reported in Fig. 3 shows indeed that the keyphrase "ionic liquid" is growing in the time window 2010-2019, but declining since 2017.

a)

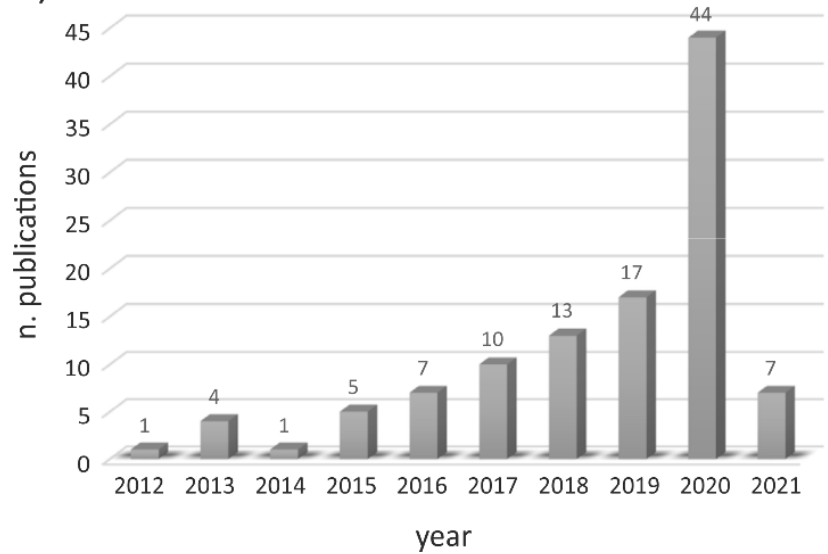

b)

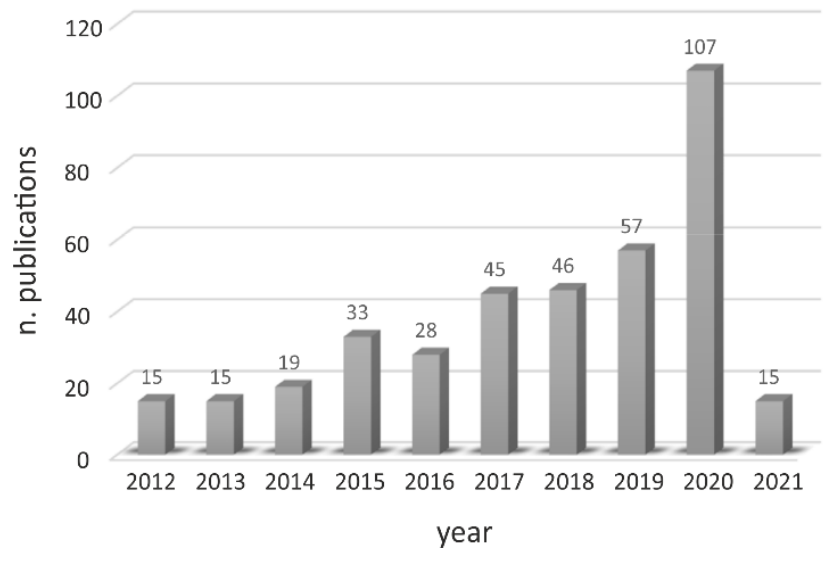

Figure 2. Number of publications over the period 2012 to 2021 obtained from a literature search using the Scopus database with the keywords (a) "deep eutectic" AND batter*, and (b) "deep eutectic" AND electrolyte, in the field "Article title, Abstract, Keywords" (search on February 08, 2021).

a)

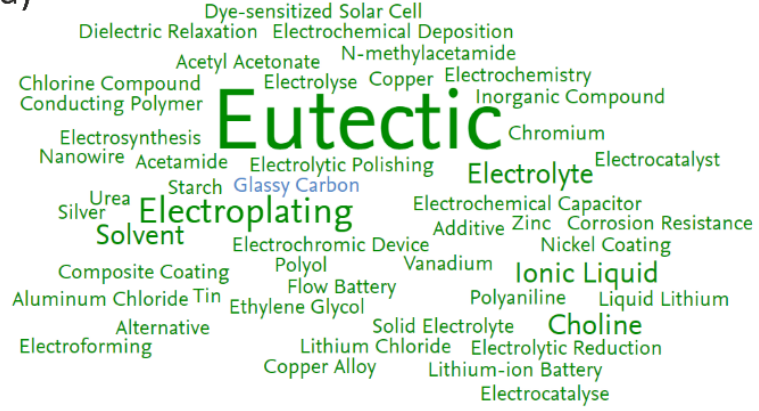

b)

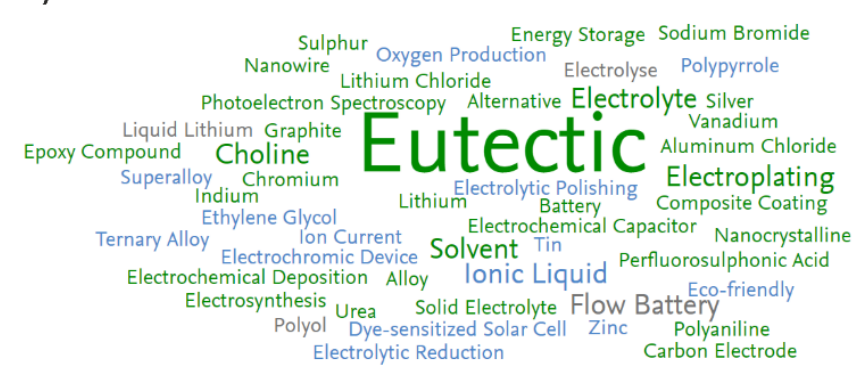

Figure 3. Keywords analysis obtained using the SciVal research tool with the keywords "deep eutectic" AND electrolyte, over the time window a) from 2010 to 2019, and b) from 2017 to > 2020 (search on February 08, 2021). Size indicates the relevance of keyphrase, while colour the declining (blue), unchanged (grey) or growing (green) trend. 
Overall, DESs promise superior performances over traditional ILs. They are easy to prepare in high purity without any purification step and with a $100 \%$ atom economy. Noteworthy is the extremely low cost and the large availability of many precursors as bulk chemicals, which make DESs manufactured at much lower costs than ILs and potentially useful for large-scale applications. ${ }^{25}$ As an example, the typical HBA choline is currently produced in a megaton per annum basis as a nutritional supplement for livestock, while the typical HBD urea has a global production rate of $\sim 190$ million tons per annum and is commonly used in commercial fertilizers. ${ }^{5,27}$ As a whole, archetypal DESs like ChCl:U or ChCl:glycerol (G), are comparable in cost to typical organic solvents such as acetonitrile or $\mathrm{N}, \mathrm{N}$-dimethylformamide. ${ }^{7}$ Another strength of DESs is that the constituents are generally biodegradable and their toxicological properties are well characterized.5,24 However, it is important to underline here that, even if DESs have been described as "green solvents", mainly due to their low vapour pressure, not all DESs are inherently "green". Not only the toxicity of the DES is different - eventually higher or much higher - than its individual components, but it should be considered that even if neat DESs are likely non-toxic as being composed of benign constituents, DESs containing metal salts will have an innate toxicity. ${ }^{28}$ Additional advantages of DESs over ILs are that the latter are known to be sensitive to air and moisture, which makes their handling difficult in largescale commercial applications, tend to be quite expensive and are unlikely to be economically viable for energy storage devices applications. ${ }^{25,29}$ Contrary, many DESs have been proved to be air and moisture stable, ${ }^{3}$ and their electrochemistry is not severely affected if experiments are conducted in the open atmosphere. ${ }^{24}$ Nevertheless, it should be kept in mind that DESs are very hygroscopic, and traces of water are often unavoidable when applied commercially. ${ }^{30}$ The presence of controlled amount of water does not disrupt the intermolecular peculiar interactions, ${ }^{31}$ while decreasing DES density and viscosity, with a concurrent increase in conductivity. ${ }^{32-34}$ Even if the presence of water does not appear to lead to the electrolyte decomposition, the residual water included in the DES structure should be considered, as it affects - mostly beneficially -electrodeposition, ${ }^{35,36}$ may reduce the electrochemical potential window, alter speciation and in general complicate the reproducible performance of measurements. ${ }^{37-39}$ An interesting work reported an atomic force microscope study of the interfacial nanostructure of three ChCl-based DESs ( $\mathrm{U}, \mathrm{G}$, or ethylene glycol EG as HBD) at a platinum (Pt) electrode as a function of applied potential and water content. ${ }^{40}$ Results revealed that the interfacial nanostructure increases upon addition of water up to $\sim 40 \mathrm{wt} \%$, after which it decreases. This differs markedly from ILs, where addition of small amounts of water rapidly decreases the interfacial nanostructure, indicating that there may be significant advantages for using wet DESs in electrochemistry. ${ }^{40}$

Despite these high number of important points, some disadvantages of DESs are often mentioned. Like ILs, some DESs show modest viscosity, which makes electrochemistry in this media challenging. ${ }^{24}$ Moreover, some DESs have a narrower electrochemical stability window (ESW) compared to ILs, which may limit their industrial electrochemical applications. ${ }^{25,41}$ In given cases, they can exhibit volatility when the HBD molecule is, for instance, EG or N-methylacetamide (NMAA). ${ }^{41,42}$ The high number of possible HBA-HBD combinations give however high chances to overcome such issues and design task-specific DESs with suitable properties.

Despite the above mentioned donwsides, DESs have been used in many electrochemical processes, ${ }^{28}$ including metal oxide processing,,$^{25,43,44}$ electropolishing, ${ }^{45-49}$ and electrodeposition of metals and alloys. . $^{16,35,36,38,39,50-75}$ DESs have been electrochemically characterized using redox couples such as ferrocene, ${ }^{24,76}$ iron (III) acetylacetonate, ${ }^{77}$ copper(II)/copper(I) ${ }^{41}$ and other metallic ions. ${ }^{78-81}$ Also, the electrochemistry and adsorption behavior at the interface DES-electrodes has been investigated. ${ }^{82-86}$ Interestingly, due to the unusually dissolving capability, some DESs (ChCl:EG, ChCl:G, ChCl:lactic acid (LA) as well as acetylcholine chloride $(\mathrm{AcChCl}): \mathrm{U})$ were used to recycle spent $\mathrm{LIBs}$, recovering foil, binder, residual conductive carbon and metal ions, such as lithium, cobalt, or silver. ${ }^{87-90}$ 
This review exclusively aims at illustrating the historical and contemporary developments regarding DES liquid electrolytes for rechargeable batteries. In detail, we survey the present state of research on cationic shuttles based on DES electrolytes and their analogues, classifying them into 4 main sections: lithium (Li), sodium ( $\mathrm{Na}$ ) and potassium (K), aluminium ( $\mathrm{Al}$ ), and zinc $(\mathrm{Zn})$ batteries. As expected Li-batteries are the most widely reported using DES electrolytes (Fig. 4). Aluminum batteries are also quite popular, whereas only a minor number of reports are dedicated to investigations of alternative sodium-, potassium- and zincbatteries. Each section is then divided into subsections according to the DES formulation or the battery type. Future perspectives are illustrated in the final section.

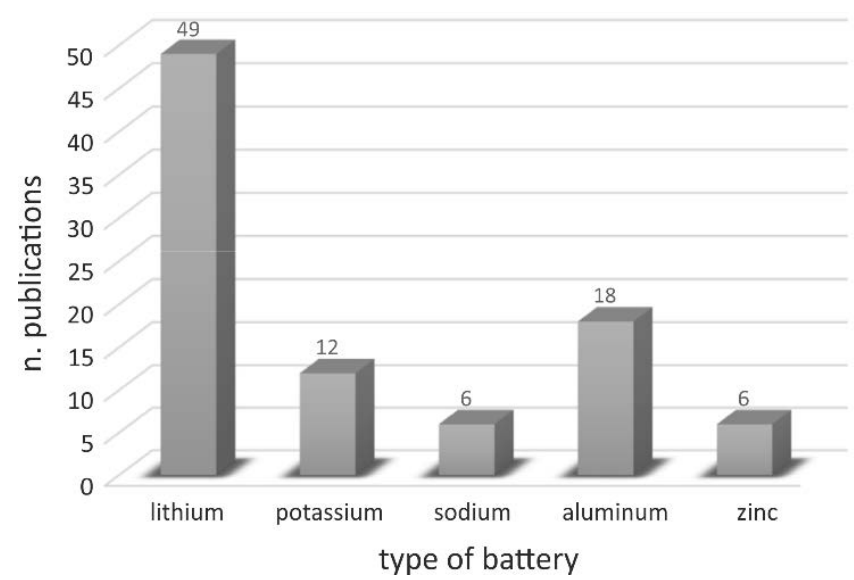

Figure 4. Number of publications over the period 2012 to 2021 obtained from a literature search using the Scopus database with the keywords "deep eutectic" AND batter* AND lithium (or, for each case, sodium, potassium, aluminum or zinc), in the field "Article title, Abstract, Keywords" (search on February 08, 2021).

The review covers a survey of the literature of the last 10 years (2012-2021), using the keywords "deep eutectic" AND batter* OR electrolyte, in Scopus database. More papers were selected and added through forward and backward citation searching. No attempts will be made to cover DES electrolyte applications in supercapacitors, ${ }^{91-101}$ dye sensitized solar cells (DSSCs), ${ }^{102-106}$ and redox flow batteries. ${ }^{25,107-117}$ Note that, for the reasons explained above, we will include all eutectic mixtures, regardless of the solid or liquid state at above-ambient temperatures of the constituents in their pure states, and of whether a deviation from ideality has been demonstrated. Solid and semi-solid electrolytes based on DES and polymer or selfassembling molecules will not be reviewed, but briefly mentioned in the outlook section. When available, viscosity/density and conductivity values will be listed in tables for each class, being the most commonly reported figures of merit, that are relevant to electrochemistry. Next to the physicochemical characterization, evaluation of performances in reported systems will be discussed and compared, underlining the limits and issues in the field and discussing promising research thrusts. Given the controversial nomenclature and classification of DESs, although we have tried our best to incorporate all the relevant literature contributions on the recent development in the application of DES as electrolytes for batteries, we may have inadvertently missed a few. 


\section{Lithium batteries}

Li-ion batteries (LIBs) are currently the best performing rechargeable batteries and undisputedly dominate the global electrochemical energy storage market being used in mobile devices, electric vehicles and various other small-scale energy storage systems. ${ }^{118,119}$ As the developers won the Nobel Prize in 2019, LIBs are gaining ever more attention. However, there are some intrinsic limitations. First, the prevailing LIBs based on Li transition metal oxide cathodes and graphite anodes deliver only limited energy densities of $<300 \mathrm{Wh} \mathrm{kg}^{-1}$ which cannot meet the growing demands for portable electronics and electric vehicles. ${ }^{119}$ Moreover, LIBs are not economically viable for large-scale applications, namely grid-connected stationary energy storage, due to the limited Li mineral reserves and their uneven distribution in the earth crust. ${ }^{119}$ As a result, both nextgeneration Li batteries (i.e. Li-metal batteries, $\mathrm{Li}$-sulfur ( $\mathrm{Li}-\mathrm{S})$ batteries, and $\mathrm{Li}$-oxygen $\left(\mathrm{Li}^{-} \mathrm{O}_{2}\right)$ batteries), and inexpensive alternatives (for instance rechargeable $\mathrm{Na}$ and $\mathrm{K}$ batteries) have been developed owing to the high theoretical energy densities of the former and the rich abundance of $\mathrm{Na}$ and $\mathrm{K}$ for the latter. ${ }^{119}$

Another crucial point when dealing with LIBs is safety. At present, battery industry state-of-the-art electrolyte solutions for rechargeable LIBs consist of a thermally unstable lithium salts (usually lithium hexafluorophosphate, $\mathrm{LiPF}_{6}$ ), and highly flammable organic solvents (carbonates and ethers). ${ }^{118-120}$ Even though these electrolytes are nowadays the best compromise at the commercial level between acceptable cost, desirable properties, and drawbacks, they are not optimal for LIB performance due to possible accidents which may lead to the uncontrollable thermal runaway of the battery system and leakage of toxic chemicals. ${ }^{119,120}$ Several highly publicized battery failures related to current electrolytes used in LIBs makes the search for flame-resistant substitutes, with (at least) comparable performances, even more impelling. ${ }^{5}$ Considerable efforts have then been spent on the design of non-flammable liquid electrolyte systems, including the development of new salts, partially fluorinated organic carbonate solvents, highly concentrated organic liquid electrolytes, or fire-retardant additives. ${ }^{119}$ Yet, a viable electrolyte solution to replace $\mathrm{LiPF}_{6} /$ carbonates mixtures in high energy or high power rechargeable LIBs does not exist.

ILs were proposed as next-generation electrolytes for LIB electrolytes, thanks to their attractive properties: wide liquid range, exceptional thermal stability, nano-Torr vapor pressures, high intrinsic ionic conductivity, very wide ESWs, and the ability to reversibly cycle metallic lithium electrodes. ${ }^{118,120}$ However, their commercial use remains limited as most if not all ILs proposed so far for LIBs have some serious drawbacks. ${ }^{12,118,120,121}$ First, the Li ionic conductivity of ILs is lower than that of conventional organic electrolytes and often decreases upon addition of a Li salt. Moreover, the low temperature conductivity of ILs is significantly lower that of traditional liquid electrolyte solutions, worsening the rate performance with decreasing temperature. This makes ILS inadequate for use in batteries that must operate at low temperatures. Also, for most IL-based Li electrolytes the Li transference number is typically less than 0.2 , against a value in the range 0.33 to 0.40 for conventional Li salt-in-solvent solutions Finally, the large cations of ILs accumulate at the electrode -electrolyte interface towards which the $\mathrm{Li}^{+}$cations are moving, leading to an increased interfacial polarization and a significant decrease in the rate capability of LIBs.

An alternative to pure ILs are DES electrolytes. They show suppressed flammability, wide liquid range, and for some compositions high conductivity, ${ }^{5}$ and may avoid the issue of the low Li transference number that plagues IL electrolytes for LIBs. ${ }^{121}$

\subsection{Type IV DESs composed of lithium salts and HBDs}

Besides the lower cost, a distinct merit of Li-based type IV DESs over ILs for Li-battery applications is the presence of a single cation species $\left(\mathrm{Li}^{+}\right) .{ }^{121,122}$ ILs typically require a relatively high concentration of dissolved 
Li salt in order to be useful for LIBs. This leads to the presence of at least three separate ionic species, a common anion and two different cations. The presence of the additional cation causes a significant reduction of the Li transference number in ILs, with values lower than 0.15 quite common. DESs can display significantly higher transport numbers (up to 0.7 for some compositions) and may therefore demonstrate acceptable cycling performance in full cells even at specific conductivity values lower than those typical for LIB industry state-of-the-art $\mathrm{LiPF}_{6}$ in organic carbonates electrolyte solutions. ${ }^{121}$

A significant number of DESs based on lithium salts have been reported in the last decade, and they are discussed in the following sections according to the HBD used in the preparation.

\subsubsection{Lithium salts and amides}

Mixtures of amides and Li salts have been revived in the last decade. The most widely used Li salt is probably lithium bis(trifluoromethane sulfone)imide (LiTFSI), due to its extensively exploitation as electrolyte salt in ILs. LiTFSI:U with a molar ratio of $1: 4.8$ exhibits for instance very low eutectic temperature close to $-37.6^{\circ} \mathrm{C}$, whereas LiTFSI and $\mathrm{U}$ have individual melting temperatures of $132.7^{\circ} \mathrm{C}$ and $234^{\circ} \mathrm{C} .{ }^{123}$ Atomistic molecular dynamics (MD) simulations indicate a competition between $U$ and TFSI to occupy the first coordination shell around $\mathrm{Li}$ ions. High $\mathrm{U}$ concentrations lead to a successive replacement of $\mathrm{TFSI}^{-}$ions, with a corresponding weaker binding of the central $\mathrm{Li}^{+}$ion and a significant increase of ionic diffusivities. ${ }^{122}$ This results into a marked increase of $\mathrm{Li}$ ion transport numbers from 0.38 (i.e. $\mathrm{TFSI}^{-}$ions more mobile than $\mathrm{Li}^{+}$) to 0.58 (i.e. $\mathrm{Li}^{+}$ ions more mobile than TFSI) with increasing $U$ concentrations, until a saturation value when the $U$ molar fraction approaches $0.65 .{ }^{124}$ These quite high transport numbers encourage the use of LiTFSI:U mixtures in Li batteries.

Binary mixtures composed of LiTFSI and several other amides (acetamide AA, 2-imidazolidinone I, methylurea MU, 1,3-dimethylurea DMU) have been also introduced in the decade 2000-2010 as electrolytes for LIBs and other energy storage devices. ${ }^{123,125-129}$ Among the various HBDs, AA has been one of the most frequently used amides because of its unique solvating power, high molecular dipole moment (3.7 D), and fairly large static dielectric constant in molten state $(\varepsilon \approx 61$ at $\sim 367 \mathrm{~K}) .{ }^{130,131}$ Also, AA has been long-known to form liquids at or near room temperature with a remarkable tendency to supercool when mixed with inorganic salts. ${ }^{132}$

Thanks to these interesting solvent properties, mixtures of AA and Li salts are one of the best-in-classes in terms of specific conductivity. For instance LiTFSI:AA has a specific conductivity of $1.07 \mathrm{mS} \mathrm{cm}^{-1}$ at $25{ }^{\circ} \mathrm{C}$ at 1:4 mole ratio, while oxidation and reduction potentials are $4.4 \mathrm{~V}$ and $0.7 \mathrm{~V}$ vs. $\mathrm{Li}^{\mathrm{L}} \mathrm{Li}^{+}{ }^{+}{ }^{120}$ The system with lithium bis(perfluoroethyl)sulfonimide (LiBETI) as HBD displays a slightly higher specific conductivity of 1.27 $\mathrm{mS} \mathrm{cm}-1$ at $30{ }^{\circ} \mathrm{C}$, but has a narrower ESW with oxidation and reduction potentials of $3.8 \mathrm{~V}$ and $0.6 \mathrm{~V}$ vs. $\mathrm{Li} / \mathrm{Li}^{+}{ }^{120}$ Alternative $\mathrm{Li}$ salts such as lithium triflate ( $\left.\mathrm{LiTfO}\right)$, lithium perchlorate $\left(\mathrm{LiClO}_{4}\right)$ and lithium bromide ( $\mathrm{LiBr}$ ) have been used as well. ${ }^{11,130,133-137}$ It has been shown that mixtures of $\mathrm{Li}$ salts $\left(\mathrm{LiClO}{ }_{4}, \mathrm{LiBr}\right.$, and lithium nitrate $\mathrm{LiNO}_{3}$ ) and $\mathrm{AA}$ in a molar ratio of approximately 1:4 form DESs having freezing points below room temperature. ${ }^{11}$ Apparently the depression of freezing points in these systems can be ascribed to the ability of these salts to break the interamide hydrogen bonding.

Mixtures of Li salts and amides are characterized by a well-studied micro-heterogeneity. ${ }^{11,130,138-140}$ The investigation of electrolytes composed $\mathrm{Li}$ salts $\left(\mathrm{LiClO}_{4}, \mathrm{LiBr}, \mathrm{LiNO}_{3}\right)$ with $\mathrm{AA}$ and other short-chain amides (propionamide $\mathrm{PA}$ and butyramide $\mathrm{BA}$ ) via time-resolved fluorescence measurements and all-atom MD simulation revealed for instance pronounced solution heterogeneity. ${ }^{11,130} \mathrm{In}$ all cases the AA-ion interactions are stronger than the $A A-A A$ ones. ${ }^{131}$ Comparing the different anions, $M D$ results indicate that the change in displacement and angle of the orientational jumps follows the order $\mathrm{Br}^{-}<\mathrm{NO}_{3}{ }^{-}<\mathrm{ClO}_{4}{ }^{-}$, which in turn follows 
the ion size sequence. ${ }^{131}$ This indicates larger affinity of perchlorate ion to amide group, which is in line with $\mathrm{LiClO}_{4}$ forming the least viscous DES at room temperature. ${ }^{11}$ Comparing ternary mixtures containing AA as $\mathrm{HBD}$ and both $\mathrm{LiBr}$ and $\mathrm{LiNO}_{3}$ as $\mathrm{HBA}$ in different relative amounts, it has been shown that viscosity increases upon successive replacement of nitrate by bromide (Table 2). ${ }^{130,137}$ The ion effect is also evident on the hydrogen bond lifetime, with AA-AA and $\mathrm{Li}^{+}-\mathrm{AA}$ clusters having higher lifetimes in presence of $\mathrm{Br}^{-}$, while $\mathrm{Li}^{+}-\mathrm{X}$ - clusters being most stable in the presence of $\mathrm{NO}_{3}{ }^{-} .140$

The nanoscale dynamics of some of these AA-based DESs (with $\mathrm{LiNO}_{3}$ or $\mathrm{LiClO}_{4}$ ) has been investigated by Srinivasan and coworkers using quasielastic neutron scattering (QENS) and MD simulations. ${ }^{134-136}$ Results indicate that the AA molecules form a hydrogen-bond network with its neighbouring set of molecules resulting in a transient cage and the molecular diffusion of AA involves a combination of localized diffusion and cage-to-cage jump diffusion. ${ }^{134,135}$ The localized diffusion process is associated with the dynamics of the molecules while it is trapped by an $\mathrm{H}$-bond with neighbouring AA molecules and ions, whereas the jump diffusion process is associated with the diffusion of the molecule between two transient cage. ${ }^{134,135}$ The dynamics of $A A$ is relevant for the $\mathrm{Li}^{+}$transport, as $\mathrm{Li}$ ions are solvated in the DES, with solvation shells predominantly made up of 3-4 AA molecules. ${ }^{136}$ In particular, the Li ionic transport is more likely to be dominated by the vehicular motion $(90 \%)$ in which the Li ion moves along with its solvation shell, rather than the structure diffusion process (10\%) which is achieved by exchange of molecules in its solvation shell. ${ }^{136}$

Overall, DESs based on Li salts and amides are potentially promising electrolytes for electrochemical devices, but many systems still suffer from some limitations, primarily the relatively high viscosity and low conductivity. The addition of suitable cosolvents to the DES electrolyte has been explored as a strategy to mitigate the drawbacks and enhance electrochemical properties, first of all conductivity. Water is the most used ingredient to alter DES properties. For instance the addition of water to a pristine DES composed of $\mathrm{LiClO}_{4}$ and AA in the molar ratio of 1:4.3 improves its conductivity, even if at the expenses of the ESW (Table 2). ${ }^{93}$ The best compromise was set at a $\mathrm{Li}^{+}: \mathrm{H}_{2} \mathrm{O}$ molar ratio equal to $1: 1$ (conductivity of $2.5 \mathrm{mS} \mathrm{cm}^{-1}$ and viscosity of $98.7 \mathrm{mPa} \cdot \mathrm{s}$ ). To further improve the electrochemical behaviour of the system, acetonitrile (AN) was selected as additional co-solvent due to its wide ESW, low viscosity, and high dielectric constant. ${ }^{93}$ The conductivity increases and the ESW decreases with the AN content in DES, with a marked drop in ESW for $\mathrm{AN}: \mathrm{H}_{2} \mathrm{O}$ molar ratio higher than 4.4. The $\mathrm{LiClO}_{4}: \mathrm{AA}: \mathrm{H}_{2} \mathrm{O}: \mathrm{AN}$ system at 1:4.3:1:4.4 mole ratio was considered the best performing one, with a conductivity of $15.6 \mathrm{mS} \mathrm{cm}^{-1}$ ( 6 times higher than that of $\mathrm{LiClO}_{4}: \mathrm{AA} \mathrm{1:4.3),} \mathrm{a}$ viscosity of $5.8 \mathrm{mPa} \cdot \mathrm{s}$, and a ESW of $2.55 \mathrm{~V}$ (82\% than that of $\left.\mathrm{LiClO}_{4}: \mathrm{AA} 1: 4.3\right)$. Importantly, while AN is a highly flammable solvent, an increase in flammability was not observed, as the new electrolyte exhibited flame-retardant property due to the existence of water and high electrolyte concentration. ${ }^{93}$

As alternative to AA, NMAA has been considered as a good and green solvent for the formulation of new DES-based electrolytes when combined to several Li salts ( $\mathrm{LiTFSI}_{\text {, LiPF }}$, and $\left.\mathrm{LiNO}_{3}\right) .{ }^{17,37,141}$ This is due to its "water-like" physical properties, namely very high dielectric constant $(\varepsilon=178.9)$, high dipolar moment $(6.8$ D), and very low vapor pressure $\left(0.050 \mathrm{kPa}\right.$ at $\left.40^{\circ} \mathrm{C}\right)$. Like $\mathrm{U}$ - and AA-based mixtures, NMAA acts as a complex agent for both $\mathrm{Li}^{+}$cation and the anion in solution, weakening and even breaking down the bonding between the $\mathrm{Li}^{+}$cation and the anion. The NMAA molecules have even stronger interactions in solution than the AA ones, translating in a higher dissociating power on Li salts of NMAA over AA. ${ }^{141}$ Following the size and the charge delocalization of the anions, the weakening process gets easier in the order $\mathrm{TFSI}^{-}>\mathrm{PF}_{6}{ }^{-}>\mathrm{NO}_{3}{ }^{-} .^{99} \mathrm{The}^{-}$ viscosities of such systems are close to those reported in the case of the imidazolium-based ILs with the TFSI anion (90-117 $\mathrm{mPa} s$ at $25^{\circ} \mathrm{C}$ ), and the conductivity increases as expected with the temperature (from 1.20 $\mathrm{mS} \mathrm{cm}{ }^{-1}$ and $1.35 \mathrm{mS} \mathrm{cm}^{-1}$ at $20{ }^{\circ} \mathrm{C}$ to $9.22 \mathrm{mS} \mathrm{cm}^{-1}$ and $10.13 \mathrm{mS} \mathrm{cm}^{-1}$ at $80{ }^{\circ} \mathrm{C}$ for LiTFSI:NMAA and $\mathrm{LiPF}_{6}$ :NMAA mixtures, respectively) (Fig. 5). ${ }^{37}$ 


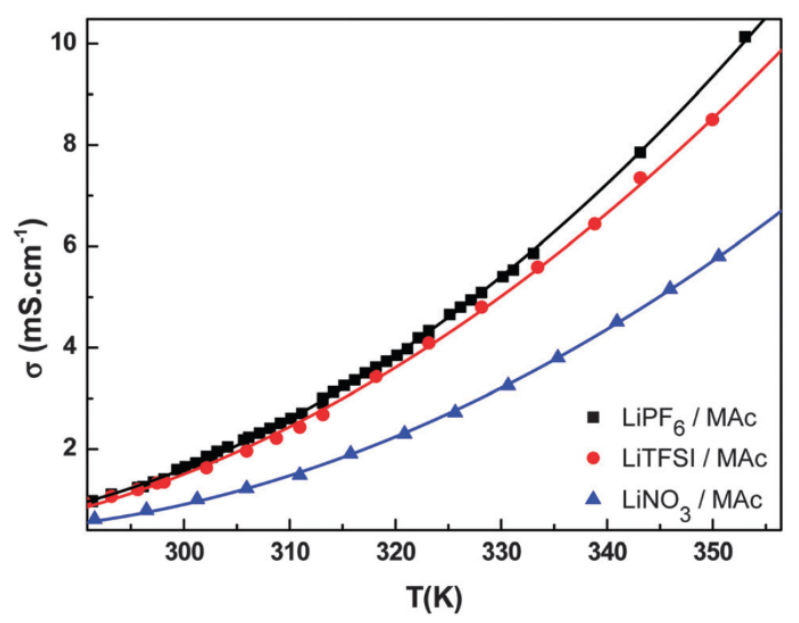

Figure 5. Influence of temperature on the conductivity $\sigma$ of the selected Li salt:NMAA mixtures (Li molar fraction equal to 0.20 ). Republished with permission of Royal Society of Chemistry, from Deep eutectic solvents based on $\mathrm{N}$-methylacetamide and a lithium salt as suitable electrolytes for lithium-ion batteries, Boisset et al., Phys. Chem. Chem. Phys. 2013, 15, 20054; permission conveyed through Copyright Clearance Center, Inc..

NMAA-based DESs have been tested as electrolytes for LIBs turning out to be good candidates. ${ }^{37,141}$ All DESs displayed a high ESW of about 4.7 to $5.3 \mathrm{~V}$ on Pt electrode and demonstrated also passivating behavior toward the Al collector. ${ }^{37}$ In a cell with lithium iron phosphate olivine (LiFePO ${ }_{4}$, LFP) and activated carbon (AC), the LiTFSI:NMAA electrolyte did not react with electrode surface, with the discharge capacity ratio after 20 cycles at $80{ }^{\circ} \mathrm{C}$ being only $1 \%$ of the first discharge capacity with more than $99 \%$ efficiency. ${ }^{141}$ In a cell containing LFP as cathode and lithium titanate (LTO) as anode tested at room temperature at a $1 \mathrm{C}$ rate, the capacity delivered by the LIB increased over cycling, and after 100 cycles the battery displayed a discharge capacity in the order of $100 \mathrm{~mA} \mathrm{~h} \mathrm{~g}^{-1} .{ }^{141}$

As previously discussed for AA-based systems, the addition of a third component has been suggested in order to mitigate some issues of NMAA-based DESs too. Fluoroethylenecarbonate (FEC, $10 \mathrm{wt} \%$ ) was introduced as additive to a LiTFSI:NMAA electrolyte at 1:4 mole ratio, leading to a sharp decrease in DES viscosity (from 73 to $37 \mathrm{mPa} \mathrm{s}^{-1}$ at $25^{\circ} \mathrm{C}$ ) and increase in ionic conductivity (from 0.89 to $2.2 \mathrm{mS} \mathrm{cm}^{-1}$ at $25^{\circ} \mathrm{C}$ ) (Table 2). ${ }^{142}$ Also the electrochemical stability versus $\mathrm{Li}$ / $\mathrm{Li}^{+}$was slightly enhanced after introduction of FEC (from $4.1 \mathrm{~V}$ to $4.2 \mathrm{~V}$ ), while the Li ion transference number increased from 0.15 to $0.53 .{ }^{142}$ The electrolyte with FEC was used in a Li metal | lithium manganese oxide $\left(\mathrm{LiMn}_{2} \mathrm{O}_{4}, \mathrm{LMO}\right)$ cell. This configuration is interesting in terms of anode and cathode materials. Li metal anode has attracted broad attention among alternative anode materials, due to its ultrahigh specific capacity $\left(3860 \mathrm{mAh} \mathrm{g}^{-1}\right)$ and low redox potential $(-3.040 \mathrm{~V}$ vs. standard hydrogen electrode (SHE)), but several obstacles limited its practical application in rechargeable batteries. ${ }^{142,143}$ Also the LMO cathode is a perspective material in the manufacture of LIBs, as alternative to the popular lithium cobalt oxide $\left(\mathrm{LiCOO}_{2}, \mathrm{LCO}\right)$, whose future is under risk because of the low recoverability and low natural reserves of cobalt. ${ }^{144}$ The binary LiTFSI:NMAA electrolyte showed poor compatibility with Li metal. Contrarily, the FEC additive constructed a thin and robust solid electrolyte interface (SEI) on the Li metal anode, hence protecting against Li dendrite growth. ${ }^{142}$ As for the LMO cathode, a high solubility of transition-metal ions was observed in LiTFSI:NMAA mixtures, while the FEC with high oxidative stability contributed to a thin and stable protective cathode electrolyte interface (CEI), thus preventing interfacial side reactions and cathode structural deterioration. ${ }^{142}$ As a result, the LiTFSI:NMAA:FEC electrolyte exhibited 
reversible capacity of $88.6 \mathrm{mAh} \mathrm{g}^{-1}$ after 200 cycles, while the Li | LiTFSI:NMAA | LMO cell suffered from rapid capacity fading and battery failure after 80 cycles. ${ }^{142}$

In the quest for novel HBA/HBD combinations, 2,2,2-trifluoroacetamide (TFAA) has been recently mixed with LiTFSI to prepare electrolytes for high voltage LIBs. ${ }^{144}$ The viscosity of DESs with LiTFSI mole fraction in the interval 0.25-0.5 ranges from 59 to $134 \mathrm{mPa} \mathrm{s}$ at $30{ }^{\circ} \mathrm{C}$ (Table 2), that is close to those reported for imidazolium-based ILs with the TFSI ${ }^{-}$anion, but higher than pyrrolidinium-based ILs. With the increase of TFAA in the mixtures, a decrease in viscosity and increase in ionic conductivity was systematically observed. ${ }^{144}$ This can be traced back to the $\mathrm{NH}_{2}$ group of TFA acting as a complex agent, which stabilizes both $\mathrm{Li}^{+}$and TFSI ${ }^{-}$ and enhances the dissociation capability of LiTFSI, thus allowing better ionic mobility. The DES with 1:4 molar ratio exhibited the most favorable properties, such as thermal stability up to $148^{\circ} \mathrm{C}$, relatively low viscosity $\left(59.2 \mathrm{mPa}\right.$ s at $\left.30^{\circ} \mathrm{C}\right)$, high ionic conductivity $\left(1.5 \mathrm{~ms} \mathrm{~cm}^{-1}\right.$ at $\left.30^{\circ} \mathrm{C}\right)$, and quite large electrochemical stability window (up to 4.9-5.3 V). ${ }^{144}$ The ionic conductivity at room temperature is approximately the same than the DES LiTFSI:AA 1:4 and LiTFSI-based IL (1.07, and $1.91 \mathrm{mS} \mathrm{cm}^{-1}$, respectively). Also, the ionic conductivity at $60^{\circ} \mathrm{C}$ was quite similar to that of $\mathrm{LiNO}_{3}: \mathrm{NMAA}\left(3.71 \mathrm{mS} \mathrm{cm}^{-1} \mathrm{vs} 3.25 \mathrm{mS} \mathrm{cm}^{-1}\right)$ but relatively lower than that of LiTFSI:NMAA ( $\left.5.59 \mathrm{mS} \mathrm{cm}^{-1}\right) .{ }^{37}$ To further reduce the viscosity, the LiTFSI:TFAA DES 1:4 was diluted with 10-30 wt\% of ethylene carbonate (EC) ${ }^{144}$ Based on infrared spectra, EC apparently joins partially the LiTFSI:TFAA coordination complexes. Compared to the pristine DES, LiTFAA:EC electrolytes demonstrated relatively lower thermal stability and oxidative strength, but an improvement in viscosity and conductivity (Fig. 6). When tested for cycling performance in a Li| LMO half-cell configuration at room temperature (cycling between 3.2 and $4.5 \mathrm{~V}$ vs $\mathrm{Li}^{+} / \mathrm{Li}$ ), the hybrid electrolyte LiTFSI:TFAA 1:4 with $10 \%$ wt EC performed the best. ${ }^{144}$ The EC-based system exhibited a good specific capacity of $102 \mathrm{mAhg}^{-1}$ at C/10 with the theoretical capacity of 148 mAhg $^{-1}$ and a good cycling behavior maintaining at $84 \%$ after 20 cycles.

a)

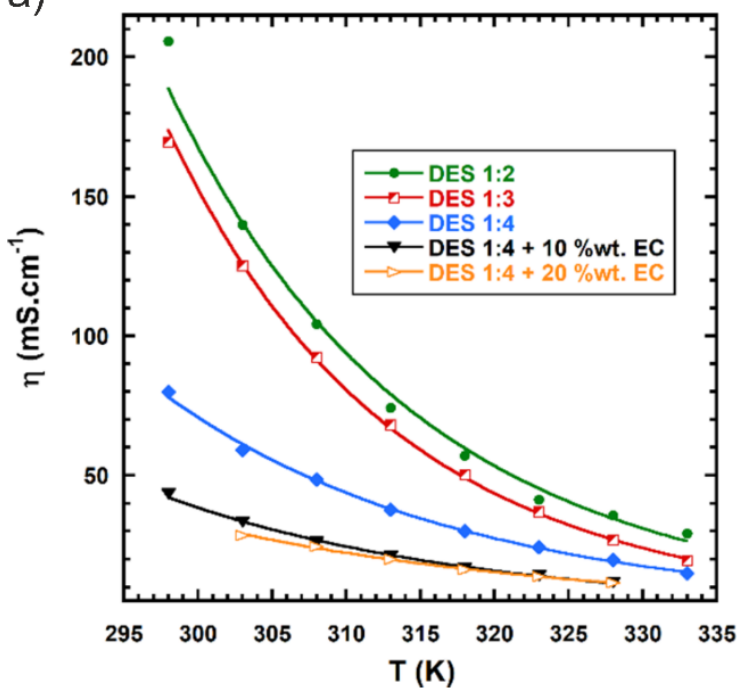

b)

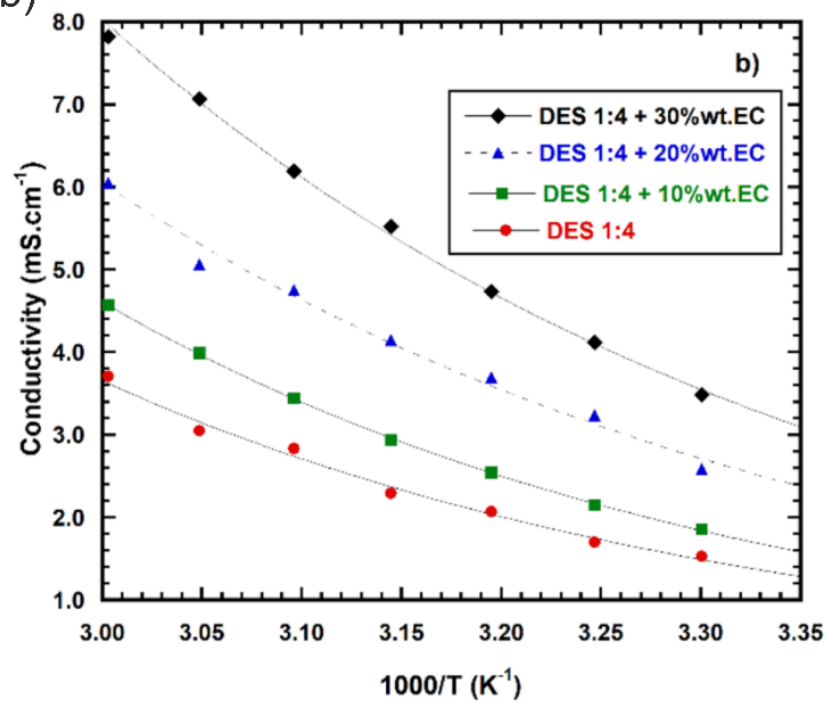

Figure 6. Temperature dependence of a) the viscosity $\eta$ and b) the conductivity, for a series of electrolytes based on the DES LiTFSI:TFAA at various molar ratio, with addition of ethylene carbonate (EC). Reprinted with permission from Dinh et al. Deep Eutectic Solvent Based on Lithium Bis[(trifluoromethyl)sulfonyl] Imide (LiTFSI) and 2,2,2-Trifluoroacetamide (TFA) as a Promising Electrolyte for a High Voltage Lithium-Ion Battery

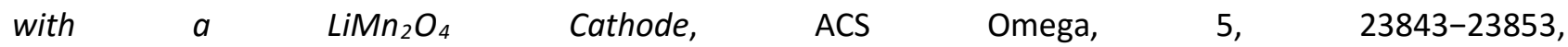
https://pubs.acs.org/doi/10.1021/acsomega.0c03099. Copyright (2020) American Chemical Society. Further permissions related to the material excerpted should be directed to the ACS. 
Despite the quite high number of works reporting new DES electrolytes based on Li salts and amides and their applications in LIBs, it is uttermost importance to devote additional effort to their basic characterization. Recently a nice comparative study reported a thermal and electrochemical investigation of a family of electrolytes composed of a series of amide derivatives (U, AA, N, $N^{\prime}$-dimethylpropyleneurea DMPU, I, tetramethylurea TMU, and 1,3-dimethyl-2-imidazolidinone DMI) and two Li-salts (lithium chloride $\mathrm{LiCl}$ and LiTFSI). ${ }^{12}$ Both amides with $\mathrm{N}-\mathrm{H}$ bonds (e.g. $\mathrm{U}, \mathrm{AA}$ and $\mathrm{I}$ ), and amides without any $\mathrm{N}-\mathrm{H}$ bonds (e.g. TMU, DMPU and DMI) were considered, in order to form "HBD-containing" and "HBD-free" electrolytes, respectively. Indeed, while DESs based on hydrogen bonding are the most common, the charge delocalization through hydrogen bonding in the amide derivatives may not necessarily be a prerequisite for the formation of eutectics. Investigating the eutectic mechanism via MD simulations, it emerged that in a DES prepared using a salt with a highly acidic Lewis acid such as $\mathrm{Li}^{+}$, a strong coordination of amide $\mathrm{C}=\mathrm{O}$ to $\mathrm{Li}^{+}$contributes to the melting point drop of the Li-salt, rather than promoting the donation of hydrogen bonds to the salt anion. ${ }^{12}$ This is then different from the eutectic mechanism in a DES containing a conventional salt such as $\mathrm{ChCl}$. Compairing the HBD-containing and HBD-free electrolytes, $\mathrm{U}$ - and I-based DESs, which have hydrogen bonding, exhibited higher viscosity and lower conductivity than electrolytes composed of TMU and DMPU (Table 2).${ }^{12}$ Also, HBD-free DESs were found to be superior in terms of reduction stability. ${ }^{12}$ Comparing on the other hand DESs prepared using a hard $\left(\mathrm{Cl}^{-}\right)$and a soft (TFSI') anion, it was shown that, unlike LiTFSI, LiCl could not form eutectics with melting points below ambient temperature with amides containing $\mathrm{N}-\mathrm{H}$ bonds such as $\mathrm{U}, \mathrm{AA}$ and I. ${ }^{12}$ As an overall trend, LiTFSI-based electrolytes had higher ionic conductivity than LiCl-based electrolytes, regardless of the amide derivatives (Table 2), probably because LiTFSI is more dissociable than $\mathrm{LiCl}$. Among the various DESs, LiTFSI:TMU at 1:5 mole ratio was the best electrolyte suitable for LIBs in terms of melting point, electrochemical stability (stable up to around $4.5 \mathrm{~V}$, below the general operating potential of LIBs of about $4.2-4.35 \mathrm{~V}$ ) and ionic conductivity $\left(2.2 \mathrm{mS} \mathrm{cm}^{-1}\right) .{ }^{12}$ 
Table 2. Density, viscosity and conductivity values for selected DES electrolytes based on the combination of Li salt and HBD.

\begin{tabular}{|c|c|c|c|c|c|c|c|c|}
\hline Metal salt & HBD & $\begin{array}{l}\text { Third } \\
\text { component }\end{array}$ & Mole ratio & $\begin{array}{l}\text { Working } \\
\text { temperature }\left({ }^{\circ} \mathrm{C}\right)\end{array}$ & $\begin{array}{l}\text { Density } \\
\left(\mathrm{gcm}^{-3}\right)\end{array}$ & $\begin{array}{l}\text { Viscosity } \\
\text { (mPa s) }\end{array}$ & $\begin{array}{l}\text { Conductivity } \\
\left(\mathrm{mS} \mathrm{cm}^{-1}\right)\end{array}$ & Reference \\
\hline $\mathrm{LiClO}_{4}$ & PA & & 0.19:0.81 & 30 & 1.154491 & 89.84 & - & 11 \\
\hline $\mathrm{LiClO}_{4}$ & $B A$ & & $0.19: 0.81$ & 30 & 1.093375 & 205.45 & - & 11 \\
\hline $\mathrm{LiClO}_{4}$ & AA & & $1: 4.3$ & a & - & 261.7 & 0.8 & 93 \\
\hline $\mathrm{LiClO}_{4}$ & AA & $\mathrm{H}_{2} \mathrm{O}$ & $\begin{array}{l}1: 4.3: 0.5 \\
1: 4.3: 1 \\
1: 4.3: 1.5 \\
1: 4.3: 5\end{array}$ & $\mathrm{a}$ & - & $\begin{array}{l}157.8 \\
98.7 \\
69 \\
14\end{array}$ & \begin{tabular}{l|}
1.3 \\
2.5 \\
3.3 \\
12.3
\end{tabular} & 93 \\
\hline LiTFSI & NMAA & & $1: 4$ & 25 & 1.276 & 80.55 & 0.96 & 14 \\
\hline LiTFSI & NMAA & & $1: 4$ & $\begin{array}{l}25 \\
60 \\
80 \\
\end{array}$ & - & $\begin{array}{l}78.38 \\
22.15 \\
14.20 \\
\end{array}$ & $\begin{array}{l}1.35 \\
5.59 \\
9.22 \\
\end{array}$ & 37 \\
\hline $\mathrm{LiNO}_{3}$ & NMAA & & $1: 4$ & $\begin{array}{l}25 \\
60 \\
80\end{array}$ & - & $\begin{array}{l}107.19 \\
23.31 \\
12.14\end{array}$ & $\begin{array}{l}0.76 \\
3.25 \\
6.30\end{array}$ & 37 \\
\hline $\mathrm{LiPF}_{6}$ & NMAA & & $1: 4$ & 25 & - & - & 1.41 & 37 \\
\hline
\end{tabular}




\begin{tabular}{|c|c|c|c|c|c|c|c|c|}
\hline & & & & $\begin{array}{l}60 \\
80\end{array}$ & & $\begin{array}{l}34.22 \\
19.73\end{array}$ & $\begin{array}{l}5.86 \\
10.13\end{array}$ & \\
\hline LiTFSI & NMAA & & $1: 4$ & 25 & - & 73 & 0.89 & 142 \\
\hline LiTFSI & NMAA & FEC & $1: 4+10 w t \%$ & 25 & - & 37 & 2.2 & 142 \\
\hline LiTFSI & TFAA & & $\begin{array}{l}1: 2 \\
1: 3 \\
1: 4\end{array}$ & 30 & $\begin{array}{l}1.650 \\
1.601 \\
1.539\end{array}$ & $\begin{array}{l}134.0 \\
120.1 \\
59.2\end{array}$ & $\begin{array}{l}0.26 \\
0.77 \\
1.53\end{array}$ & 144 \\
\hline LiTFSI & TFAA & $E C$ & $\begin{array}{l}1: 4+10 w t \% \\
1: 4+12 w t \% \\
1: 4+30 w t \%\end{array}$ & 30 & $\begin{array}{l}1.527 \\
1.513 \\
1.509 \\
\end{array}$ & $\begin{array}{l}30.5 \\
28.6 \\
-\end{array}$ & $\begin{array}{l}1.86 \\
2.59 \\
3.49\end{array}$ & 144 \\
\hline $\mathrm{LiCl}$ & $\mathrm{U}$ & & $1: 5$ & 25 & - & - & 0.22 & 12 \\
\hline LiTFSI & $\mathrm{U}$ & & $1: 5$ & 25 & - & - & 0.21 & 12 \\
\hline $\mathrm{LiCl}$ & AA & & $1: 5$ & 25 & - & - & 0.35 & 12 \\
\hline LiTFSI & AA & & $1: 5$ & 25 & - & 136.2 & 1.6 & 12 \\
\hline $\mathrm{LiCl}$ & DMPU & & $1: 5$ & 25 & - & 38.4 & 0.87 & 12 \\
\hline LiTFSI & DMPU & & $1: 5$ & 25 & - & 64.0 & 1.1 & 12 \\
\hline LiTFSI & 1 & & $1: 5$ & 25 & - & 2841.6 & 0.11 & 12 \\
\hline $\mathrm{LiCl}$ & TMU & & $1: 5$ & 25 & - & 7.5 & 0.53 & 12 \\
\hline LiTFSI & TMU & & $1: 5$ & 25 & - & 22.8 & 2.2 & 12 \\
\hline LiFSI & MSA & & $1: 3$ & 20 & - & 174 & 2.6 & 120 \\
\hline LiFSI & DMMSA & & $1: 4$ & 20 & - & 54 & 3.1 & 120 \\
\hline LiTFSI & DMMSA & & $1: 4$ & 20 & - & 121 & 1.0 & 120 \\
\hline $\mathrm{LiClO}_{4}$ & MSM & $\mathrm{H}_{2} \mathrm{O}$ & $\begin{array}{l}1: 1.8: 0.5 \\
1: 1.8: 1 \\
\end{array}$ & 22 & - & $\begin{array}{l}213 \\
148\end{array}$ & $\begin{array}{l}2.27 \\
3.71\end{array}$ & 145 \\
\hline LiTFSI + LiDFOB & SN & & 0.17:0.03:0.8 & 25 & - & 753 & 2.86 & 143 \\
\hline $\mathrm{LiCl}$ & $\mathrm{EG}$ & & $1: 3$ & $\mathrm{a}$ & 1.14 & - & 1.45 & 7 \\
\hline $\mathrm{LiCl}$ & $\mathrm{G}$ & & $1: 3$ & a & 1.34 & - & 0.29 & 7 \\
\hline LiTFSI & EG & & $\begin{array}{l}1: 1 \\
1: 2 \\
1: 3\end{array}$ & 30 & $\begin{array}{l}1.471 \\
1.307 \\
1.236 \\
\end{array}$ & $\begin{array}{l}58.8 \\
30.24 \\
23.79 \\
\end{array}$ & $\begin{array}{l}2.75 \\
2.81 \\
2.91 \\
\end{array}$ & 146 \\
\hline
\end{tabular}




\begin{tabular}{|c|c|c|c|c|c|c|c|c|}
\hline & & & $\begin{array}{l}1: 4 \\
1: 5 \\
1: 6\end{array}$ & & $\begin{array}{l}1.203 \\
1.197 \\
1.184\end{array}$ & $\begin{array}{l}21.40 \\
19.25 \\
18.14\end{array}$ & $\begin{array}{l}3.05 \\
2.75 \\
1.29\end{array}$ & \\
\hline LiTFSI & $E G$ & & $1: 2$ & 25 & 1.582 & 372.35 & 1.07 & 14 \\
\hline LiTFSI & G4 & HFE & $1: 1: 4$ & 30 & - & - & 5.2 & 147 \\
\hline LiFSI & $\mathrm{MP}$ & & $1: 1$ & 30 & - & 1220 & 0.43 & 148 \\
\hline LiFSI & $\mathrm{MA}$ & & $1: 1$ & 30 & - & 270 & 1.51 & 148 \\
\hline LiFSI & $\mathrm{ML}$ & & $1: 1$ & 30 & - & 1030 & 0.37 & 148 \\
\hline
\end{tabular}

a Temperature for viscosity and conductivity measurements not indicated 


\subsubsection{Lithium salts and sulfonamides or sulfones}

A class of DES electrolytes prepared by mixing an alkyl sulfonamide (methanesulfonamide MSA, melting point $85{ }^{\circ} \mathrm{C}$, and $\mathrm{N}, \mathrm{N}$-dimethylmethanesulfonamide DMMSA, melting point $49{ }^{\circ} \mathrm{C}$ ) with a lithium perfluoroalkylsulfonimide salts (lithium bis(fluorosulfonyl) imide LiFSI, and LiTFSI) has been reported in 2016. ${ }^{120}$ Also in this study, HBD-contaning (with MSA) and HBD-free (with DMMSA) electrolytes were considered. DMMSA enables higher conductivities and lower viscosities than MSA at all temperatures (Fig. 7 and Table 2). ${ }^{120}$ The higher viscosities observed in MSA over DMMSA can be ascribed to the increased hydrogen bonding capacity of MSA, when compared to DMMSA. ${ }^{121}$ LiFSI-based electrolytes display higher conductivity over the the LiTFSI-based ones, but at the expenses of a lower thermal stability. ${ }^{120}$ The three best performing materials, LiFSI:DMMSA 1:4, LiFSI:MSA 1:3 and LiTFSI:DMMSA 1:4, showed acceptable specific conductivity at $20^{\circ} \mathrm{C}\left(3.1,2.6\right.$ and $1.0 \mathrm{mS} \mathrm{cm}^{-1}$, respectively). ${ }^{120}$ However, to match the conductivity of standard $\mathrm{LiPF}_{6}$ in carbonates electrolytes, the specific conductivity needs improving by factors of 3-4 at room temperature. An increase by factors $40-60$ is needed at low temperatures $\left(-30^{\circ} \mathrm{C}\right)$, where values of only 20 to $30 \mu \mathrm{S} \mathrm{cm}^{-1}$ are reached even for the most promising eutectics. Also the viscosities $(54,121$, and 174 mPa s for LiFSI:DMMSA 1:4, LiFSI:MSA 1:3 and LiTFSI:DMMSA 1:4, respectively) are still quite high when compared to typical values for $\mathrm{LiPF}_{6}$ dissolved in carbonate solvents $(2-5 \mathrm{mPa} \mathrm{s}) .{ }^{120}$ An interesting point is that, although LiTFSI-based electrolytes have lithium conductivities lower traditional $\mathrm{LiPF}_{6} / \mathrm{carbonates}$ electrolytes, pulsed field gradient (PFG) NMR measurements indicate that the Li transport number is in the range $0.40-0.71$, which is the same or higher than transport numbers of state-of-the-art $\mathrm{LiPF}_{6} / \mathrm{mixed}$ organic carbonates LIB electrolytes. ${ }^{121}$ Combining NMR experiments and MD simulations it has been suggested that dipole-dipole attractive interactions hinder overall diffusion, but can nevertheless enhance the Li transport number by slowing the translational motion of the TFSI anions more than that of the $\mathrm{Li}^{+}$cations. ${ }^{121}$ The cycling behaviour of the most promising materials for LIB applications was tested in half cells with petroleum coke, $\mathrm{LiMn}_{1 / 3} \mathrm{Ni}_{1 / 3} \mathrm{Co}_{1 / 3} \mathrm{O}_{2}$ (NMC 111) and $\mathrm{LiNi}_{0.8} \mathrm{Co}_{0.15} \mathrm{Al}_{0.05} \mathrm{O}_{2}$ (NCA) electrodes. Reasonably good cycling behaviour was obtained with capacities of 220,130 , and $175 \mathrm{mAh} \mathrm{g}^{-1}$ at low rates, respectively. ${ }^{120}$ The addition of only a small amount (2\%) of FEC to LiTFSI:DMMSA significantly improved the Coulombic efficiency (CE) from 0.94 to 0.99 .120

a)

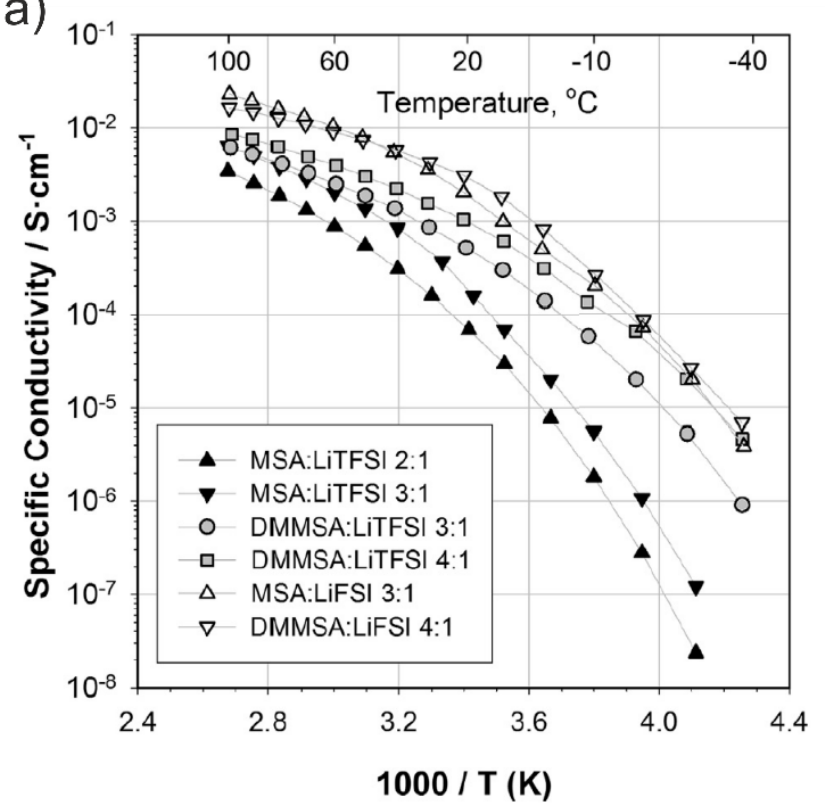

b)

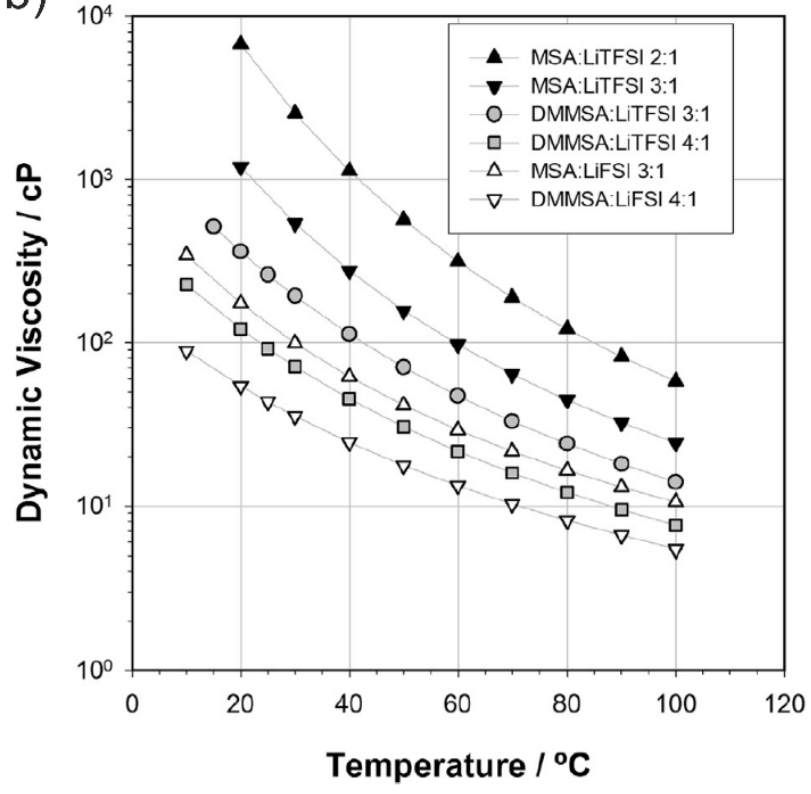


Figure 7. Temperature dependence of a) the specific conductivity and b) the viscosity in selected binary mixtures of a sulfonamide with a lithium perfluoroalklysulfonimide salt. Reprinted from Journal of Power Sources, 307, Geiculescu et al., Novel binary deep eutectic electrolytes for rechargeable Li-ionbatteries based on mixtures of alkyl sulfonamides and lithiumperfluoroalkylsulfonimide salts, 519-525, 2016, with permission from Elsevier."

Chemically related to sulphonamides are sulfones. A few electrolytes composed of methylsulfonylmethane (MSM, also dimethylsulfone) and lithium salts ( $\mathrm{LiTFSI},{ }^{149} \mathrm{LiNO}_{3}$ and $\mathrm{LiClO}_{4}{ }^{150}$ ) have been reported as promising electrolytes for medium-temperature LIBs. These systems were referred to as "salt-solvates", being formed by a mixture of a solvate and a salt, unlike a mixture of a solvate and a solvent as usual. In the 2012-2021 period, which is the time span covered by this review, a few examples of combinations of Li salts with sulfones have been reported. In 2019 Jiang et al. prepared aqueous ternary DESs by mixing MSM, $\mathrm{LiClO}_{4}$, and $\mathrm{LiClO}_{4} \cdot 3 \mathrm{H}_{2} \mathrm{O}$ at different percentage to be used as electrolytes for room temperature LIBs. ${ }^{145} \mathrm{~A}$ series of $\mathrm{LiClO}_{4}: \mathrm{MSM}: \mathrm{H}_{2} \mathrm{O}$ systems with mole ratio from 1:1.8:0.5 to 1:1.8:38 have been investigated and results indicate that adding a controlled amount of water into the $\mathrm{LiClO}_{4}: \mathrm{MSM}$ system significantly improves conductivity and viscosity, and is beneficial to prepare high performing room-temperature electrolytes. The system with $\mathrm{LiClO}_{4}: \mathrm{MSM}: \mathrm{H}_{2} \mathrm{O}$ mole ratio equal to 1:1.8:1 exhibited the best properties: conductivity of 3.71 $\mathrm{mS} \mathrm{cm}{ }^{-1}$, viscosity of $148 \mathrm{mPa} \mathrm{s}$, and $\mathrm{Li}^{+}$diffusion coefficient of $2.27 \times 10^{-11} \mathrm{~m}^{2} \mathrm{~s}^{-1} \cdot{ }^{145} \mathrm{~A}$ combination of Raman, FTIR, NMR and Density functional theory (DFT) studies pointed towards a structure with one $\mathrm{Li}^{+}$well-hydrated in its primary solvation sheath by coordinating with the oxygen atom in one $\mathrm{H}_{2} \mathrm{O}$, two $\mathrm{MSM}$, and one $\mathrm{ClO}_{4}{ }^{-}$. In addition, one $\mathrm{Li}^{+}$coordinates with one $\mathrm{H}_{2} \mathrm{O}$, and one $\mathrm{H}_{2} \mathrm{O}$ hydrogen bonds with two MSMs. Using bare carbon paper and Ti electrodes at a scan rate of $2 \mathrm{mV} \mathrm{s}^{-1}$, the electrolyte showed a wide ESW higher that 3.5 $\mathrm{V}$, which are 2 times higher than those of aqueous $\mathrm{LiClO}_{4} \cdot{ }^{145}$ The system was then tested in a $\mathrm{LiMn}_{2} \mathrm{O}_{4} \mid \mathrm{Li}_{4} \mathrm{Ti}_{5} \mathrm{O}_{12}$ cell for 1000 charge/discharge cycles at a high current density of 4.5C. A CE of 98.9-99.5\% and $72.2 \%$ of retention capacity were observed, demonstrating good potential as electrolyte for high-voltage aqueous LIBs at a high rate. ${ }^{145}$ Note however that under the rate of $2 \mathrm{C}$, the capacity decreased rapidly, likely due to a non stabilized electrode/electrolyte interface, confirming the urgency of deeper studies.

\subsubsection{Lithium salts and nitriles}

Thanks to their high dielectric constants, the use of nitriles (e.g. succinonitrile, SN) as an additive to carbonate electrolytes has been reported to widen the ESW of the electrolyte and stabilize the $\mathrm{LiCoO}_{2}$ cathode in LIBs. ${ }^{151}$ SN-based ternary DES electrolytes were recently developed combining the nitrile with two Li salts, LiTFSI and lithium difluoro(oxalato)borate (LiDFOB). ${ }^{143,151} \mathrm{~A}$ LiTFSI:LiDFOB:SN DES at 0.17:0.03:0.8 mole ratio was employed as electrolyte in $\mathrm{Li}$ metal batteries ( $\mathrm{Li} \mid \mathrm{LiCOO}_{2}$ cell), displaying superior interfacial stability toward both the lithium metal anode and the high-voltage cathode. ${ }^{143} \mathrm{~A}$ critical effect of the LiDFOB salt on the interface of the $\mathrm{LiCOO}_{2}$ cathode was also observed by Xian et al. in $\mathrm{LiCoO}_{2} \mid \mathrm{Li}$ and $\mathrm{LiCO}_{2} \mid \mathrm{Li}_{4} \mathrm{Ti}_{5} \mathrm{O}_{12}$ cells. ${ }^{151}$ Compared with a LiTFSI:SN electrolyte at $0.75: 1$ mass ratio, the addition of a $4 \mathrm{wt} \%$ of LiDFOB resulted in a more stable cathode interface layer, suppressed parasitic reaction between $\mathrm{SN}$ and $\mathrm{Co}^{4+}$, and reduced dissolution of the transition metal Co. ${ }^{151}$ It was found that compared with other lithium salts, $\mathrm{Li}^{+}$in LiTFSI and LiDFOB displayed stronger coordination and hydrogen-bond interactions with $-\mathrm{C} \equiv \mathrm{N}$ from $\mathrm{SN}$, thus restraining the direct contact of lithium metal with nitrile molecules. ${ }^{143}$ The confined mobility of SN molecules would be responsible of the improved reduction-resistant properties on the surface of metal Li. As depicted in Fig. 8, the two salt anions on the one hand chemically reacted with the Li metal, prior to SN molecules, forming an insoluble functional SEI layer, on the other participated in the cathode/electrolyte interphase- 
forming reactions, resulting in a stable CEI. ${ }^{143}$ As a result, the ternary DES exhibited high ionic conductivity $\left(2.86 \mathrm{mS} \mathrm{cm}^{-1}\right)$ and a Li ion transference number of 0.44 at room temperature, close to that of commercial 1 $M$ LiPF $_{6}-\mathrm{EC} /$ dimethyl carbonate (DMC) electrolyte. ${ }^{143}$ This behavior protected both $\mathrm{Li}$ anode and LCO cathode, allowing for high performances of the cells. A Li| LiCoO ${ }_{2}$ cell with LiTFSI:LiDFOB:SN at 0.17:0.03:0.8 mole ratio as electrolyte achieved a capacity retention of about $80 \%$ for 1000 cycles and $77 \%$ for 750 cycles under cut-off voltages of 3.0-4.2 and 3.0-4.5 V, respectively. ${ }^{143}$ Even under a very high cut-off voltage of 4.7 $V$, the capacity retention over $70 \%$ was retained after 500 cycle. A capacity retention of about $94 \%$ for 100 cycles was also demonstrated in a $\mathrm{LiCOO}_{2} \mid \mathrm{Li}$ cell with $4 \mathrm{wt} \%$ of LiDFOB (about $0.5 \mathrm{M}$ ) as the additive of $2 \mathrm{M}$ LiTFSI:SN (mass ratio: $0.6: 1$ ) electrolyte. ${ }^{151}$ The safety and potential practical application of the LiTFSI:LiDFOB:SN electrolyte at 0.17:0.03:0.8 mole ratio was tested in a $\mathrm{LiCOO}_{2} \mid \mathrm{Li}$ pouch cell and compared with common carbonate electrolytes. ${ }^{143}$ While pouch cells with a commercial $1 \mathrm{M}$ LiPF 6 -EC/DMC electrolyte delivered severe gas evolution and swelled after several cycles, no volume expansion was detected for the pouch cell with the DES electrolyte after cycling. ${ }^{143}$

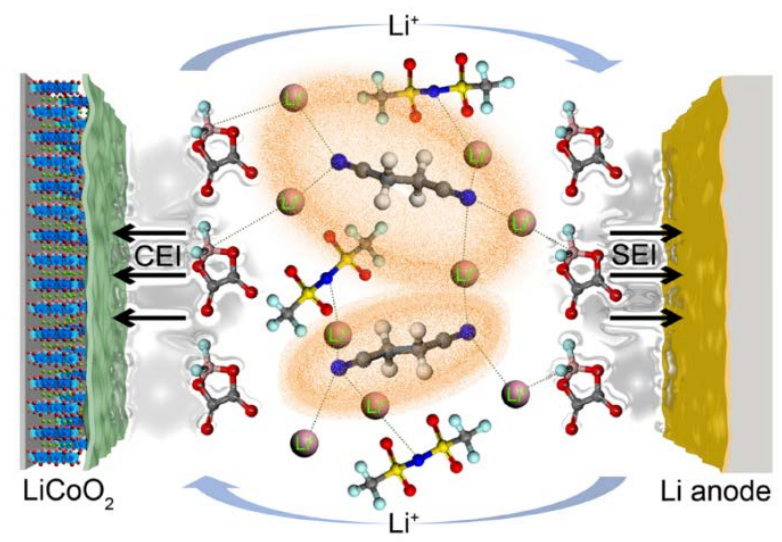

Figure 8. Schematic of the SEI and CEI formation and working mechanism in the ternary LiTFSI:LiDFOB:SN DES. Reprinted with permission from Hu et al. Nonflammable Nitrile Deep Eutectic Electrolyte Enables HighVoltage Lithium Metal Batteries, Chemistry of Materials, 32, 3405-3413. Copyright (2020) American Chemical Society.

\subsubsection{Lithium salts and alcohols}

A wide array of alcohols have been used so far as HBDs for DESs, ${ }^{5}$ but to the best of our knowledge their mixtures with lithium salts have not been applied as electrolytes for batteries yet. A few reports investigate their application for electrochemical double layer capacitors, ${ }^{146}$ or electrochromic devices, ${ }^{7,152,153}$ giving some insights into their characterization for electrochemical applications. Cruz et al. showed for instance that for the same lithium salt ( $\mathrm{LiCl}$ or lithium iodide Lil) DESs containing $\mathrm{G}$ showed lower conductivity values than the EG analogues. ${ }^{7,153}$ The same HBD EG was used by Tran et al. to prepare mixtures with LiTFSI, ${ }^{146}$ as alternative electrolytes to LiTFSI:amide systems, which are characterized by high viscosity at ambient temperature. The viscosity values of mixtures with mole ratio between $1: 1$ and 1:5 range from ca. 20 to $60 \mathrm{mPa}$ s at $30^{\circ} \mathrm{C}$ (Table 2), which is higher than the conventional electrolyte solution ( $1 \mathrm{M} \mathrm{LiTFSI}$ in EC or AN), even if markedly lower than those of other mixtures formed between Li-salts and amides (for instance LiTFSI:NMAA, $80 \mathrm{mPa}$ s, or $\left.\mathrm{LiNO}_{3}: \mathrm{NMAA}, \sim 110 \mathrm{mPa} \mathrm{s}\right) .{ }^{37}$ It should be noted that the decrease in viscosity does not necessarily translate into an enhancement of ionic conductivity. Among the synthesized DESs, LiTFSI:EG 1:4 exhibited the highest ionic conductivity value $\left(3.05 \mathrm{mS} \mathrm{cm}^{-1}\right.$ at $\left.30{ }^{\circ} \mathrm{C}\right) .{ }^{146}$ With the increase in the $\mathrm{EG}$ amount up to $80 \mathrm{wt} \%$, the ionic conductivity of the corresponding DES increased since EG promotes the hydrogen interaction between $\mathrm{Li}^{+}$ 
and the oxygen of EG or the - $\mathrm{SO}_{2}$ group of TFSl' and the hydrogen of EG. When EG concentration exceeded $80 \mathrm{wt} \%$, the conductivity started to decrease, likely due to the significant decrease in charge carrier concentration.

\subsubsection{Lithium salts and glymes}

A series of low-melting complexes formed by lithium salts (including $\mathrm{LiNO}_{3}$, LiTfO, lithium tetrafluoroborate $\mathrm{LiBF}_{4}, \mathrm{LiClO}_{4}$, lithium trifluoroacetate LiTFA, LiTFSI, LiBETI, and LiFSI) and oligo(ethyleneglycol) dimethyl ethers $\left(\mathrm{CH}_{3} \mathrm{O}\left(\mathrm{CH}_{2} \mathrm{CH}_{2} \mathrm{O}\right)_{n} \mathrm{CH}_{3}\right.$, known as glymes) have been extensively studied in the last two decades by Watanabe and coworkers. ${ }^{154-157}$ They have been categorized into a fourth family of ILs, the solvate (or chelate) ILs. ${ }^{158}$ However, they are included in the present discussion as they share many properties with DESs: (i) they can be prepared by simple mixing of glymes with Li salts; (ii) in appropriate combinations, the oxygen atoms in a glyme coordinate with $\mathrm{Li}^{+}$to form a complex cation [Li(glyme $\left.)_{n}\right]^{+}$in which $\mathrm{Li}^{+}$acts as Lewis acid and the glyme as a Lewis base; (iii) the melting points of some glyme-Li salt complexes are sufficiently low to keep them liquid at room temperature; (iv) they exhibit similar properties to DESs and RTILs, such as low flammability, low volatility, high lithium ion concentration, and a wide window of electrode potential.

According to the anion, [Li(glyme $\left.)_{n}\right] \mathrm{X}$ can be classified into two categories, dominated by the competitive interactions between glymes and counteranions and between glymes and $\mathrm{Li}^{+}$ions. ${ }^{157,159,160}$ [Li(glyme $\left.)_{n}\right] \mathrm{X}$ mixtures with weak Lewis basic anions (i.e. $\mathrm{TFSI}^{-}$and $\mathrm{ClO}_{4}{ }^{-}$) are reffered to as genuine solvate ILs (Fig. 9), where the amount of free glyme is a few percent, and glyme and $\mathrm{Li}^{+}$diffuse together as complex cations with a long life-time. In [Li(glyme) $\left.)_{n}\right] \mathrm{X}$ with strong Lewis basic anions (i.e. $\mathrm{TFA}^{-}$and $\mathrm{NO}_{3}{ }^{-}$), the interaction of the anion with the $\mathrm{Li}^{+}$is stronger than the $\mathrm{Li}^{+}$-glyme interaction, and a considerable amount of free glyme is present (Fig. 9). Hence they could be considered as traditional concentrated solutions. $\mathrm{BF}_{4}{ }^{-}$shows typically intermediate behaviors.

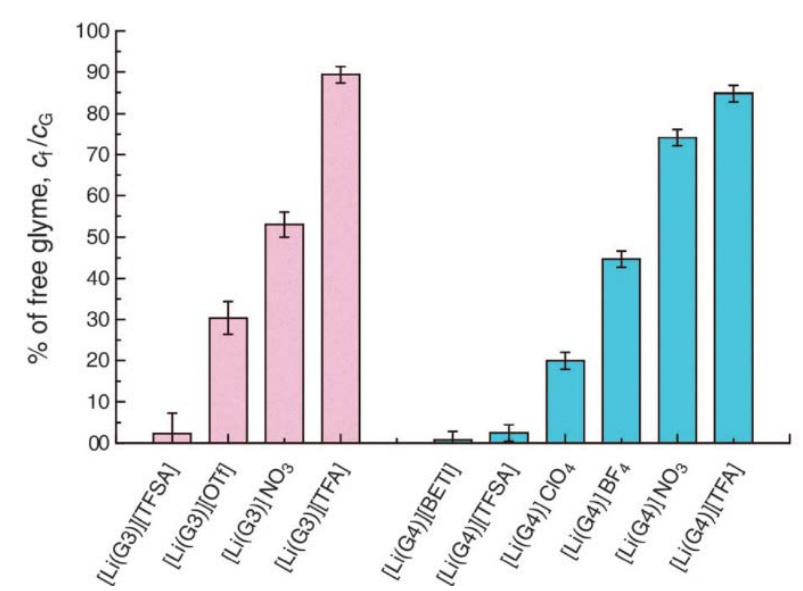

Figure 9. Estimated percentages of free glyme in equimolar molten mixtures [Li(glyme $\left.{ }_{1}\right] \mathrm{X}$ at $30{ }^{\circ} \mathrm{C}$. Republished with permission of Royal Society of Chemistry, from $\mathrm{Li}^{+}$solvation in glyme-Li salt solvate ionic liquids, Ueno et al., Phys. Chem. Chem. Phys. 2015, 17, 8248; permission conveyed through Copyright Clearance Center, Inc..

The most representative solvate ILs are the equimolar mixtures of triglyme (G3) or tetraglyme (G4) with LiTFSI. ${ }^{160}$ In $\left[\mathrm{Li}(\mathrm{G} 3)_{1}\right]$ TFSI and $\left[\mathrm{Li}(\mathrm{G} 4)_{1}\right] \mathrm{TFSI}$ a strong complexation occurs between all the glymes and the $\mathrm{Li}^{+}$ ions, resulting in [Li(G3 or G4) $]^{+}$formation. ${ }^{160,161}$ Due to the high ionicity $(0.6-0.7)$ and high concentration 
$\left(\sim 3 \mathrm{~mol} \mathrm{dm}^{-3}\right)$ of the $\left[\mathrm{Li}(\mathrm{G} 3 \text { or } \mathrm{G} 4)_{1}\right]^{+}$complex, ionic conductivities at room temperature up to $1.0-1.6 \mathrm{mS} \mathrm{cm}^{-}$

${ }^{1}$ are achieved. ${ }^{154}$

Noteworthy is that the complex formation enhances the oxidation stability of the ether structure because of the donation of lone pairs of ether oxygen to the $\mathrm{Li}^{+}$cation, so that the extraction of electrons from the lone pairs of equimolar complex cation [Li(glyme $\left.)_{1}\right]^{+}$becomes more difficult than that of free glyme. ${ }^{155,156}$ In this respect glyme-Li salt equimolar complexes differ from the diluted solutions containing the excess glymes. When the latter are used as electrolytes, the cells could not be operated stably due to the oxidation of free glymes and the corrosion of the aluminium current collector of the cathode. ${ }^{155}$

Equimolar mixtures of $\mathrm{G} 3$ or $\mathrm{G} 4$ were proved to be effective electrolytes in LIBs using different cathode $\left(\mathrm{LiCoO}_{2},{ }^{156} \mathrm{LiFePO}_{4},{ }^{162,163}\right.$ and elemental sulfur ${ }^{164}$ ) and anode (graphite ${ }^{162,163}$ and $\mathrm{Li}_{4} \mathrm{Ti}_{5} \mathrm{O}_{12}{ }^{163}$ ) materials. A LiTFSI:G3 1:1 electrolyte showed good electrochemical and battery performances in $3 \mathrm{~V}$-class $\left[\mathrm{LiFePO}{ }_{4} \mid \mathrm{Li}\right.$ metal], and $4 \mathrm{~V}$-class [ $\mathrm{LiNi}_{1 / 3} \mathrm{Mn}_{1 / 3} \mathrm{Co}_{1 / 3} \mathrm{O}_{2} \mid \mathrm{Li}$ metal] cells. ${ }^{165}$ Although relatively low discharge capacity (approximately $130 \mathrm{~mA} \mathrm{~h} \mathrm{~g}^{-1}$ per positive electrode) and CE (approximately 83\%) were observed at the first cycle, the calculated CEs were found to be close to $100 \%$ after two cycles, and stable charge/discharge capacities (over $140 \mathrm{~mA} \mathrm{~h} \mathrm{~g}^{-1}$ per positive electrode) were obtained within five cycles. The electrolyte/Li metal electrode interface was sufficiently stable for use in LIBs. Long cycle life tests were performed reaching up to 600 charge-discharge cycles for $\mathrm{LiFePO}_{4}(2.5-4.0 \mathrm{~V})$ and $60 \%$ of initial discharge capacity after 400 cycles for $\mathrm{LiNi}_{1 / 3} \mathrm{Mn}_{1 / 3} \mathrm{CO}_{1 / 3} \mathrm{O}_{2}$ (2.7-4.2 V). ${ }^{165}$ Non-equimolar mixtures having a higher Li salt concentration (e.g. [Li(G3) $0_{0.8}$ ]TFSI with molar ratio LiTFSI:G3 equal to 1:0.8) have also been tested. ${ }^{166}$ Despite an increase in the electrolyte's viscosity, the excess $\mathrm{Li}$ salts in glyme solvent compensate the $\mathrm{Li}$ cations close to the $\mathrm{LiCoO}_{2}$ electrode during the charge/discharge process limiting $\mathrm{G} 3$ decomposition. This improves the electrochemical stability at the electrolyte/electrode interface with respect to the charge/discharge reaction and leads to a longer cycle life of the batteries.

Li salt:glyme systems have also been tested as electrolytes for Li-S batteries. Elemental sulfur is one of the most promising cathode materials, as it is abundant, inexpensive and shows high theoretical capacity (1675 mAh $\left.{ }^{-1}\right) .{ }^{167,168}$ However, Li-S batteries usually face a few common troubles, especially the dissolution of lithium polysulfides, which are formed by the redox reaction at the $S$ cathode and lead to low $C E$ and quick capacity decay. ${ }^{167}$ The use of LiTFSI:G3 and LiTFSI:G4 allowed to suppress the dissolution of lithium polysulfides compared with solutions containing an excess amount of glyme, leading to the stable operation of the Li-S battery over more than 400 cycles with discharge capacities higher than $700 \mathrm{mAh} \mathrm{g}^{-1}$ and with CEs higher than $98 \%$ throughout the cycles. ${ }^{147}$ To further improve the Li-S cell performance, especially the conductivity of the LiTFSI:glyme electrolyte (ca. $10^{-3} \mathrm{~S} \mathrm{~cm}^{-1}$ at $30^{\circ} \mathrm{C}$ ), a second solvent, 1,1,2,2tetrafluoroethyl 2,2,3,3-tetrafluoropropyl ether (HFE), was added. A $1 \mathrm{M}\left[\mathrm{Li}(\mathrm{G} 4)_{1}\right] \mathrm{TFSI}$ in HFE showed reduced viscosity and increased ionic conductivity $\left(5.210^{-3} \mathrm{~S} \mathrm{~cm}^{-1}\right.$ at $\left.30^{\circ} \mathrm{C}\right) .{ }^{147}$ The dissolution of lithium polysulfide in the Li-S cell was further suppressed after addition of HFE as a second solvent, resulting in high coulombic and energy efficiencies, good cycle stability, and improved rate capabilities. The discharge capacity of the cell with [Li(G4) $)_{1}$ TFSI/HFE was $510 \mathrm{mAh} \mathrm{g}^{-1}$, even at a relatively high current density of $1672 \mathrm{~mA} \mathrm{~g}^{-1}$, compared to $180 \mathrm{mAh} g-1$ for the cell with $\left[\mathrm{Li}(\mathrm{G} 4)_{1}\right] \mathrm{TFSA}$ at the same rate. ${ }^{147}$

\subsubsection{Lithium salts and ketoesters}

In the quest for alternative electrolytes, Watanabe's group recently reported a series of liquid 1:1 equimolar mixtures composed of LiFSI and ketoesters with two carbonyl coordinating sites of increasing intramolecular distance (methyl pyruvate MP, methyl acetoacetate MA, and methyl levulinate ML, with zero, one or two methylene groups between the two carbonyl groups, respectively). ${ }^{148} \mathrm{MP}$ - and ML-based electrolytes 
exhibited high viscosities exceeding $1000 \mathrm{mPa} s$ at $30^{\circ} \mathrm{C}$, leading to a relatively low conductivity of $10^{-4} \mathrm{~S} \mathrm{~cm}^{-}$ ${ }^{1}$ (Table 2). For unclear reasons, the MA-based electrolyte showed a one-order of magnitude lower viscosity, and higher conductivity and diffusion constants.

The transport mechanism of the mixtures was investigated and it turned out to be different from Li-glymes complexes. ${ }^{148}$ In the glyme-Li salt solvate ILs, the Li ion transport tipycally occurs via the physical diffusion mechanism (vehicle mechanism). Contrarily, in the LiFSI:ketoester systems other transport mechanisms, namely Li ion hopping/exchange (analogous to the proton-hopping Grotthuss or structural diffusion mechanism), make a significant contribution to Li ion diffusion.

Moreover, the ionic transport behavior in MP- and MA-based electrolytes turned out to be different than in ML-based electrolytes, being driven by a unique Li ion coordination structure. ${ }^{148}$ Diffusivity measurements showed that in shorter MP- and MA-based electrolytes Li ion diffused the fastest. This was explained considering a predominant $\mathrm{Li}$ ion hopping and exchange in a structure characterized by solvent-shared, extended chain-like coordinating sites, and highly aggregated ion pairs or multiionic ionic clusters between $\mathrm{FSI}^{-}$and $\mathrm{Li}^{+}$. In contrast, FSI anions moved the fastest in ML-based electrolytes, as a result of frequent anion exchange reactions. Indeed, due to the greater intramolecular distance between the carbonyl moieties, ML would be more prone to form a bidentate complex with a Li cation, so that the appearance of the solvent bridged structure was less-pronounced. Even though $\mathrm{Li}^{+}$and $\mathrm{FSI}^{-}$can still diffuse through the ion exchange mechanism in aggregated ion pairs structures, the lack of the solvent-shared, extended structures made an additional Li ion exchange mechanism unlikely.

\subsection{Lithium salt-added type III DESs}

Next to DESs composed of a Li salt as HBA, type III DESs added with Li salts have been considered to possess favorable properties as electrolyte media for LIBs. A number of neat DESs, composed of different ammonium and phosphonium salts and a wide array of HBDs, have been characterized in terms of viscosity and conductivity in the light of a potential use as electrolytes in LIBs. ${ }^{4,714,20,76,169} \mathrm{ChCl}$-based DESs are the most widely investigated, thanks to the multiple benefits of this HBA: it is biodegradable, inexpensive, water soluble, and can be simply and efficiently produced through a gas phase reaction between ethylene oxide, trimethylamine, and $\mathrm{HCl}$ with a Roger Sheldon "E factor" close to zero (i.e. almost no waste products during the reaction). ${ }^{170} \mathrm{An}$ interesting conductivity of $0.75 \mathrm{mS} \mathrm{cm}^{-1}$ was measured for the archetypical DES reline, ${ }^{20}$ and higher values were found by replacing $U$ with other $H B D$ s such as $G, E G$ or oxalic acid (OA). ${ }^{7,14,76}$ As already seen in DESs composed of Li salts and alcohols, EG-based type III DESs showed lower viscosities and higher conductivity values compared to the G-based series $\left(7.12 \mathrm{mS} \mathrm{cm}^{-1}\right.$ for ChCl:EG vs $1.02 \mathrm{mS} \mathrm{cm}^{-1}$ for ChCl:G). ${ }^{14}$ Of interest is the comparison made by Cruz et al. for the same HBD, going from Li salt to $\mathrm{ChCl}$. The conductivity values of ChCl-based DESs were at least six times higher than similar LiCl-based DESs (8.85 vs $1.45 \mathrm{mS} \mathrm{cm}^{-1}$ for the EG series, and 2.08 vs $0.29 \mathrm{mS} \mathrm{cm}^{-1}$ for the $\mathrm{G}$ series). ${ }^{7}$ Alternative organic salts used as HBA yielded even higher conductivities (for instance values of 10.29 and $17.76 \mathrm{mS} \mathrm{cm}^{-1}$ at $25{ }^{\circ} \mathrm{C}$ were reported for tetramethylammonium chloride (TMCl):EG 1:3 and allyltrimethylammonium chloride (AMCl):EG 1:2, respectively $)^{14}$. A decrease in conductivity and a parallel increase in viscosity was observed with the increase in the alkyl chain lengths of the HBA (for instance changing HBA from $\mathrm{TMCl}$ to tetraethylammonium chloride (TECI) to tetrabutylammonium chloride (TBCl), the viscosities of the corresponding DESs with EG were 26.12, 50.43 and $61.16 \mathrm{mPa}$ s, respectively, while conductivities $10.29,5.65$ and $1.57 \mathrm{mS} \mathrm{cm}^{-1}$, respectively $)^{14}$. Similarly, comparing $\mathrm{ChCl}$-based DESs with three butanediols having different functional group positions ( 1 , 2-butanediol, 1, 3-butanediol and 1, 4- butanediol) it was shown that the conductivity decreased (1.26, 1.12 
and $0.96 \mathrm{mS} \mathrm{cm}^{-1}$, respectively), and viscosity increased (56.99, 72.02 and $100.69 \mathrm{mPa}$ s, respectively) following the increase in the number of carbon atoms between the two hydroxyl groups. ${ }^{171}$

Another key parameter in electrochemical applications is the ESW, as it allows the determination of the anodic and cathodic limit, where it is possible to work without the degradation of the DES. Comparing the $\mathrm{LiCl}$ - and the $\mathrm{ChCl}$-series, the largest ESWs were observed for the former ( $\mathrm{LiCl}: \mathrm{EG}$ 3.8 $\mathrm{V}$ and $\mathrm{LiCl}: \mathrm{G} 3.7 \mathrm{~V}){ }^{7} \mathrm{The}$ same HBD EG promoted an increase of almost $500 \mathrm{mV}$ from the replacement of $\mathrm{ChCl}$ to $\mathrm{LiCl}$ (3.3 vs $3.8 \mathrm{~V}$ ), and an even higher increase was observed for the case of $\mathrm{G}(700 \mathrm{mV}$, from 3.0 to $3.7 \mathrm{~V}$ for $\mathrm{ChCl}$ to $\mathrm{LiCl})$. This can be traced back to the lithium cation which would stabilize the DES more than $\mathrm{ChCl}^{7}$ In a study of $23 \mathrm{Ch}$ based DESs ( $\mathrm{ChCl}$, choline iodide $\mathrm{Chl}$, choline bromide $\mathrm{ChBr}$, choline tetrafluoroborate $\mathrm{ChBF}_{4}$, choline nitrate $\mathrm{ChNO}_{3}$, choline perchlorate $\mathrm{ChClO}_{4}$ ) it was shown that the DESs composed of $\mathrm{ChCl}$ displayed the largest ESW, with $\mathrm{ChCl}: \mathrm{MU}$ the one with the largest value $(4.72 \mathrm{~V}) .{ }^{172}$

Investigations of neat DESs are clearly fundamental, but to enable the exploitation of these media in electrochemical applications including LIBs, dissolution of Li salts have to be considered and hence a preliminary understanding of the change in the DES structural organization upon addition of the salt is needed. As the archetypal DES, reline has been studied upon addition of the Li salt containing the same anion, $\mathrm{LiCl}^{173,174}$ In the pioneering paper by Abbott et al., a high solubility of $\mathrm{LiCl}\left(>2.5 \mathrm{~mol} \mathrm{dm}^{-3}\right)$ in reline was already observed. ${ }^{3}$ With increasing $\mathrm{LiCl}$ content, the density of $\mathrm{LiCl}$-added reline increases linearly and the dynamic viscosity increases exponentially. ${ }^{173}$

Mixtures of $\mathrm{ChCl}$ with different $\mathrm{HBDs}$ (EG, G, LA) were also tested upon addition of a Li salt (LiTFSI, LiPF 6 ). ${ }^{175,176}$ The addition of the salt significantly perturbs the nano/microstructural organization of the pristine DESs. Overall, the Li salt causes an increase in viscosity (with LiPF ${ }_{6}<$ LiTFSI, Table 3), decrease in conductivity (Table 3), and decrease in ${ }^{1} \mathrm{H}$ diffusion values (for instance from $2.2 \times 10^{-11} \mathrm{~m}^{2} \mathrm{~s}^{-1}$ in neat ChCl:EG to $0.65 \times 10^{-11} \mathrm{~m}^{2} \mathrm{~s}$ ${ }^{1}$ after addition of LiTFSI at 0.3 mole fraction). ${ }^{175,176}$ In line with previous observations, EG-based systems exhibited lower viscosities, higher diffusivities and higher conductivity than systems based on $G$ or LA, due to the presence of a less extensive hydrogen bonding network between $\mathrm{ChCl}$ and $\mathrm{EG}$ as well as within $\mathrm{EG}$ molecules. ${ }^{175,176} \mathrm{ChCl}$ :EG containing $\mathrm{Li}$ salts has then the potential to act as a discrete medium for electrochemical applications. In particular $\mathrm{ChCl}: \mathrm{EG}+\mathrm{LiPF}_{6} 0.5 \mathrm{M}$ displayed a ionic conductivity of $7.95 \mathrm{mS}$ $\mathrm{cm}^{-1}$ and viscosity of $88.4 \mathrm{mPa}$ s at room temperature, together with a reasonable electrochemical stability against glassy carbon as the working electrode $(3.5 \mathrm{~V}) .{ }^{176}$

As previously discussed in several examples, the addition of a third component may be favorable in mitigating some limitations of DESs. In this context it is of interest a study of a mixture of ChCl:EG 1:2, $\mathrm{LiClO}_{4}$ and propylene carbonate (PC). ${ }^{177}$ The viscosities of the mixtures increases with addition of $\mathrm{LiClO}_{4}$ to the $\mathrm{PC}$ or $\mathrm{PC}$ + DES systems and by increasing the mass fraction of DES (Fig. 10). DFT results revealed that the interactions between DES and $\mathrm{LiClO}_{4}$ are stronger than those between $\mathrm{LiClO}_{4}$ and $\mathrm{PC}$ and DES-PC, leading to an enhancement of solute-solvent interaction as a result of DES addition. ${ }^{177}$ 


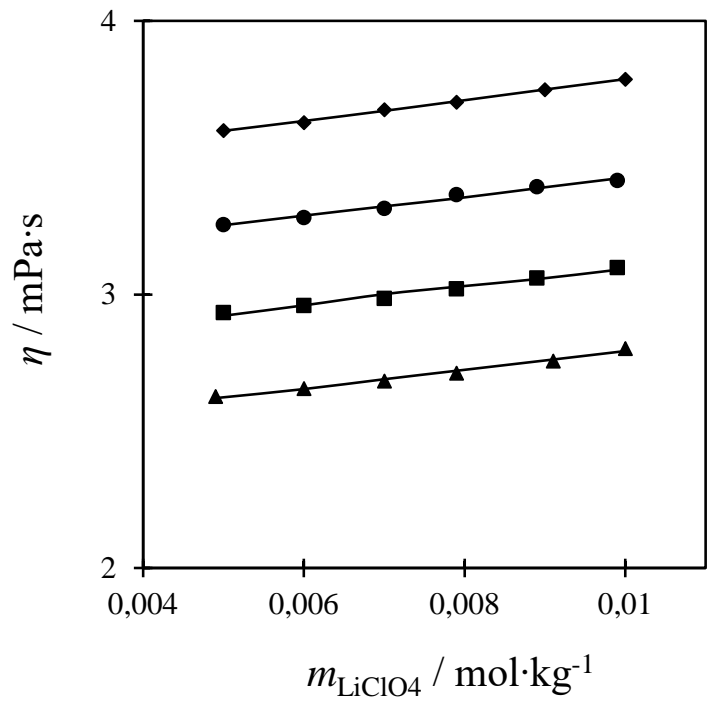

Figure 10. Experimental and calculated viscosity $\eta$ at $25^{\circ} \mathrm{C}$ versus molality of $\mathrm{LiClO}_{4}\left(m_{\mathrm{LiclO} 4}\right)$ in propylene

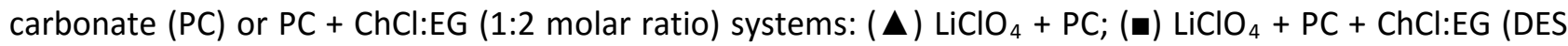
mass fraction of 0.05$) ;(\bullet) \mathrm{LiClO}_{4}+\mathrm{PC}+\mathrm{ChCl}$ :EG (DES mass fraction of 0.1$) ;(\bullet) \mathrm{LiClO}_{4}+\mathrm{PC}+\mathrm{ChCl}$ :EG (DES mass fraction of 0.15). Reprinted from Journal of Molecular Liquids, 319, Zafarani-Moattar et al., Investigation of solute-solvent interactions in binary and quaternary solutions containing lithium perchlorate, propylenecarbonate, and the deep eutectic solvent (cholinechloride/ethylene glycol) at $T=(288.15$ to 318.15) $K, 114090$, Copyright (2020), with permission from Elsevier. 
Table 3. Density, viscosity and conductivity values for selected type III DES electrolytes added with litiuhm salts.

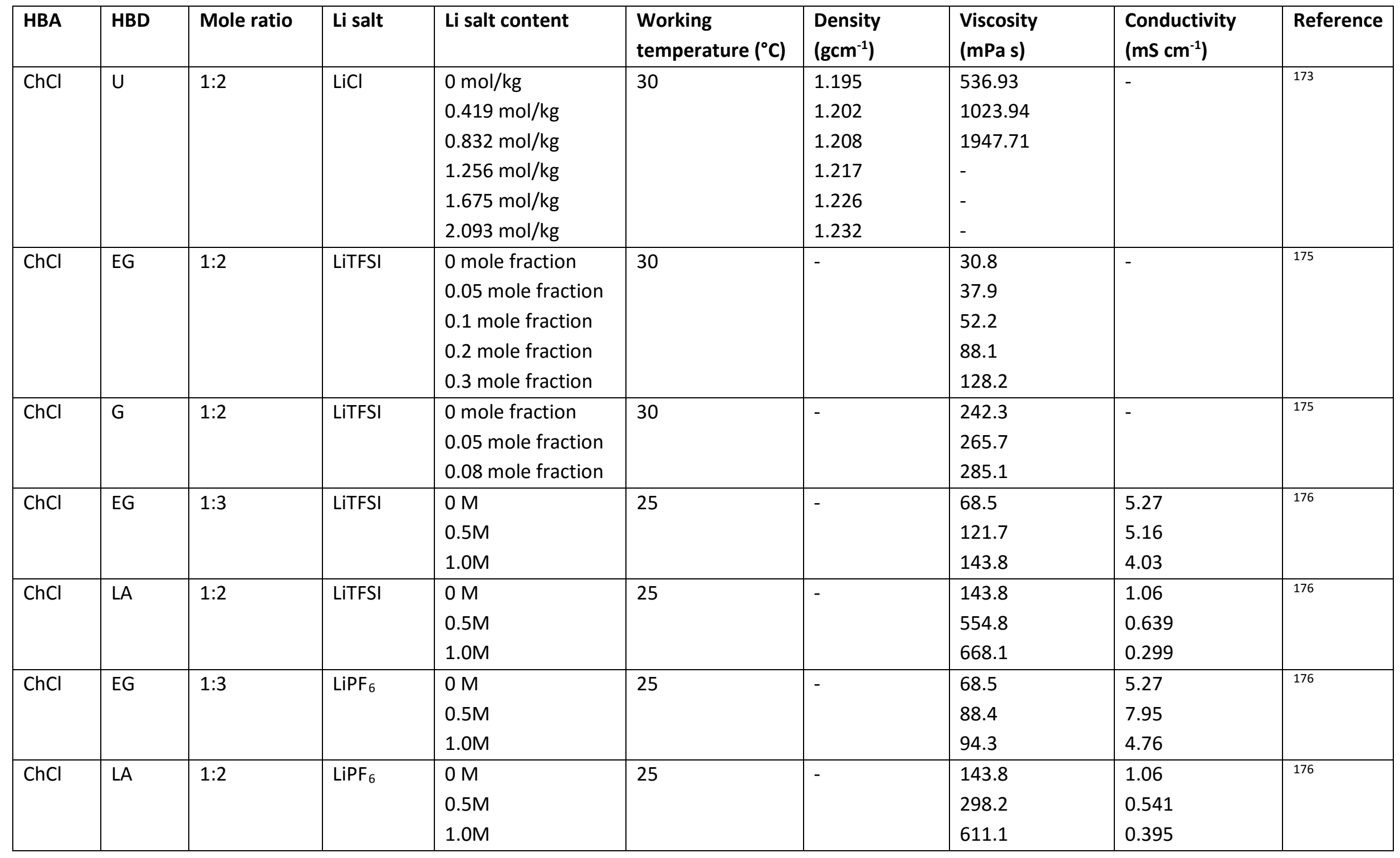




\section{Sodium and Potassium batteries}

To replace the lithium based energy storage technology, other alkali metal-based batteries ( $\mathrm{Na}$ and $\mathrm{K}$ ) are the most evident solutions. ${ }^{178,179}$ Contrary to Li mineral reserves which are limited and unevenly distributed in the earth crust, $\mathrm{Na}$ and $\mathrm{K}$ resources are globally abundant (for instance $\mathrm{Na}$ primarily in seawater as sodium chloride $\mathrm{NaCl}$ ) and attainable at low cost making it possible to develop inexpensive alternatives to LIBs. ${ }^{98,119,180,181}$ This is attractive especially for large-scale applications, where price per kWh precedes power considerations. The fundamental similarities in the electrochemistry and physicochemical properties of alkali metal K, Na and Li have largely driven the development of Na and K ion batteries (NIBs and KIBs), and in general the know-how gained from LIB electrolyte development is extensively applied to NIBs and KIBs. There are however some features that differ and in contrast to LIB, which is a mature technology, only limited numbers of electrolytes based on sodium and potassium ions are available so far, mainly based on organic carbonate solutions of a K/Na salt. As members of light metals, $\mathrm{Na}$ and $\mathrm{K}$ have been paid less attention than $L i$ because of their higher chemical reactivity. Together with the wide application of highly flammable electrolytes in NIBs and KIBs, these overactive chemical properties bring potential safety hazards such as thermal run-away. ${ }^{119,182}$ Hence, the design of non-flammable organic liquid electrolytes to hinder the safety concerns of NIBs and KIBs is imperative. The unique merits of DESs - low vapor pressure, non-flammability, good solubility of salts, low cost, manufacturing ease, non-toxicity, and biodegradability - make them ideal choice as electrolytes for alkali metal-based batteries. Although DES-based electrolytes have been successfully applied in Li batteries, to the best of our knowledge, their applications in $\mathrm{Na}$ and $\mathrm{K}$ batteries have scarcely been reported yet.

\subsection{Type IV DESs composed of sodium/potassium salts and HBDs}

A few works reported a basic characterization of mixtures of some $\mathrm{Na}$ and $\mathrm{K}$ salts and a handful of HBDs.

DES composed of sodium salts ( $\mathrm{NaCl}$, sodium bromide $\mathrm{NaBr}$, sodium iodide $\mathrm{Nal}$, sodium nitrate $\mathrm{NaNO}_{3}$ ) as the HBA with EG or NMAA as the HBD were introduced and preliminarily suggested for application in supercapacitors and fuel cells. ${ }^{98,183-185}$ For the systems based on sodium halides, density and viscosity were in the ranges $1.12-1.50 \mathrm{~g} \cdot \mathrm{cm}^{-3}$ and $7.35-81.23 \mathrm{mPa} \cdot \mathrm{s}$ in the temperature interval $20-60{ }^{\circ} \mathrm{C}$, and increased in the order $\mathrm{NaCl}<\mathrm{NaBr}<\mathrm{Nal}$ (note however that different molar ratio were used for the three DESs, 1:16, 1:6 and 1:4 for $\mathrm{NaCl}, \mathrm{NaBr}$ and $\mathrm{Nal}$, respectively) (Table 4). ${ }^{184}$ For the same salt, e.g. Nal, the viscosity increased with the salt content: Nal:EG at mole ratio $1: 4$ had about $36 \%$ and $94 \%$ higher viscosities than 1:6 and 1:10 mole ratios at $20^{\circ} \mathrm{C}$, respectively. ${ }^{183}$ Electric conductivities of $\mathrm{NaCl}: \mathrm{EG}, \mathrm{NaBr}$ :EG ad Nal:EG were in the range 3.55-14.46 mS $\cdot \mathrm{cm}^{-1}$ in the temperature interval $20-60{ }^{\circ} \mathrm{C}$ (Table 4), which is several order of magnitude higher than the corresponding values for pure EG $\left(11.6 \mu \mathrm{S} \mathrm{cm}^{-1}\right) .{ }^{184}$ Water addition was used as a strategy to reduce viscosity and increase conductivity. For instance the addition of $15 \mathrm{wt} \%$ water in NaBr:EG at molar ratio $1: 10$ caused about a $173 \%$ drop in DES viscosity at $20{ }^{\circ} \mathrm{C}$ compared to the pristine DES, while the presence of 5,10 and 15 wt\% water increased the proton conductivity at $100{ }^{\circ} \mathrm{C}$ up to $17 \%, 31 \%$ and $36 \%$, respectively. ${ }^{185}$

As far as potassium is concerned, potassium carbonate $\mathrm{K}_{2} \mathrm{CO}_{3}$ was used in combination to $\mathrm{G}$ and $\mathrm{EG}$. ${ }^{186} \mathrm{G}$ based DESs showed very high viscosities, with values of 28, 18 and $5.5 \mathrm{~Pa} s$ at molar ratio 1:4, 1:5 and 1:6 (Table 4). Contrarily, as seen for Li salts, EG-based DESs exhibited considerably lower viscosities and higher conductivities.

Watanabe's group extended the concept of solvate ILs initially developed for Li salts also to $\mathrm{Na}$ and K salts. A series of mixtures were then prepared combining glymes of different length (monoglyme G1, diglyme G2, 
G3, G4, pentaglyme G5 and hexaglyme G6) with a few Na (sodium bis(trifluoromethanesulfonyl)imide NaTFSI, sodium bis(fluorosulfonyl)imide $\mathrm{NaFSI}$, sodium perchlorate $\mathrm{NaClO}_{4}$, and sodium hexafluorophosphate $\mathrm{NaPF}_{6}$ ) and $\mathrm{K}$ (potassium bis(trifluoromethanesulfonyl)imide $\mathrm{KTFSI}$, and potassium hexafluorophosphate $\mathrm{KPF}_{6}$ ) salts. ${ }^{187-189}$ Both the glyme length and $\mathrm{M}^{+}$ion were key factors in defining the compositions at which stable 1:1 or 1:2 complexes were formed (Fig. 11). As for Li-analogues, in the equimolar binary mixtures all the glyme molecules coordinate to $\mathrm{Na}^{+}$or $\mathrm{K}^{+}$cations and free glyme molecules scarcely exist. ${ }^{189}$ Like previous studies with Li salts, such complexation enhanced the oxidative and thermal stability of the equimolar mixtures in comparison with those of diluted systems. Anodic limits higher than $\sim 4.5 \mathrm{~V} \mathrm{vs} \mathrm{Li}^{\prime} / \mathrm{Li}^{+}$were observed for the studied systems, while typical ether molecules are electrochemically oxidized at $\sim 4.0 \mathrm{~V}$ vs $\mathrm{Li} / \mathrm{Li}^{+}{ }^{189}$ As a result of a fine balance among complicated competitive interactions, Na-based systems possessed higher thermal stabilities than electrolytes incorporating $\mathrm{Li}$ and $\mathrm{K}$ salts, regardless of the glyme length. ${ }^{189}$

$\left[\mathrm{Na}(\mathrm{G} 5)_{1}\right]$ TFSI was the best Na-based performing system with appreciable conductivity of ca. $0.6 \mathrm{mS} \mathrm{cm}^{-1}$ at $30{ }^{\circ} \mathrm{C}$ and high ionicity comparable to that of typical imidazolium-based ILs and [Li(G3) $\left.{ }_{1}\right]$ TFSI without any other additional solvent (Table 4). ${ }^{187}$ It was further tested in a [Na metal|[ $\left.\mathrm{Na}(\mathrm{G} 5)_{1}\right]$ TFSI| $\mathrm{Na}_{0.44} \mathrm{MnO}_{2}$ ] cell operated at $60{ }^{\circ} \mathrm{C}$, showing reversible charge-discharge behavior with a capacity of ca. $100 \mathrm{~mA} \mathrm{~h} \mathrm{~g}^{-1} \mathrm{for}_{50}$ cycles $^{188}$ The charge-discharge CE was approximately $90 \%$ in the second cycle and the efficiency improved with increasing cycle number, reaching over $95 \%$ after 30 cycles. Although the capacity gradually decreased through cycling, the cell with [ $\left.\mathrm{Na}(\mathrm{G} 5)_{1}\right] \mathrm{TFSI}$ exhibited a highly reversible charge- discharge behavior in the voltage range of $2.0-4.0 \mathrm{~V}$. On the contrary, the cell using as electrolyte $\left[\mathrm{Na}(\mathrm{G} 5)_{x>1}\right] \mathrm{TFSI}$ with excess glymes could not be operated because of undesired reactions originating from the oxidation of excess glymes. ${ }^{188}$

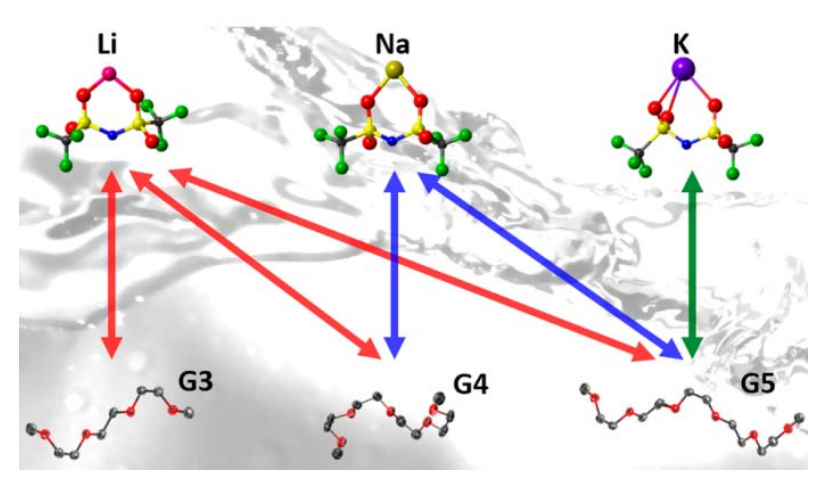

Figure 11. Combinations of alkali metal salts and glymes giving stable solvate ILs. Reprinted with permission from Mandai et al. Effect of Ionic Size on Solvate Stability of Glyme-Based Solvate Ionic Liquids, The Journal of Physical Chemistry B, 119, 1523-1534. Copyright (2015) American Chemical Society. 
Table 4. Density, viscosity and conductivity values for selected DES electrolytes based on the combination of $\mathrm{Na} / \mathrm{K}$ salt and HBD.

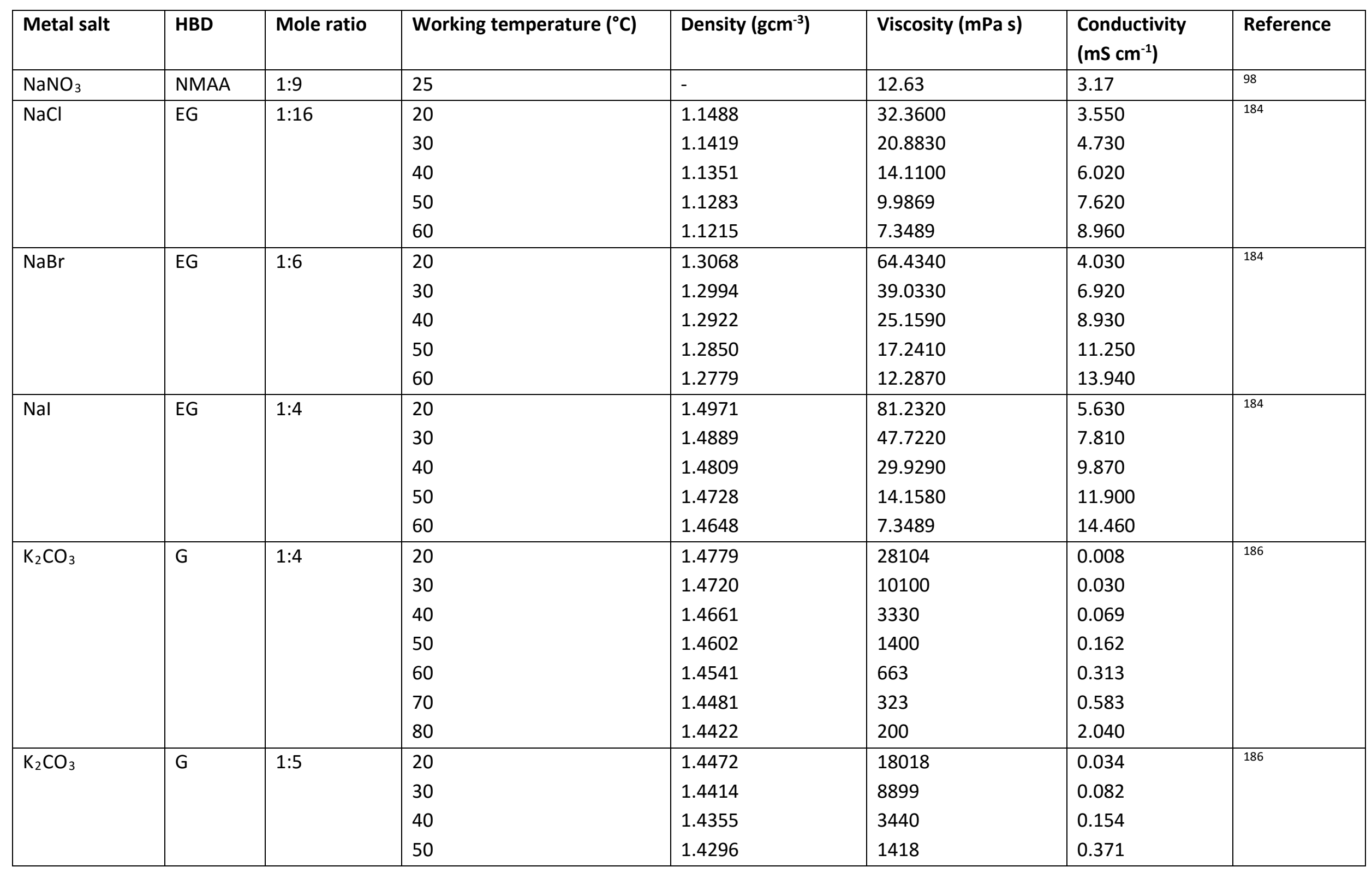




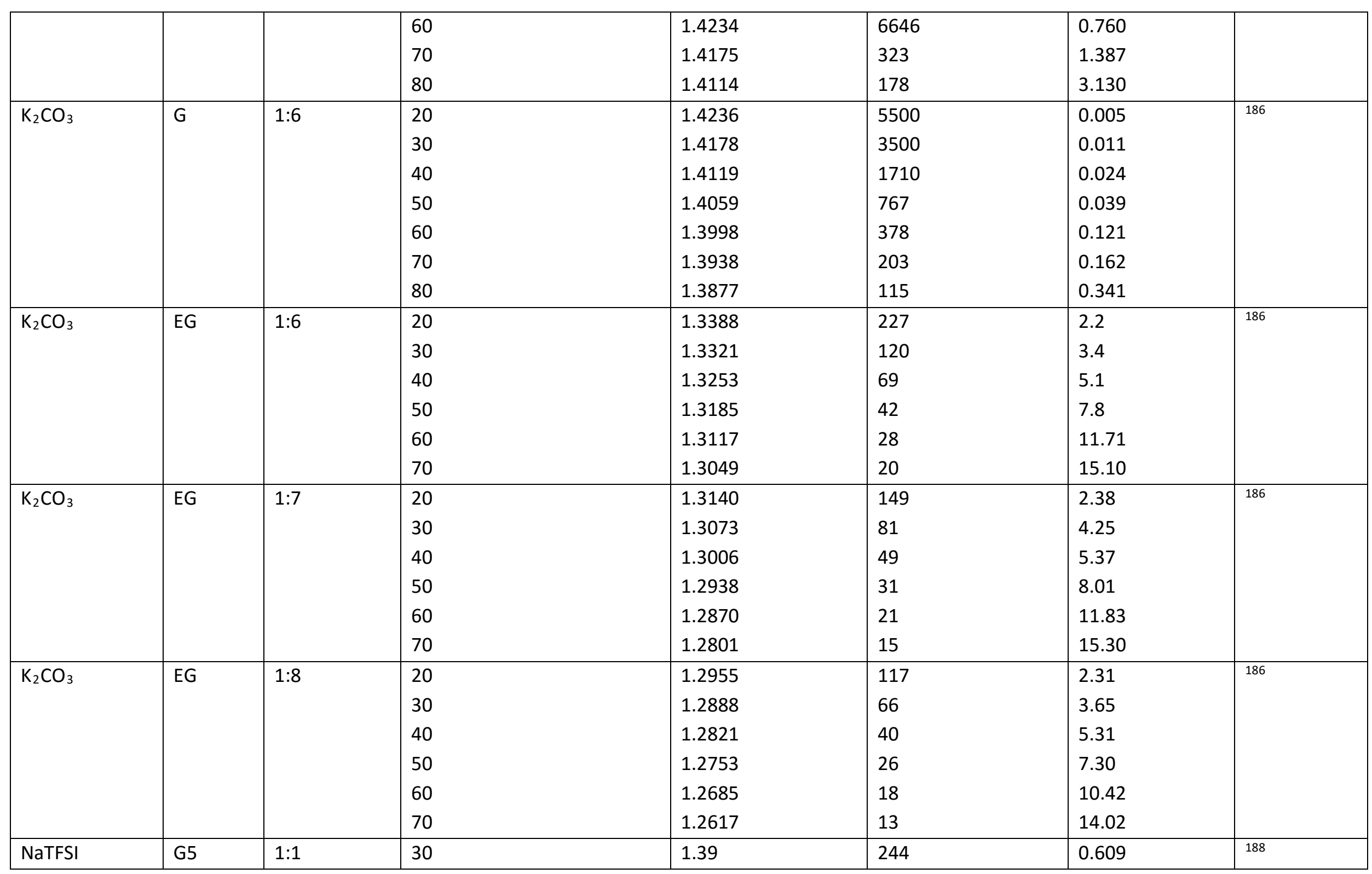




\section{Aluminium batteries}

Rechargeable batteries based on Al chemistry may represent a low cost and safe option for grid-scale energy storage systems. ${ }^{190}$ Indeed, the currently used methodologies, lead-acid batteries and LIBs, are far from being ideal. ${ }^{13,191}$ On the one hand, lead-acid batteries are low-cost, but show low energy density (30-50 W h kg${ }^{-1}$ ) and pose a serious threat to the environment. ${ }^{13}$ On the other hand, long-term, large-scale application of LIBs appears to be problematic due to a number of already mentioned factors, including the limited Li natural reserves, the natural scarcity and limited production capacity of key materials containing $\mathrm{Co}$ and $\mathrm{Ni}$, the flammable nature of organic-based solvents, and difficulty in recycling. ${ }^{192,193} \mathrm{Al}$-based batteries offer a viable alternative because $\mathrm{Al}$ is lightweight, low cost and abundant (the most abundant metal and the third most abundant element in the Earth's crust). ${ }^{190,193}$ Moreover, the inertia of Al, and ease of handling at ambient conditions can significantly enhance the safety of Al battery systems. ${ }^{194}$ In addition, Al batteries are a good choice for energy storage due to Al three-electron redox properties which can provide a theoretical gravimetric capacity of $2980 \mathrm{mAhg}^{-1}$, comparable to that of Li metal $\left(3860 \mathrm{mAh} \mathrm{g}^{-1}\right) \cdot{ }^{195}$ Although Al also has a higher redox potential ( $-1.76 \mathrm{~V}$ vs SHE) than other metals, the much higher volumetric capacity ( $8046 \mathrm{mAh}$ $\mathrm{cm}^{-3}$, almost 4 times higher than $\mathrm{Li}, 2062 \mathrm{mAh} \mathrm{cm}^{-3}$ ) is expecte to yield energy densities close to or even higher than those of battery systems using other metals. ${ }^{194,195}$ However, Al batteries face some issues: on the one side, fatal drawbacks related to aqueous electrolytes, such as passive oxide film formation, hydrogen side reactions and anode corrosion; one the other, various technical and scientific hurdles to the design of non-aqueous Al batteries with high capacity and long cycling life. ${ }^{194}$ A number of DES systems based on Al salts have been proposed as nonflammable electrolytes of low toxicity in Al batteries to minimize safety hazard and environmental impact.

\subsection{Type IV DESs composed of aluminium salt and HBDs}

DES electrolytes for Al batteries are all based on the same Al salt, aluminum (III) chloride $\left(\mathrm{AlCl}_{3}\right)$, and a handful of HDBs, primarily amides with few exceptions. Their applications is however growing at a rapid pace, and Al batteries with DES electrolytes are the second most widely investigated after Li batteries (Fig. 4). This section is then divided according to the type of battery rather then the DES formulation.

\subsubsection{Aluminium ion batteries}

Various mixtures of $\mathrm{AlCl}_{3}$ and amides (U, AA, NMAA, N,N-dimethylacetamide DMAA) have been reported in 2010s. ${ }^{19,196,197} \mathrm{The} \mathrm{AlCl}_{3}: \mathrm{U}$ system was then used in 2017 independently by Angell et al. and Jiao et al. to develop Al ion batteries (AIBs).

Angell and coworkers developed an Al battery operating using aluminum as the anode, graphite as the cathode, and a mixture of $\mathrm{AlCl}_{3}$ and $\mathrm{U}$ at 1.3:1 molar ratio as electrolyte. ${ }^{13}$ Addition of two drops of ethylaluminum dichloride as an additive enabled the operation at room temperature. ${ }^{194}$ The battery yielded a specific cathode capacity of $\sim 73 \mathrm{mAh} \mathrm{g}^{-1}$ at a current density of $100 \mathrm{~mA} \mathrm{~g}^{-1}(\sim 1.4 \mathrm{C})$. Initial cycling at $100 \mathrm{~mA}$ $\mathrm{g}^{-1}$ required $\sim 5-10$ cycles for stabilization of the capacity and $C E$, suggesting side reactions occurring during this time. The CE during first cycle was consistently around $90 \%$, and increased above $100 \%$ during the first 5-10 cycles, until a stable capacity with CE at $\sim 99.7 \%$ was reached. ${ }^{13}$ The cell was demonstrated to be stable over $\sim 180$ cycles with high CE.

In the same period, Jiao et al reported an $\mathrm{AIB}$ established at $120^{\circ} \mathrm{C}$ using an $\mathrm{AlCl}_{3}: \mathrm{U}$ electrolyte at mole ratio 1.5:1, and graphite and pure aluminum as cathode and anode, respectively. ${ }^{191}$ Unlike the device reported by Angell and coworkers, this battery operated at a temperature higher than room temperature, in order to overcome the poor conductivity. At a current density of $100 \mathrm{~mA} \mathrm{~g}^{-1}$ a high initial specific capacity of $93 \mathrm{~mA} \mathrm{~h}$ 
$\mathrm{g}^{-1}$ and CE higher than $99 \%$ were observed, with the specific capacity remaining $95.3 \%$ of the initial value after 100 cycles. ${ }^{191}$ Long-term cycling stability of the AIB was evaluated at $200 \mathrm{~mA} \mathrm{~g}^{-1}$ for 500 cycles, demonstrating that the specific capacity remained at $75 \mathrm{~mA} \mathrm{~h} \mathrm{~g}^{-1}$ with a high CE of $99 \%$. A considerable capacity of about $78 \mathrm{~mA} \mathrm{~h} \mathrm{~g}^{-1}$ was retained even at a high current density of $1000 \mathrm{~mA} \mathrm{~g}^{-1} .{ }^{191}$ Also, the cell exhibited good cycling stability and rate performance, as the specific capacity went back to approximately 83 $\mathrm{mA} \mathrm{h} \mathrm{g}{ }^{-1}$ with a CE above $99 \%$, once the current density was set at $400 \mathrm{~mA} \mathrm{~g}^{-1}$ after cycling at $1000 \mathrm{~mA} \mathrm{~g}^{-1} .191$ Instead of pure Al as anode material, the same group suggested the replacement with aluminium alloy foil. ${ }^{198}$ This would solve some issues related from the one side to the price of pure aluminum, and from the other to the high $\mathrm{Al}$ content of pure $\mathrm{Al}$ anode, which is susceptible to be corroded in $\mathrm{AlCl}_{3}: \mathrm{U}$, resulting in capacity decay. Batteries composed of Al alloy foil (thickness $0.6 \mathrm{~mm}$ ) as anode, pyrolyzed graphite as cathode and $\mathrm{AlCl}_{3}: \mathrm{U}$ (1.4 and 1.5 molar ratio) as electrolyte were assembled in a Teflon cell operated at $110-130{ }^{\circ} \mathrm{C} .{ }^{198}$ The discharge voltage of the battery was about $1.9 \mathrm{~V}$ and $1.6 \mathrm{~V}$, and at the current density of $100 \mathrm{~mA} \mathrm{~g}^{-1}$ the cell produced a specific capacity of ca. $94 \mathrm{~mA} \mathrm{~h} \mathrm{~g}^{-1} .198$

Aiming at improving the performances of the $\mathrm{AlCl}_{3}: U$-based battery proposed by Angell et al., while operating at ambient temperature, alternative cathode materials based on natural graphite (NG) flakes obtained by ultrasonication or graphene nanoplatelets (GNP) were proposed. ${ }^{27,199}$ Appreciable specific capacities and CEs

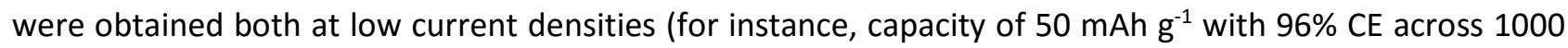
cycles at $600 \mathrm{~mA} \mathrm{~g}^{-1}$ with NG and $\mathrm{AlCl}_{3}: \mathrm{U} 1.3: 1{ }^{199}$ or capacity of $74 \mathrm{mAh} \mathrm{g}^{-1}$ with $78 \% \mathrm{CE}$ at $100 \mathrm{~mA} \mathrm{~g}^{-1}$ with GNP and $\mathrm{AlCl}_{3}: \mathrm{U} 1.4: 1^{27}$ ) and at a high current density of $1000 \mathrm{~mA} \mathrm{~g}^{-1}$ (capacity of $32 \mathrm{mAh} \mathrm{g}^{-1}$ with $~ 98 \% \mathrm{CE}$ with NG and $\mathrm{AlCl}_{3}: \mathrm{U} 1.3: 1,{ }^{199}$ and capacity of $40 \mathrm{mAh} \mathrm{g}^{-1}$ with $93 \% \mathrm{CE}$ with GNP and $\mathrm{AlCl}_{3}: \mathrm{U}^{1.4: 1}{ }^{27}$ ).

In all these studies, it was pointed out that the molar ratio of $\mathrm{AlCl}_{3}$ to $\mathrm{U}$ plays a vital role in the electrolyte properties and hence the battery performance. At room temperature, only compositions with mole ratio of $\mathrm{AlCl}_{3}$ to $\mathrm{U}$ in the range 1.0-1.5 are clear liquids, and beyond 1.5 molar, $\mathrm{AlCl}_{3}$ white solids are formed due to supersaturation. ${ }^{27}$ The reactions occurring in the $\mathrm{AlCl}_{3}: \mathrm{U}$ system are:27,191,198

$$
\begin{aligned}
& n(\mathrm{U})+2 \mathrm{AlCl}_{3} \rightarrow\left[\mathrm{AlCl}_{2} \cdot n(\mathrm{U})\right]^{+}+\mathrm{AlCl}_{4}^{-} \\
& \mathrm{AlCl}_{4}^{-}+\mathrm{AlCl}_{3} \rightarrow \mathrm{Al}_{2} \mathrm{Cl}_{7}^{-} \\
& \mathrm{Al}_{2} \mathrm{Cl}_{7}^{-}+\mathrm{AlCl}_{3} \rightarrow \mathrm{Al}_{3} \mathrm{Cl}_{10}^{-}
\end{aligned}
$$

where $n$ is the coordination number of $\mathrm{U}$, and $\left[\mathrm{AlCl}_{2} \cdot n(\mathrm{U})\right]^{+}$is the cationic species in the mixture.

When the mole ratio of $\mathrm{AlCl}_{3}$ to $\mathrm{U}$ is 1.0 , only $\mathrm{AlCl}_{4}^{-}$is detected, and $\mathrm{Al}_{2} \mathrm{Cl}_{7}^{-}$is not present in this composition. With the increase in molar ratio, $\mathrm{Al}_{2} \mathrm{Cl}_{7}^{-}$is generated, and the amount of the cationic species $\left[\mathrm{AlCl}_{2} \cdot(\mathrm{U})_{2}\right]^{+}$ also increases. With further increase in the molar ratio, the $\mathrm{Al}_{2} \mathrm{Cl}_{7}^{-}$anions are consumed to form $\mathrm{Al}_{3} \mathrm{Cl}_{10}^{-}$. At high concentrations, the acidity of the electrolyte increases, which may lead to the corrosion of the anode (i.e. aluminum foil) and fast capacity decay of the battery, compromising the battery performance. ${ }^{191}$ Looking for the best compromise between relevant properties (viscosity and conductivity from the one hand, and electrochemical performance on the other), compositions with a molar ratio of $1.3,13,1991.4,{ }^{27}$ or $1.5,{ }^{191}$ were considered as the best performing mixtures. In these compositions both $\mathrm{AlCl}_{4}^{-}, \mathrm{Al}_{2} \mathrm{Cl}_{7}^{-}$anions as well $\left[\mathrm{AlCl}_{2}\right.$. $\left.(\mathrm{U})_{2}\right]^{+}$cations are present in the electrolyte as confirmed by Raman spectroscopy and ${ }^{27} \mathrm{Al}$ NMR.

According to Angell et al., ${ }^{13}$ during the charging process, the $\mathrm{AlCl}_{4}^{-}$anions are intercalated into the graphite layer at the cathode following the graphite intercalation reaction

cathode: $\mathrm{AlCl}_{4}^{-}+\mathrm{C}_{\mathrm{x}} \rightarrow \mathrm{C}_{\mathrm{x}}^{+}\left[\mathrm{AlCl}_{4}\right]^{-}+\mathrm{e}^{-}$ 
with $\mathrm{x}$ the number of carbon atoms per intercalated anion.

Wang et al also suggested a secondary intercalation reaction: ${ }^{198}$

cathode: $\mathrm{Al}_{2} \mathrm{Cl}_{7}^{-}+\mathrm{C}_{\mathrm{x}} \rightarrow \mathrm{C}_{\mathrm{x}}^{+}\left[\mathrm{Al}_{2} \mathrm{Cl}_{7}\right]^{-}+\mathrm{e}^{-}$

The deposition may occur through two pathways: ${ }^{13}$

anode: $4 \mathrm{Al}_{2} \mathrm{Cl}_{7}^{-}+3 \mathrm{e}^{-} \rightarrow \mathrm{Al}+7 \mathrm{AlCl}_{4}^{-}$

$$
2\left[\mathrm{AlCl}_{2} \cdot(\mathrm{U})_{2}\right]^{+}+3 \mathrm{e}^{-} \rightarrow \mathrm{Al}+\mathrm{AlCl}_{4}^{-}+4(\mathrm{U})
$$

Although the pathway involving $\left[\mathrm{AlCl}_{2} \cdot(\mathrm{U})_{2}\right]^{+}$cations would be dominant, ${ }^{13}$ it cannot be responsible alone for Al deposition and the combination of the two equations with contribution of both electroactive cationic $\left(\left[\mathrm{AlCl}_{2} \cdot(\mathrm{U})_{2}\right]^{+}\right)$and anionic $\left(\mathrm{Al}_{2} \mathrm{Cl}_{7}^{-}\right)$species has to be considered: ${ }^{199}$

anode: $\left[\mathrm{AlCl}_{2} \cdot(\mathrm{U})_{2}\right]^{+}+2 \mathrm{Al}_{2} \mathrm{Cl}_{7}^{-}+3 \mathrm{e}^{-} \rightarrow \mathrm{Al}+4 \mathrm{AlCl}_{4}^{-}+2(\mathrm{U})$

$\mathrm{Ng}$ et al. suggested that the concentration of $\mathrm{Al}_{2} \mathrm{Cl}_{7}^{-}$in the electrolyte is the limiting factor in determining the anodic capacity, with a practically attainable cell-level energy density of $\mathrm{Al}\left|\mathrm{AlCl}_{3}: \mathrm{U}\right|$ graphitic material system in the range of $50-60 \mathrm{Wh} \mathrm{kg}^{-1} .199$

The suggested battery discharging mechanism is illustrated schematically in Fig. 12.

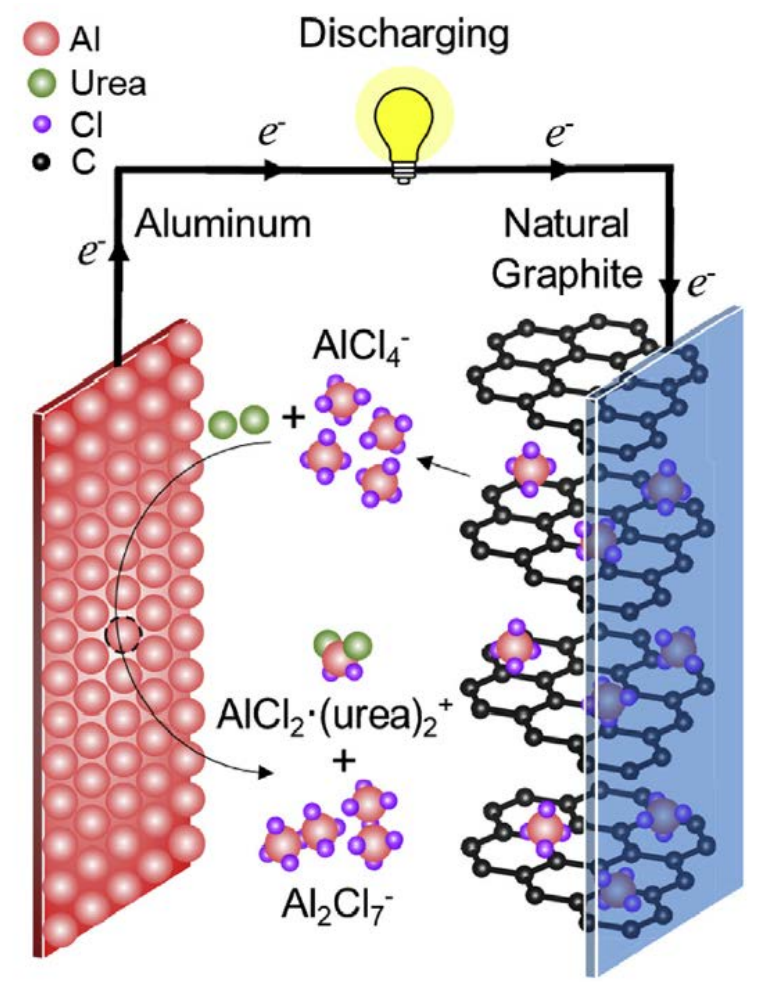

Figure 12. Schematic representation of the system during battery discharging. Reprinted from Electrochimica Acta, 327, Ng et al. A low-cost rechargeable aluminum/natural graphite battery utilizing urea-based ionic liquid analog, 135031, Copyright (2019), with permission from Elsevier.

Alternative $\mathrm{HBDs}$ have been proposed in combination to $\mathrm{AlCl}_{3}$ to overcome the undesirable relatively high viscosity and low conductivity of U-based electrolyte, especially when compared to chloroaluminate ILs with 
organic cations (i.e. conventional 1-ethyl-3-methylimidazolium chloride EMImCl-based electrolytes). Mixture of $\mathrm{AlCl}_{3}$ and $\mathrm{AA}$ at molar ratio of 1.1:1, 1.3:1, and 1.5:1 have been tested. ${ }^{200}$ The system with $\mathrm{AlCl}_{3}$ to $\mathrm{AA}$ molar ratio equal to 1.3 performed better than both the 1.1 molar ratio (because of reduced viscosity and higher ion mobility), and the 1.5 molar ratio (due to the change in the anionic composition of the latter). $A$ molar ratio of 1.3:1 was also found the best conducting when PA and BA were used as HBD. ${ }^{201}$ To further reduce the viscosity of the $\mathrm{AlCl}_{3}$ :AA electrolytes, addition of dichloromethane (DCM) was evaluated, showing excellent miscibility and no apparent reactivity. ${ }^{200}$ Dilution of $\mathrm{AlCl}_{3}: \mathrm{AA} 1.3: 1$ with $\mathrm{DCM}$ between 10 and 30 $\mathrm{v} / \mathrm{v} \%$ significantly increased the specific capacity of the AIB using pyrolytic graphite paper as the working electrode (increase in discharge capacity from 46 to $67 \mathrm{~mA} \mathrm{~h} \mathrm{~g}^{-1}$ for $10 \% \mathrm{DCM}$ and to $77 \mathrm{~mA} \mathrm{~h} \mathrm{~g}^{-1}$ for $30 \%$ $\mathrm{DCM}$ ) without impairing its $\mathrm{CE}$, reaching similar cycling performance to the more traditional $\mathrm{EMImCl-based}$ electrolytes for a fraction of the cost. ${ }^{200}$

Given the important role played by speciation in Al salt-based electrolytes, the impact of the amide replacement has been probed. Physicochemical investigations of DESs with a series of amides that differ in the alkyl chain length $(\mathrm{U}, \mathrm{AA}, \mathrm{PA}, \mathrm{BA})$ and varied molar fractions of $\mathrm{AlCl}_{3}$ indicate that the higher the symmetry of the amide ( $\mathrm{U}>\mathrm{AA}>\mathrm{PA}>\mathrm{BA}$ ), the lower the content of $\mathrm{Al}_{2} \mathrm{Cl}_{7}^{-}$species to $\mathrm{AlCl}_{4}^{-}{ }^{202}$ Other $\mathrm{U}$-derivatives with reduced possibility for $\mathrm{H}$-binding (MU and ethyl urea $\mathrm{EU}$ ) were used. ${ }^{203}$ For the same $\mathrm{AlCl}_{3}$ content, density and viscosity decrease in the order $U>M U>E U$, and conductivity increase (Table 5). An analysis of electrolyte speciation revealed that $\mathrm{MU}$ - and EU-based electrolytes had an appreciably lower concentration of ionic species, and as a result neutral $\mathrm{Al}_{2} \mathrm{Cl}_{6}([\mathrm{MU}$ or $\mathrm{EU}])$ and $\mathrm{AlCl}_{3}([\mathrm{MU}$ and $\mathrm{EU}])$ moieties were likely present. ${ }^{203}$ This is directly responsible for the viscosity decrease and conductivity increase, due to fewer overall cation-anion interactions. The $\mathrm{AlCl}_{3}: \mathrm{EU} 1.4: 1$ system has the lowest viscosity $(45.0 \mathrm{mPa}$ s) and the highest conductivity $\left(1.56 \mathrm{mS} \mathrm{cm}^{-1}\right.$ ) of all systems investigated (Table 5). ${ }^{203}$ The associated battery exhibited improvements in capacity and a significant increase in discharge voltage (+0.13 $\mathrm{V}$ compared to $\left.\mathrm{AlCl}_{3}: \mathrm{U}\right)$. Interestingly, operando Raman spectroscopy performed during cyclic voltammetry indicated that aluminum deposition primarily occurred through reduction of $\mathrm{Al}_{2} \mathrm{Cl}_{7}^{-}$(Eq 6), unlike the previous studies where $\mathrm{Al}$ deposition occurred primarily through the Al-containing cationic species (Eq 7). ${ }^{13}$ This proves that a very simple perturbation to the system (i.e., adding one ethyl group to $\mathrm{U}$ ) greatly reduced the viscosity (by a factor of three), increased ionic conductivity (by $40 \%$ ) and modified electrolytes speciation modulating battery performances.

In this framework, a more severe substitution includes the use of 4-ethylpyridine (EP) as a neutral ligand to form a new electrolyte in combination with $\mathrm{AlCl}_{3}{ }^{204}$ Increasing $\mathrm{AlCl}_{3}$ ratio from 1.1 to 1.4 leads to an improvement in ionic conductivity (from 0.71 to $0.91 \mathrm{mS} \mathrm{cm}^{-1}$ ) due to the increase of ionic species, and a slight increase in viscosity (from 17.8 to $23.6 \mathrm{mPa}$ s), probably due to enhanced interactions/aggregations between ions at high concentrations (Table 5). Contrary to previous studies, regardless of the $\mathrm{AlCl}_{3}$ to EP ratio, $\mathrm{Al}_{2} \mathrm{Cl}_{7}^{-}$anions were not detected, then the deposition is expected to accur via the following reaction:204

anode: $2\left[\mathrm{AlCl}_{2} \cdot(\mathrm{EP})_{n}\right]^{+}+3 \mathrm{e}^{-} \rightarrow \mathrm{Al}+\mathrm{AlCl}_{4}^{-}+2 n(\mathrm{EP})$

The electrolyte with $\mathrm{AlCl}_{3}$ to $\mathrm{EP}$ ratio equal to 1.3 turned out to be the optimal composition in Al|graphite cells in terms of capacity and rate capability $\left(95 \mathrm{mAh} \mathrm{g}^{-1}\right.$ at $25 \mathrm{~mA} \mathrm{~g}^{-1}$ and $32 \%$ capacity retention at $300 \mathrm{~mA}$ $\mathrm{g}^{-1}$, against 41,55 , and $80 \mathrm{mAh} \mathrm{g}^{-1}$, with $20 \%, 25 \%$, and $26 \%$ retention, for molar ratios of $1.1,1.2$ and 1.4, respectively). ${ }^{204}$ The cell with $\mathrm{AlCl}_{3}$ :EP 1.3:1 also exhibited decent cycling stability, with $\approx 85 \%$ of the initial capacity retained after 1000 charge-discharge cycles at a rate of $100 \mathrm{~mA} \mathrm{~g}^{-1}$. This electrolyte also possesses additional upsides. First, it is moisture-insensitive when opened at ambient atmosphere: the capacity of the graphite cathode in a All graphite open cell was only slightly lower than that found in a $\mathrm{N}_{2}$-filled glovebox (22 
mAh g ${ }^{-1}$ vs $30 \mathrm{mAh} \mathrm{g}^{-1}$ at $300 \mathrm{~mA} \mathrm{~g}^{-1}$ ), with a capacity retention upon 100 cycles as high as $75 \% .{ }^{204}$ Moreover, due to the absence of $\mathrm{Al}_{2} \mathrm{Cl}_{7}^{-}$and the use of the neutral $\mathrm{EP}$, it shows considerably lower corrosivity toward $\mathrm{Al}, \mathrm{Cu}$, and $\mathrm{Ni}$ electrodes compared with that of the conventional EMImCl IL. ${ }^{204}$

For the sake of completeness, we also mention that two more HBD classes were reported in combination with $\mathrm{AlCl}_{3}$ for reversible $\mathrm{Al}$ deposition. Glymes (G2, G3 and G4) were mixed with $\mathrm{AlCl}_{3}$, with $\mathrm{AlCl}_{3}: \mathrm{G} 2$ at 1:5 the composition having the highest molar conductivity $\left(4.08 \mathrm{mS} \mathrm{cm}^{-1}\right.$ at $28^{\circ} \mathrm{C}$, an order of magnitude smaller than conventional imidazolium aluminate ILs) and the lowest viscosity $\left(2.71 \mathrm{mPa} \mathrm{s}\right.$ at $28^{\circ} \mathrm{C}$, an order of magnitude smaller than ILs and very similar to the case of 60 vol\% benzene-added IL). ${ }^{205,206}$ The coordination behavior of $\mathrm{AlCl}_{3}: \mathrm{G} 2$ was found to be similar to that of $\mathrm{AlCl}_{3}$ :amide with the $\left[\mathrm{AlCl}_{2} \cdot(\mathrm{G} 2)_{2}\right]^{+}$cations as the active species, paired with the $\mathrm{AlCl}_{4}^{-}$anions. ${ }^{207,208}$ Finally, mixtures of $\mathrm{AlCl}_{3}$ and $\gamma$-butyrolactone (GBL) at

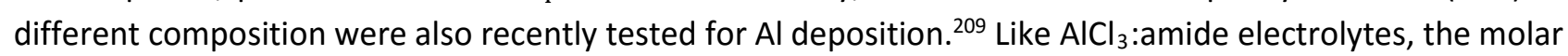
ratio plays a key role: at relatively low $\mathrm{AlCl}_{3}$ concentration ( $\mathrm{AlCl}_{3}: \mathrm{GBL}$ molar ratio in the range 1:10 to 1:2.6) the $\left[\mathrm{AlCl}_{2} \cdot(\mathrm{GBL})_{2}\right]^{+}$cations and the $\mathrm{AlCl}_{4}^{-}$anions are formed; at increasing $\mathrm{AlCl}_{3}$ content $\left(\mathrm{AlCl}_{3}: \mathrm{GBL}\right.$ mole ratio between $1.1: 1$ and $1.5: 1) \mathrm{Al}_{3} \mathrm{Cl}_{10}^{-}$anions become the electrochemically active species for $\mathrm{Al}$ deposition. Equimolar mixtures represent an intermediate state, composed of chloroaluminate species including $\left[\mathrm{AlCl}_{2} \cdot(\mathrm{GBL})_{2}\right]^{+}, \mathrm{AlCl}_{4}^{-}$, and $\mathrm{AlCl}_{3} \cdot \mathrm{GBL}$ with no free (uncoordinated) $\mathrm{GBL}$ molecule.

\subsubsection{Aluminium-air batteries}

One of the advantages of DESs over ILs is the relatively low air- and water-sensitivity of the former. This has been exploited to evaluate the feasibility of $\mathrm{AlCl}_{3}: \mathrm{AA}$ and $\mathrm{AlCl}_{3}: \mathrm{U}$ DESs as electrolytes for rechargeable aluminium-air batteries (AABs). ${ }^{210} \mathrm{AABs}$ - and in general metal-air batteries - are potential candidates for sustainable energy storage applications, due to their high theoretical energy density and capacity, low toxicity, low cost and low propensity to thermal runaway like Li-based systems. In particular, AABs possess a high theoretical voltage $(2.7 \mathrm{~V})$ and an energy density $\left(8.1 \mathrm{kWh} \mathrm{kg}^{-1}\right)$ and are large enough to be considered for next-generation rechargeable batteries. ${ }^{211}$ However, some inherent drawbacks related to the metal electrode hinder their large scale commercialization, including irreversibility (not electrochemically rechargeable), passivation and parasitic hydrogen evolution as well as low energy efficiency in alkaline media. ${ }^{210} \mathrm{AlCl}_{3}: \mathrm{AA}$ and $\mathrm{AlCl}_{3}: \mathrm{U}$ DESs with a molar ratio of 1:1.5 were prepared and compared with $\mathrm{AlCl}_{3}: \mathrm{EMImCl}$ system. Best results in half-cell measurements were obtained with EMImCl, but AA- and Ubased systems performed better in full-cell, both in terms of current ( $84 \%$ and $80 \%$ respectively) and energy efficiency (56\% and 55\%, respectively), during first 15 charge/discharge cycles at $100 \mu \mathrm{A} \mathrm{cm} \mathrm{cm}^{-2}$ for $3 \mathrm{~h}$. Although the feasibility of electrically rechargeable $\mathrm{Al} /$ air system with $\mathrm{AlCl}_{3}: \mathrm{AA}$ and $\mathrm{AlCl}_{3}: \mathrm{U}$ electrolytes was demonstrated for about $200 \mathrm{~h}$, the overall reversible capacity was quite low and limited to about $0.64 \mathrm{~mA} \mathrm{~h}$ at $100 \mu \mathrm{A} \mathrm{cm}{ }^{-2}$, which means only $2.5 \%$ of the theoretical reversible electrolyte capacity (evaluated to approximately $28 \mathrm{mAh}){ }^{210}$

\subsubsection{Aluminium sulfur batteries}

As already mentioned, sulfur is considered to be a superior cathode with a high theoretical capacity, and can be assembled with Al anode to develop aluminum-sulfur (Al-S) batteries. However, the design of a satisfactory electrolyte compatible to room-temperature Al-S batteries is still a bottleneck for improved battery performance. ${ }^{212}$ Till now, a few reversible Al-S cells based on chloroaluminate IL electrolytes have been reported, but the performances of these IL-based AI-S batteries are still inadequate in terms of cyclability, capacity and $\mathrm{CE} .{ }^{212}$ The low cycling efficiency is probably due to the chemical instability of sulfur-containing species in the electrolyte. ${ }^{213}$ In contrast to the instability of $\mathrm{S}$ in the conventional $\mathrm{AlCl}_{3}: \mathrm{EMImCl}$ electrolyte, Bian et al. showed that sulfur is apparently insoluble in the $\mathrm{AlCl}_{3}: \mathrm{U}$ at room temperature. ${ }^{213}$ This allowed the 
development of a Al-S cell using $\mathrm{AlCl}_{3}: \mathrm{U}$ 1.4:1, aluminum foil, and multiwalled carbon nanotube (MWCNT)/S composite with improved charge/discharge cycle life: the Al-S cell delivered an initial capacity of $740 \mathrm{mAhg}^{-}$ 1 , with $85.3 \%$ capacity retention $\left(\sim 520 \mathrm{mAhg}^{-1}\right)$ after 100 charge/discharge cycles. ${ }^{213}$

Replacing $\mathrm{U}$ with AA Chu et al. assembled a reversible room-temperature AI-S device using Al foil as the anode and $50 \mathrm{wt} \%$ sulfur encapsulated in the ordered mesoporous carbon CMK-3 as the cathode. ${ }^{212}$ Raman and ${ }^{27} \mathrm{Al}$ NMR spectroscopies were used to identify the electrolyte composition, confirming the coexistence of $\mathrm{AlCl}_{4}^{-}$ and $\mathrm{Al}_{2} \mathrm{Cl}_{7}^{-}$when the $\mathrm{AlCl}_{3}$ to $\mathrm{AA}$ molar ratio is 1.3. The battery exhibited an initial capacity above $1500 \mathrm{~mA}$ $\mathrm{h} \mathrm{g}^{-1}$ at a current density of $100 \mathrm{~mA} \mathrm{~g}^{-1}$, and a capacity retention of $500 \mathrm{~mA} \mathrm{~h} \mathrm{~g}^{-1}$ for 60 cycles, with a good rate performance and long cycle life. Two electrochemical reaction pathways involving either $\mathrm{Al}_{2} \mathrm{Cl}_{7}^{-}$or $\left[\mathrm{AlCl}_{2} \cdot(\mathrm{AA})_{2}\right]^{+}$were proposed using DFT calculations (Fig. 13): ${ }^{212}$

Pathway 1

anode: $2 \mathrm{Al}+14 \mathrm{AlCl}_{4}^{-} \rightarrow 8 \mathrm{Al}_{2} \mathrm{Cl}_{7}^{-}+6 \mathrm{e}^{-}$

catode: $8 \mathrm{Al}_{2} \mathrm{Cl}_{7}^{-}+3 \mathrm{~S}+6 \mathrm{e}^{-} \rightarrow \mathrm{Al}_{2} \mathrm{~S}_{3}+14 \mathrm{AlCl}_{4}^{-}$

Pathway 2

anode: $2 \mathrm{Al}+2 \mathrm{AlCl}_{4}^{-}+8 \mathrm{AA} \rightarrow 4\left[\mathrm{AlCl}_{2} \cdot(\mathrm{AA})_{2}\right]^{+}+6 \mathrm{e}^{-}$

catode: $4\left[\mathrm{AlCl}_{2} \cdot(\mathrm{AA})_{2}\right]^{+}+3 \mathrm{~S}+6 \mathrm{e}^{-} \rightarrow \mathrm{Al}_{2} \mathrm{~S}_{3}+2 \mathrm{AlCl}_{4}^{-}+8 \mathrm{AA}$

Pathway 1 was more kinetically favorable in the discharging/charging process showing a lower dissociation energy barrier. Pathway 2, was less kinetically favored but it appeared as a unique - still possible - process of $\mathrm{AlCl}_{3}: \mathrm{AA}$ electrolyte.

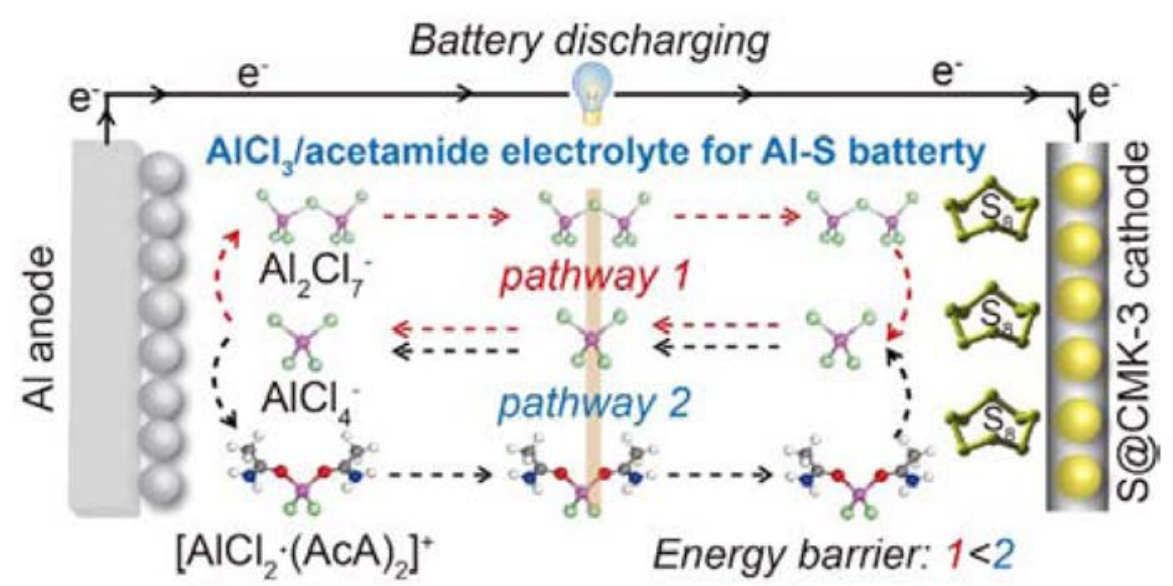

Figure 13. Schematic illustration of the discharging process of the Al-S battery using Al foil as the anode, 50 wt\% sulfur encapsulated in the ordered mesoporous carbon CMK-3 as the cathode, and $\mathrm{AlCl}_{3}: \mathrm{AA}$ as electrolyte. Reprinted from Energy Storage Materials, 22, Chu et al. A low-cost deep eutectic solvent electrolyte for rechargeablealuminum-sulfur battery, 418-423, Copyright (2019), with permission from Elsevier.

Despite the promising results reported by Bian et al. and Chu et al., ${ }^{212,213}$ a recent work comparing $\mathrm{U}$ - and AAbased DES electrolytes (1.5:1 mole ratio) with conventional $\mathrm{AlCl}_{3}: \mathrm{EMImCl}$ demonstrated that the latter is still the best performing system at present. ${ }^{192}$ Aiming at achieving high energy from a light Al-S battery, a thick 
cathode with a high sulfur content (approximately $60 \mathrm{wt} \%$ ) was prepared. Unfortunately the effect of sulfur loading was dramatic on the electrochemical performance in $\mathrm{AlCl}_{3}: \mathrm{U}$ and $\mathrm{AlCl}_{3}: \mathrm{AA}$, and much much more moderate in the IL (Fig. 14). The reason was probably related to the high viscosity of DES electrolytes, which limited ion transport within the porous electrode, thus hampering the full utilization of thick electrodes. Furthermore, experimental specific capacities higher than the theoretical limit expected for full reduction of sulfur to sulfide were measured in cells using very thin $S$ cathodes, indicating the occurrence of degradation reactions in DES electrolytes, e.g. reduction of $U$ or AA. ${ }^{192}$. As the electrolyte degradation was not observed in S-free carbon electrodes, the polysulfide species formed during the reduction of sulfur to sulfide were assumed to trigger the degradation reactions. Contrarily, capacities exceeding the theoretical limit were not observed with $\mathrm{AlCl}_{3}: \mathrm{EMImCl}$, demonstrating a higher stability under the experimental conditions. ${ }^{192}$
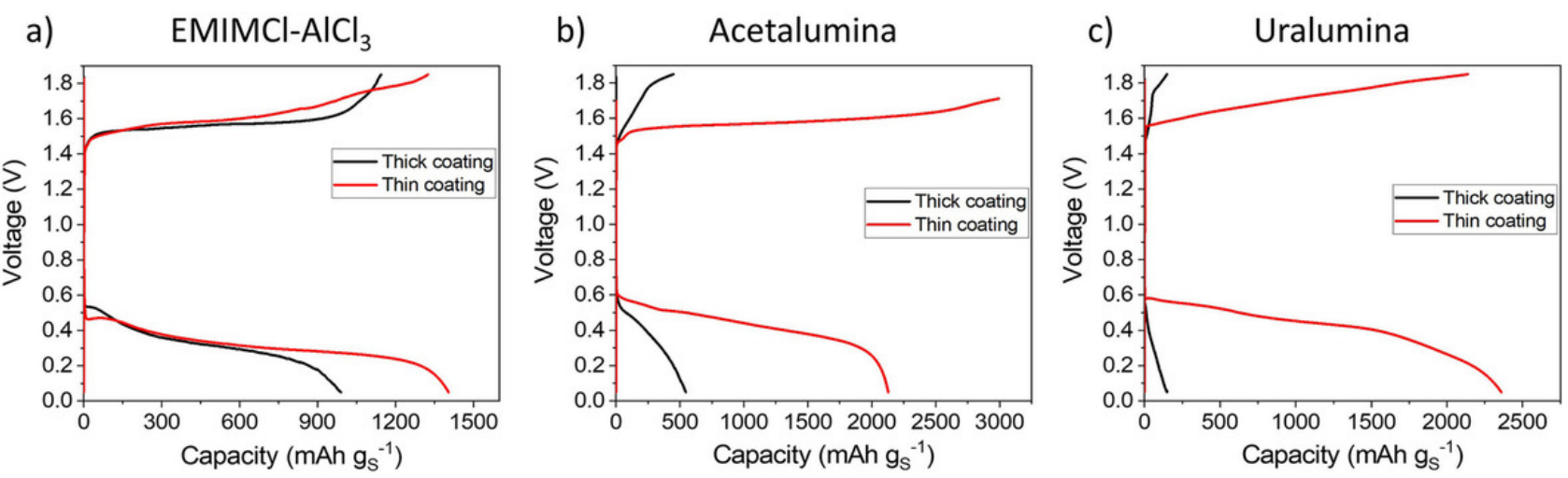

Figure 14. 1st cycle voltage profiles of thick $(139 \mu \mathrm{m})$ and thin $(22 \mu \mathrm{m})$ cathode coatings using a) $\mathrm{AlCl}_{3}: \mathrm{EMImCl}$ b) $\mathrm{AlCl}_{3}: \mathrm{AA}$ (acetalumina), and c) $\mathrm{AlCl}_{3}: \mathrm{U}$ (uralumina) electrolytes. A specific current of $50 \mathrm{mAg}^{-}$ ${ }^{1}$ and a $0.05-1.85 \mathrm{~V}$ voltage range was used. Cathodes contained $60 \%$ sulfur and CNT as conductive additive. Reprinted from Lampkin et al. A Critical Evaluation of the Effect of Electrode Thickness and Side Reactions on Electrolytes for Aluminum-Sulfur Batteries, ChemSusChem (2020) 13, 3514- 3523 (Creative Commons Attribution 4.0 International License http://creativecommons.org/licenses/by/4.0/).

\subsubsection{Aluminium selenium batteries}

In the development of rechargeable Al-chalcogenide batteries, selenium ( $\mathrm{Se}$ ) is a candidate as cathode material, being a chemical analogue of $S$ with much higher electronic conductivity $\left(1 \times 10^{-3} \mathrm{~S} \mathrm{~m}^{-1} \mathrm{vs} 5 \times 10^{-28}\right.$ $\mathrm{S} \mathrm{m}^{-1}$ ) and lower ionization potentials (9.7 eV vs $\left.10.4 \mathrm{eV}\right) .{ }^{168} \mathrm{~A} \mathrm{DES}$ based on $\mathrm{AlCl}_{3}$ and thiourea (SU) at 1.3:1 molar ratio was proposed as electrolyte for rechargeable aluminum-selenium (Al-Se) batteries with Se nanowires grown directly on a flexible carbon cloth substrate by a low-temperature selenization process. The $\mathrm{AlCl}_{3}$ :SU-based cell delivered a high specific capacity of $260 \mathrm{mAh} \mathrm{g}^{-1}$ at $50 \mathrm{~mA} \mathrm{~g}^{-1}$ with a high CE of $\sim 99 \%$ from the $5^{\text {th }}$ to $20^{\text {th }}$ cycles. ${ }^{168}$ The electrolyte demonstrated good reversibility allowing a long cycling life of 100 times at a specific current of $100 \mathrm{~mA} \mathrm{~g}^{-1}$ with capacity of $195 \mathrm{mAh} \mathrm{g}^{-1}$ and CE of nearly $93 \%$. The remarkable cycling performance were ascribed to the existence of multiple ionic species, $\left[\mathrm{AlCl}_{2} \cdot(\mathrm{SU})_{2}\right]^{+}$, $\mathrm{AlCl}_{4}^{-}$, and $\mathrm{Al}_{2} \mathrm{Cl}_{7}^{-}$, according to the following reactions: ${ }^{168}$

anode: $6 \mathrm{Al}+24 \mathrm{AlCl}_{4}^{-}+12 \mathrm{SU} \rightarrow 6\left[\mathrm{AlCl}_{2} \cdot(\mathrm{SU})_{2}\right]^{+}+12 \mathrm{Al}_{2} \mathrm{Cl}_{7}^{-}+18 \mathrm{e}^{-}$

catode: $24 \mathrm{Al}_{2} \mathrm{Cl}_{7}^{-}+9 \mathrm{Se}+18 \mathrm{e}^{-} \rightarrow 3 \mathrm{Al}_{2} \mathrm{Se}_{3}+42 \mathrm{AlCl}_{4}^{-}$ 
Table 5. Density, viscosity and conductivity values for selected DES electrolytes based on the combination of Al salt and HBD.

\begin{tabular}{|c|c|c|c|c|c|c|c|}
\hline Metal salt & HBD & Mole ratio & $\begin{array}{l}\text { Working } \\
\text { temperature }\left({ }^{\circ} \mathrm{C}\right)\end{array}$ & Density $\left(\mathrm{gcm}^{-3}\right)$ & Viscosity (mPa s) & $\begin{array}{l}\text { Conductivity (mS } \\
\mathrm{cm}^{-1} \text { ) }\end{array}$ & Reference \\
\hline $\mathrm{AlCl}_{3}$ & DMAA & $1.5: 1$ & 25 & - & 87.6 & 1.114 & 19 \\
\hline $\mathrm{AlCl}_{3}$ & $\mathrm{U}$ & $\begin{array}{l}1.2: 1 \\
1.3: 1 \\
1.4: 1 \\
1.5: 1\end{array}$ & 60 & $\begin{array}{l}1.5606 \\
1.5721 \\
1.5860 \\
1.5921\end{array}$ & $\begin{array}{l}23.9292 \\
24.2543 \\
25.5722 \\
26.8873\end{array}$ & $\begin{array}{l}4.35 \\
4.31 \\
4.20 \\
4.11\end{array}$ & 202 \\
\hline $\mathrm{AlCl}_{3}$ & AA & $\begin{array}{l}1.0: 1 \\
1.1: 1 \\
1.3: 1 \\
1.5: 1\end{array}$ & 60 & $\begin{array}{l}1.4427 \\
1.4520 \\
1.4738 \\
1.4986\end{array}$ & $\begin{array}{l}30.3189 \\
23.7268 \\
23.0081 \\
21.6600\end{array}$ & $\begin{array}{l}3.57 \\
3.75 \\
4.11 \\
4.32\end{array}$ & 202 \\
\hline $\mathrm{AlCl}_{3}$ & PA & $\begin{array}{l}1.0: 1 \\
1.1: 1 \\
1.3: 1 \\
1.5: 1 \\
1.7: 1\end{array}$ & 60 & $\begin{array}{l}1.3776 \\
1.3925 \\
1.4241 \\
1.4481 \\
1.4548\end{array}$ & $\begin{array}{l}18.0417 \\
14.3743 \\
13.6828 \\
13.7973 \\
13.8283\end{array}$ & $\begin{array}{l}4.51 \\
4.61 \\
4.99 \\
4.83 \\
4.74\end{array}$ & 202 \\
\hline $\mathrm{AlCl}_{3}$ & $U$ & $\begin{array}{l}1.1: 1 \\
1.2: 1 \\
1.3: 1 \\
1.4: 1 \\
1.5: 1 \\
1.0: 1 \\
1.1: 1 \\
1.2: 1\end{array}$ & $\begin{array}{l}25 \\
55\end{array}$ & - & - & $\begin{array}{l}0.91 \\
1.41 \\
1.45 \\
1.42 \\
1.27 \\
4.58 \\
4.18 \\
4.59\end{array}$ & 27 \\
\hline
\end{tabular}




\begin{tabular}{|c|c|c|c|c|c|c|c|}
\hline & & $\begin{array}{l}1.3: 1 \\
1.4: 1 \\
1.5: 1\end{array}$ & & & & $\begin{array}{l}4.62 \\
4.24 \\
3.97\end{array}$ & \\
\hline $\mathrm{AlCl}_{3}$ & U & $\begin{array}{l}1: 1 \\
1.2: 1 \\
1.4: 1 \\
1.5: 1\end{array}$ & 25 & $\begin{array}{l}1.56 \\
1.59 \\
1.60 \\
1.61\end{array}$ & $\begin{array}{l}133.2 \\
113.8 \\
87.1 \\
88.9\end{array}$ & $\begin{array}{l}1.02 \\
1.10 \\
1.12 \\
1.17\end{array}$ & 203 \\
\hline $\mathrm{AlCl}_{3}$ & $\mathrm{MU}$ & $\begin{array}{l}1: 1 \\
1.2: 1 \\
1.4: 1 \\
1.5: 1\end{array}$ & 25 & $\begin{array}{l}1.46 \\
1.50 \\
1.51 \\
1.52\end{array}$ & $\begin{array}{l}86.6 \\
87.6 \\
67.2 \\
77.7\end{array}$ & $\begin{array}{l}1.19 \\
1.18 \\
1.27 \\
1.21\end{array}$ & 203 \\
\hline $\mathrm{AlCl}_{3}$ & EU & $\begin{array}{l}1: 1 \\
1.2: 1 \\
1.4: 1 \\
1.5: 1\end{array}$ & 25 & $\begin{array}{l}1.38 \\
1.41 \\
1.43 \\
1.45\end{array}$ & $\begin{array}{l}52.4 \\
48.0 \\
45.0 \\
44.7\end{array}$ & $\begin{array}{l}1.43 \\
1.52 \\
1.56 \\
1.49\end{array}$ & 203 \\
\hline $\mathrm{AlCl}_{3}$ & G2 & $1: 5$ & $\begin{array}{l}28 \\
40 \\
50 \\
60\end{array}$ & - & $\begin{array}{l}2.71 \\
2.67 \\
2.35 \\
2.03\end{array}$ & $\begin{array}{l}4.08 \\
4.48 \\
5.53 \\
6.48\end{array}$ & 206 \\
\hline $\mathrm{AlCl}_{3}$ & G3 & $1: 5$ & 28 & - & 4.54 & 2.07 & 206 \\
\hline $\mathrm{AlCl}_{3}$ & G4 & 1:5 & 28 & - & 6.24 & 1.10 & 206 \\
\hline
\end{tabular}




\section{Zinc batteries}

Zinc batteries have an old history as an important area in the electrochemical power supply and in recent years they have been revisited and made rechargeable. ${ }^{214} \mathrm{Zn}$ batteries have received extensive attention thanks to the merits of metal $\mathrm{Zn}$, first of all its non-toxicity, low cost and high abundance. ${ }^{215}$ Also, the zinc anode displays a high theoretical capacity of $820 \mathrm{mAh} \mathrm{g}^{-1}$ and a low redox potential of $-0.76 \mathrm{~V}$ vs SHE. ${ }^{215}$ Importantly, $\mathrm{Zn}$ has good compatibility with water and allows reversible plating/stripping in aqueous electrolytes, which guarantees innate safety and environmental friendliness. ${ }^{215}$ This makes aqueous ZMBs promising candidates to implement large scale devices alternative to rechargeable batteries based on organic electrolyte. A major obstacle lies in the poor reversibility of aqueous $\mathrm{Zn}$ chemistry, mainly due to the free water. ${ }^{214-216}$ Free water participates in all the parasitic reactions during recharging: first a competing hydrogen evolution reaction that builds up internal pressure and induces $\mathrm{Zn}$ pulverization, eventually leading to cell failure even in trace amounts of $\mathrm{H}_{2}$; second, non-faradaic reactions, namely corrosion and passivation, which facilitate the electrolyte depletion, reduce the utilization of $\mathrm{Zn}$, and thus reduce battery performance. ${ }^{214,216}$ Non aqueous electrolytes have been proposed as an alternative, mainly AN or ILs. ${ }^{216}$ However they suffer from inherent drawbacks, the former being flammable, toxic and very volatile, and the latter costly and highly sensitive to moisture. DESs and their mixtures with cosolvents have emerged recently as viable alternatives.

\subsection{Zinc salt-added type III DESs}

Looking for non-aqueous electrolytes to overcome the poor reversibility of aqueous $\mathrm{Zn}$ chemistry, a medium viscous liquid composed of $\mathrm{ChCl:U} \mathrm{(1:2} \mathrm{mole} \mathrm{ratio)} \mathrm{added} \mathrm{with} \mathrm{zinc} \mathrm{chloride} \mathrm{ZnCl}_{2}(0.3 \mathrm{M})$ was reported as electrolyte for rechargeable zinc ion batteries (ZIBs). ${ }^{216}$ Testing coin cells were fabricated using $\mathrm{Zn}$ and deltatype manganese oxide $\left(\delta-\mathrm{MnO}_{2}\right)$ electrodes and operated according to the following main reactions: ${ }^{216}$

anode: $x \mathrm{Zn}+4 x \mathrm{Cl}^{-} \rightarrow x\left[\mathrm{ZnCl}_{4}\right]^{2-}+2 x \mathrm{e}^{-}$

cathode: $x\left[\mathrm{ZnCl}_{4}\right]^{2-}+\mathrm{MnO}_{2}+2 x \mathrm{e}^{-} \rightarrow \mathrm{Zn}_{x} \mathrm{MnO}_{2}+4 x \mathrm{Cl}^{-}$

During discharge, the $\mathrm{Zn}$ and $\delta-\mathrm{MnO}_{2}$ served as anode and cathode, respectively (Fig. 15a). $\mathrm{Zn}$ oxidation in $\mathrm{ChCl}: \mathrm{U}$ forms $\mathrm{Zn}^{2+}$ that coordinates with $\mathrm{Cl}^{-}$to give $\left[\mathrm{ZnCl}_{4}\right]^{2-}$, which in turn carries $\mathrm{Zn}^{2+}$ to the positive electrode, where it intercalates into the $\delta-\mathrm{MnO}_{2}$ structure forming $\mathrm{Zn}_{\times} \mathrm{MnO}_{2}$. During recharge, the $\mathrm{Zn}$ electrode and $\mathrm{MnO}_{2}$ electrode functioned as the cathode and anode, respectively (Fig. 15b). The extraction of $\mathrm{Zn}^{2+}$ from $\mathrm{Zn}_{\times} \mathrm{MnO}_{2}$ at the positive electrode forms $\left[\mathrm{ZnCl}_{4}\right]^{2-}$, which transfers across the cell to the negative electrode, where the deposition of $\mathrm{Zn}$ from $\left[\mathrm{ZnCl}_{4}\right]^{2-}$ occurs. The fabricated battery exhibited good electrochemical performance with a maximum specific capacity of $170 \mathrm{mAhg}^{-1}$ (higher than the non-aqueous AN-based system, $123 \mathrm{mAhg}^{-1}$, but lower than aqueous-based systems) and good cyclability. ${ }^{216}$ In addition, no dendrite formation during long-term cycling and no passivation layer on the $\mathrm{Zn}$ electrode were observed. 

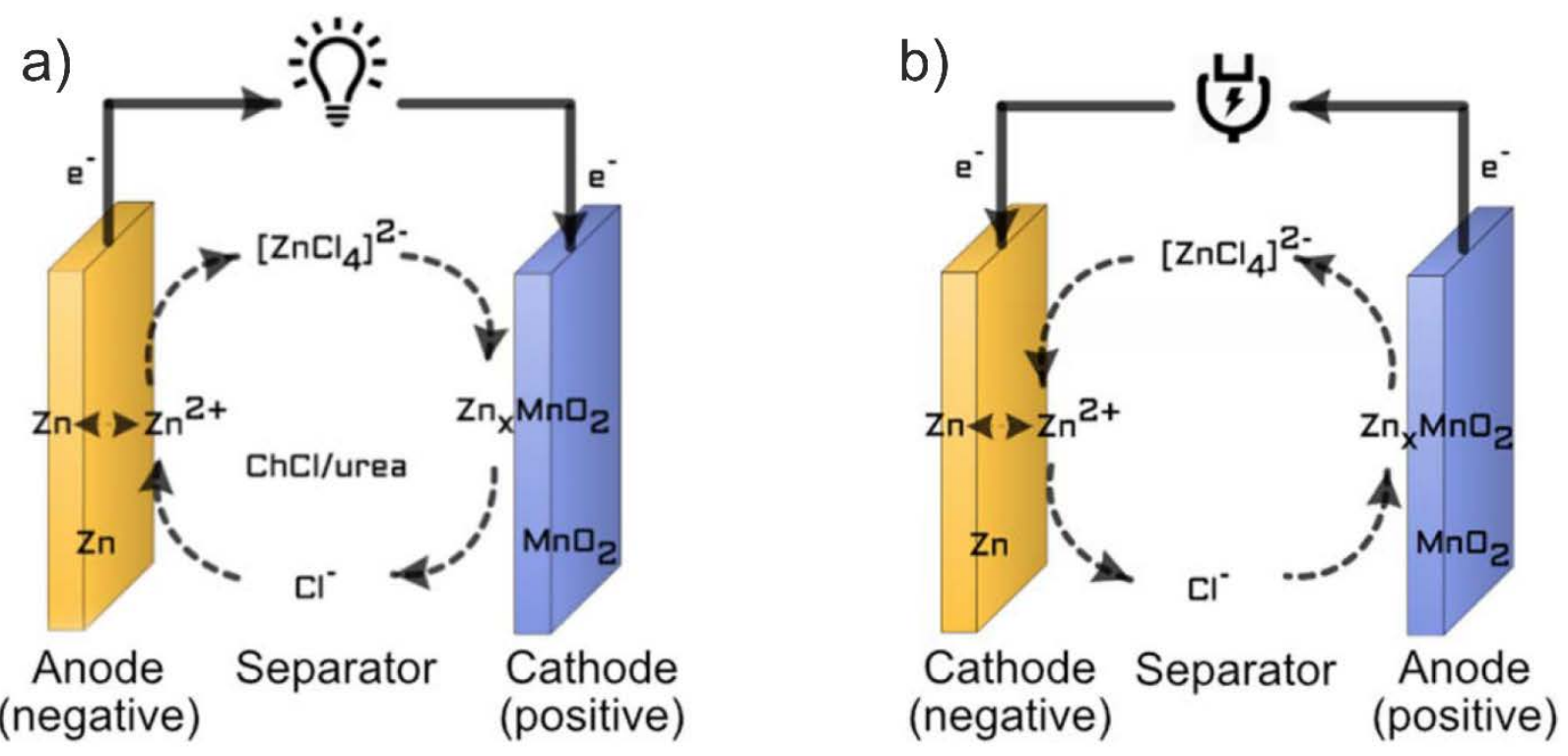

Figure 15. Schematic diagram of the battery during a) discharge ( $\mathrm{Zn}$ anode and $\mathrm{MnO}_{2}$ cathode), and b) recharge ( $\mathrm{Zn}$ cathode and $\mathrm{MnO}_{2}$ anode). Reprinted from Kao et al. Rechargeable Zinc-lon Battery Based on Choline Chloride-Urea Deep Eutectic Solvent, Journal of the Electrochemical Society (2019) 166, A1063 (Creative Commons Attribution 4.0 International License http://creativecommons.org/licenses/by/4.0/).

The same type III DES, ChCl:U, added with a different zinc salt, zinc sulfate $\mathrm{ZnSO}_{4} 0.1 \mathrm{M}$, was employed as electrolyte for $\mathrm{Zn}$-air batteries. ${ }^{217} \mathrm{Zn}$-air batteries are very promising devices for energy storage at high energy density due to their intrinsic safety, environmental friendliness, and low cost. Non-aqueous solvents like DESs were suggested to solve the issues of poor cyclability in aqueous solvents. Unfortunately, by operando scanning soft X-ray microscope analysis, the $\mathrm{Zn}$ behaviour in DES was followed during the cathodic and anodic phase formation processes, and unstable growth features were observed in battery charge and discharge. ${ }^{217}$ This dendrite development and electrode shape change may lead to capacity fade and short circuiting of batteries, impairing their durability.

\subsection{Type IV DESs composed of zinc salts and HBDs}

Besides mixtures of type III DESs and zinc salts, also type I and type IV DESs are in principle candidates as electrolytes for $\mathrm{Zn}$ batteries. Unfortunately, poor conductivities and high viscosities at room temperature were measured for most of these type I (composed of an ammonium or phosphonium salt, and $\mathrm{ZnCl}_{2}$ ) $^{218}$ and type IV (composed of $\mathrm{ZnCl}_{2}$ and EG, AA or U) ${ }^{14,15}$ DESs.

Notably, Qiu et al. reported in 2019 a rechargeable ZIB based on a zinc bis(trifluoromethylsulfonyl)imide $\mathrm{Zn}(\mathrm{TFSI})_{2}$-AA eutectic electrolyte. ${ }^{219} \mathrm{~A}$ large portion of $\mathrm{TFSI}^{-}$was found to coordinate in different ways to $\mathrm{Zn}^{2+}$ forming anion-containing $\mathrm{Zn}$ complexes with various configurations $\left(\left[\mathrm{ZnTFSI}_{\mathrm{m}} \cdot(\mathrm{AA})_{\mathrm{n}}\right]^{(2-\mathrm{m})+}, \mathrm{m}=1-2, \mathrm{n}=\right.$ 1-3) (Fig. 16). The DES with a molar ratio of $1: 7$ exhibits commercially acceptable ionic conductivity (0.31 mS $\mathrm{cm}^{-1}$ ) and low viscosity (0.789 Pa.s) at $25^{\circ} \mathrm{C}$ (Table 6), as well as an expanded anodic stability limit of $2.4 \mathrm{~V}$ (vs. $\mathrm{Zn} / \mathrm{Zn}^{2+}$ ) and a high $\mathrm{Zn}^{2+}$ transference number (0.572), outperforming both an aqueous electrolyte of $1 \mathrm{M}$ $\mathrm{Zn}(\mathrm{TFSI})_{2}$ and DESs formed by other common $\mathrm{Zn}$ salts (e.g., zinc perchlorate $\mathrm{Zn}\left(\mathrm{ClO}_{4}\right)_{2}$, zinc acetate $\mathrm{Zn}\left(\mathrm{CH}_{3} \mathrm{COO}\right)_{2}$, and zinc tetrafluoroborate $\left.\mathrm{Zn}\left(\mathrm{BF}_{4}\right)_{2}\right) \cdot{ }^{219}$ This excellent behaviour was related to the intimate 
interaction of $\mathrm{TFSI}^{-}$with $\mathrm{Zn}^{2+}$, which induces the preferential reductive decomposition of $\mathrm{TFSI}^{-}$prior to $\mathrm{Zn}$ deposition during the initial cycling, and the formation of a well-defined anion-derived SEI layer with a rich content of $\mathrm{ZnF}_{2}$ and $\mathrm{Zn}^{2+}$-permeable organic components. Thanks to this in situ SEI protection, the cyclic stability of ZIBs using $\mathrm{Zn}$, vanadium pentoxide $\left(\mathrm{V}_{2} \mathrm{O}_{5}\right)$, and $\mathrm{Zn}(\mathrm{TFSI})_{2}$ :AA performed better than the aqueous electrolytes at all current densities. At $200 \mathrm{~mA} \mathrm{~g}^{-1}$ the cells showed a high capacity retention of $91.3 \%$ and a CE of $\sim 99.34 \%$ for 100 cycles, and achieved the cyclability of $92.8 \%$ capacity retention over 800 cycles $(99.9 \%$ CEs after activation). ${ }^{219}$

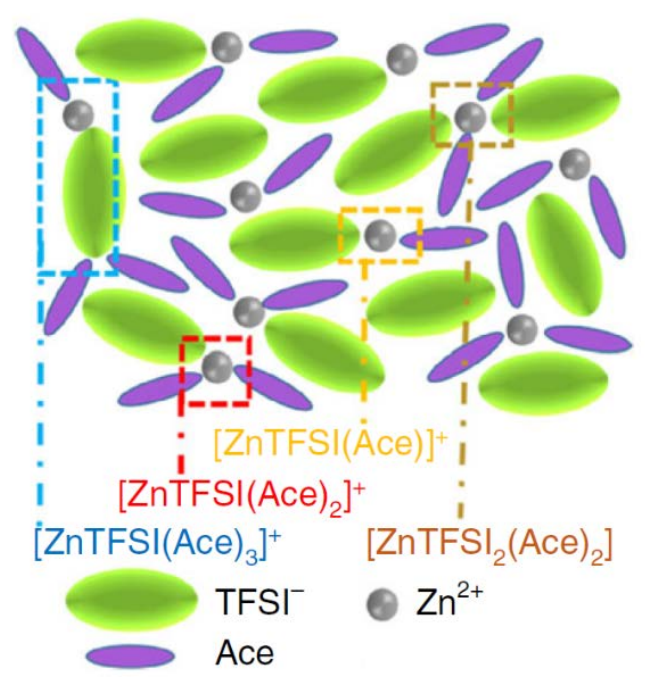

Figure 16. Illustration of representative environment of active $\mathrm{Zn}$ species within the DES $\mathrm{Zn}(\mathrm{TFSI})_{2}: \mathrm{AA}$. Reprinted from Qiu et al. Zinc anode-compatible in-situ solid electrolyte interphase via cation solvation modulation, Nature Communications (2019) 10, 5374 (Creative Commons Attribution 4.0 International License http://creativecommons.org/licenses/by/4.0/).

A striking feature of DESs is the possibility to easily vary the combination of the starting materials, and even mixing together more salts or HBDs. A ternary type IV DES composed of AA and two electrochemically active ions, zinc trifluoromethylsulfonate $\left(\mathrm{Zn}(\mathrm{TfO})_{2}\right)$ and LiTFSI, was proposed by Zhang et al. as electrolyte for zinc batteries. ${ }^{220}$ The composition with LiTFSI:Zn(TfO) 2 :AA molar ratio of 1:20:3.5 showed a decent conductivity $\left(0.35 \mathrm{mS} \mathrm{cm}^{-1}\right.$ at $\left.30^{\circ}\right)$, low viscosity (0.29 Pa s), and relatively wide electrochemical window ( 3.0 V). Unlike conventional aqueous electrolytes, the ternary DES suppressed $\mathrm{Zn}$ dendrite growth, and was able to accommodate various cathode materials (LFP, LMO, $\mathrm{V}_{2} \mathrm{O}_{5}$ ) achieving highly reversible $\mathrm{Zn} / \mathrm{Zn}^{2+}$ redox reactions. Both Zn/LMO and Zn/LFP batteries showed good cycling stability with high capacity retention (75\% and $86 \%$ after 150 cycles at $0.2 \mathrm{C}$, respectively) and near $98 \%$ CE. ${ }^{220}$

A more recent development in the field comes from the incorporation of controlled amounts of water ( 6 wt\%, $\sim 30$ mol.\%) in a ternary type IV DES composed of LiTFSI:Zn(TFSI) $2: U$ to prepare a stable aqueous electrolyte for zinc batteries. ${ }^{214}$ As detected by FTIR and ${ }^{17} \mathrm{O}$ NMR spectroscopy and supported by DFT-MD simulations, in this concentration (dubbed "water-in-DES" regime), DES's nature is retained and all water molecules participate in DES's internal interaction (H-bonding and coordinating) network, leading to a suppressed reactivity with $\mathrm{Zn}$ anode. The addition of water increases conductivity and decreases viscosity of the pristine DES, with the electrolyte LiTFSI: $\mathrm{Zn}(\mathrm{TFSI})_{2}: \mathrm{U}: \mathrm{H}_{2} \mathrm{O}$ at mole ratio 1:0.05:3.8:2 the best performing 
one (Table 6 and Fig. 17). The quaternary electrolyte showed enhanced chemical and electrochemical stability compared to typical aqueous electrolytes, i.e. $0.25 \mathrm{M} \mathrm{Li}_{2} \mathrm{SO}_{4}+0.5 \mathrm{M} \mathrm{ZnSO}_{4}$ and $0.5 \mathrm{M} \mathrm{LiTFSI}+0.5 \mathrm{M}$ $\mathrm{Zn}(\mathrm{TFSI})_{2} \cdot{ }^{214}$ After immersion in the typical aqueous electrolytes for 15 days, $\mathrm{Zn}$ foils tarnished and formed complex coatings, likely due to non-faradaic reactions, whilst no visible change was detected in the hydrated DES electrolyte. Moreover, the open-circuit voltage step of a Zn|Zn cell using $0.5 \mathrm{M} \mathrm{LiTFSI}+0.5 \mathrm{M} \mathrm{Zn}(\mathrm{TFSI})_{2}$ showed spontaneous $\mathrm{H}_{2}$ evolution, whereas no $\mathrm{H}_{2}$ evolution was observed for the quaternary systems during the entire operando testing. The $\mathrm{Zn} \mid \mathrm{Zn}$ cell with hydrated DES was cycled steadily over $2400 \mathrm{~h}$ at a rate of $0.1 \mathrm{mAcm}^{-2}$, and even at a low rate of $0.02 \mathrm{~mA} \mathrm{~cm}^{-2}$, where interface side reactions are more competitive, a stable and reversible $\mathrm{Zn}$ plating/stripping was accomplished with over twentyfold enhancement in cycling life compared to aqueous electrolytes. When tested in a 2 Ah pouch-type cell, the DES electrolyte enabled a capacity retention of $84.8 \%$ after 160 cycles, an average CE of $>96.0 \%$, and a practical energy density of 52 $\mathrm{Wh} \mathrm{kg}{ }^{-1}$, which is comparable to nickel metal hydride $\left(60-120 \mathrm{Wh} \mathrm{kg}^{-1}\right)$ and higher than lead-acid (25 -50 Wh $\mathrm{kg}^{-1}$ ) batteries. ${ }^{214}$ It should be noted that the ESW of hydrated DES evaluated in a three-electrode cell with a stainless steel foil as working electrode was slightly narrower than pristine LiTFSI:Zn(TFSI) $2: \mathrm{U}$, even if beyond the limits of routine aqueous electrolytes. ${ }^{214} \mathrm{~A}$ fine regulation of the water content with identification of the specific water state in the DES may allow to reach the optimum balance between ESW reduction and beneficial effects (reduced viscosity and enhanced electrochemical kinetics).

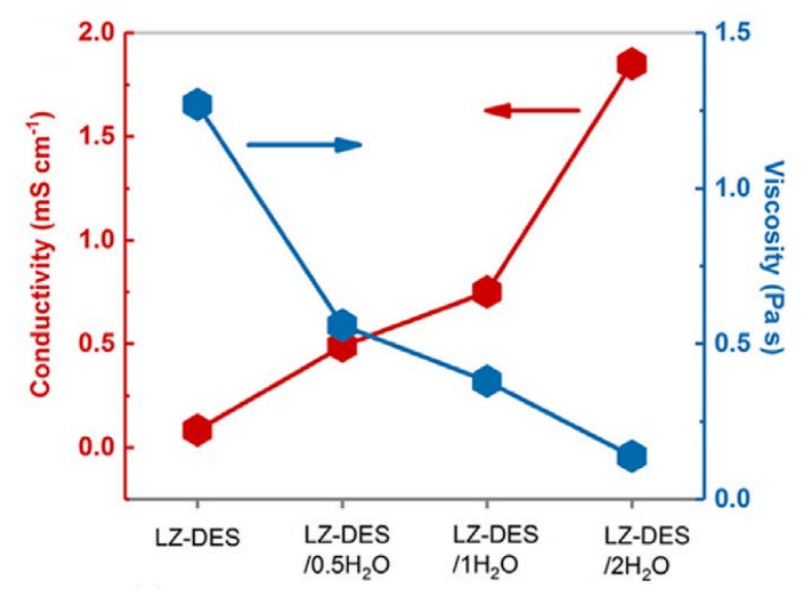

Figure 17. Variation of viscosity and conductivity at $30^{\circ} \mathrm{C}$ for the DES LiTFSI: $\mathrm{Zn}(T F S I)_{2}: \mathrm{U}: \mathrm{H}_{2} \mathrm{O}$ at mole ratio 1:0.05:3.8:n (dubbed "LZ-DES/ $\mathrm{nH}_{2} \mathrm{O}$ ") with increasing the water content. Reprinted from Nano Energy, 57, Zhao et al., "Water-in-deep eutectic solvent" electrolytes enable zinc metalanodes for rechargeable aqueous batteries, 625-634, Copyright (2019), with permission from Elsevier. 
Table 6. Density, viscosity and conductivity values for selected DES electrolytes based on the combination of Zn salt and HBD.

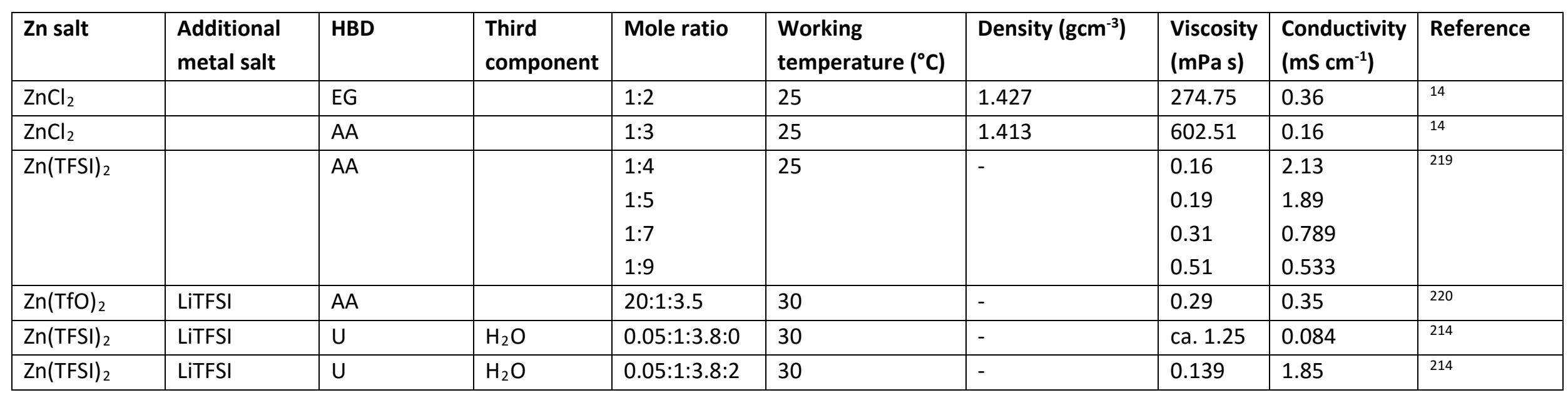




\section{Outlook and future perspectives}

The field of DESs as electrolytes in batteries has boomed in the past years, meeting the demand for high power - yet sustainable and environment friendly - energy storage systems. Although the electrolytes for batteries are typically given much less attention than the electrodes, their role is critical in defining battery lifetime, electrochemical performance and safety. In a larger perspective, DES electrolytes should not be considered just electrolytes enabling ion-conduction, but electrochemically active, capacity- and rate-limiting battery components.

We have overviewed the research status on cationic ( $\mathrm{Li}, \mathrm{Na}, \mathrm{K}, \mathrm{Al}, \mathrm{Zn}$ ) shuttles based on type III and type IV DES electrolytes and their analogues by analyzing the information provided in research papers over the 20122021 time span, and we have comprehensively discussed the current status in terms of density, viscosity and conductivity parameters, as well as electrochemical stability and overall battery performances. It emerged that some compositions have encouraging properties for battery applications, such as high thermal and electrochemical stability, low viscosity and relatively high conductivity. However, this might be still inadequate for room temperature applications and seriously deficient at low temperatures, especially when compared to state-of-the-art liquid organic electrolytes and considering that the requirement for the electrolyte conductivity for commercial LIBs is $5-15 \mathrm{mS} \mathrm{cm}^{-1}$. ${ }^{167}$ Also, electrode compatibility and sluggish kinetics remain challenging issues, and most batteries have insufficient capacity.

Even considering the significant economic and environmental cost advantages of DES-based energy storage systems, they have considerable development ahead before becoming commercially available. Luckily, DESs are still a relatively unexplored class of solvents and research on their application in batteries is in a primordial stage. There is hence significant room for improvement, making them very promising candidates as alternatives to current solutions. To facilitate the improvement we individuated a number of open questions and possibile research thrusts.

Library expansion. In the search for formulations with improved properties, significant room for further research is available through an expansion of the sample space. Since the introduction of $\mathrm{ChCl:U}$, the field has grown incorporating a large number of known DESs and has identified a library of potential constituents allowing for an estimated $10^{6}-10^{8}$ possible binary combinations. ${ }^{5}$ In the DES design it should be kept in mind that, while DESs based on hydrogen bonding are the most common, this is not a stringent requirement and in general DESs may be formed through self-associated intermolecular interactions, caused by van der Waals interactions, hydrogen bonding, and/or ionic bonding. Type $V$ non-ionic DESs, for instance, lack an ionic contribution and yet still exhibit DES characteristics. ${ }^{23}$ We note here that the present review did not cover the use of type I and II DESs, but there are some examples reporting their application in batteries, ${ }^{221-223}$ and they might represent viable alternatives. Also hydrophobic DESs have been reported which may overcome the viscosity issue associated with eutectics based on large quaternary ammonium salts and have better water-stability. ${ }^{104}$ Moreover, it would be wise to explore not only the eutectic composition but other molar ratios. It has been shown for instance that the eutectic point is not always the composition with optimal conductivity (i.e. the highest conductivity for $\mathrm{ChCl}$ :EG was found at a molar ratio of 2:5, while the eutectic composition is at a molar ratio of 1:2 $)^{14}$ Hence optimal properties could be achieved by optimizing the molar ratio of the components. Finally, the design of multiple-component mixtures is particularly attracting. Some ternary and quaternary DESs have been reported but have so far been scarcely explored. As a novel component, also water or other cosolvent may result in a positive impact on viscosity, density, conductivity and electrochemical stability window, and may even impart DESs with flame retardant and antifreeze properties. 
Importance of all-embracing fundamental studies. To practically exploit the tunability of DESs avoiding wasted time and effort in an exhaustive trial-and-error through millions of possible binary combinations, a primary objective of current DES research is the development of a proper fundamental understanding of all the electrolyte basics. A strong establishment of coordination geometry, molecular structure, formation mechanism and structure-property relationship of these solvents is required to to provide important guidelines for the design of functionalized electrolytes for rechargeable batteries. Also, additional careful studies in terms of thermal and electrochemical properties are needed. It is known that DESs may decompose at high temperatures, ${ }^{29}$ and even evaporate at room temperature and atmospheric pressure. ${ }^{30}$ This point has to be taken into account as the evaporation of the volatile component in the DES change its properties such as melting point, viscosity and conductivity, thus influencing the performances of the energy storage device. Moreover, given the potential applicability of these solvents, their toxicity profiles have to be scrutinized. Though most of these solvents have been found to be practically harmless to the ecosystem, their environmental benignity cannot be guaranteed and additional studies are needed..$^{224-228}$ Of high relevance is also the understanding of the hygroscopic nature of DESs and its effect on the electrochemical behavior. On the one hand, the presence of small amounts of water is beneficial due to the decrease of viscosity and increase of conductivity that originate from increasing the ion mobility in the electrolyte. On the contrary, the hygroscopicity of DESs might be disadvantageous as the increase of water content may cause a decrease of the electrochemical potential window. Since DESs are never water-free, understanding the effect of water on these type of electrolytes is of high importance. Only the development of robust basic knowledge on DESs will allow a quantum jump in the achievement of industrial-scale reliability of DES-based energy storage devices.

Multivalent systems. Next to $\mathrm{Al}$ and $\mathrm{Zn}$-based batteries, the development of other multivalent ion-based rechargeable batteries such as magnesium $(\mathrm{Mg}$ ) or calcium (Ca) ion batteries is an attractive concept. In principle, these multivalent charge carrier ions enable higher capacities compared to using monovalent-ion charge carriers such as $\mathrm{Li}^{+}$or $\mathrm{Na}^{+} .{ }^{180,229-231}$ Also, these element are largely abundant and may have competitive volumetric capacities, ${ }^{180,229,230}$ and are safer to handle than Li. ${ }^{178}$ However, Mg and Ca batteries are still nascent technologies, and to the best of our knowledge the use of IL-based electrolytes is reported in a few papers for $\mathrm{Mg}$ batteries and in one single study for a non-aqueous $\mathrm{Ca}-\mathrm{O}_{2}$ battery. ${ }^{178,231} \mathrm{~A}$ recent study demonstrated interesting conductivity (around $1.8 \mathrm{mS} \mathrm{cm}^{-1}$ ), stability ( $\sim 3.8 \mathrm{~V}$ ), and CE ( $94 \%$ in the first cycle) for a mixture of a magnesium carborane and G4. ${ }^{178}$ Neverthless, this post-Li cationic battery technology is still in its infancy and suffers from several drawbacks, such as low ion diffusion rates, high reduction potential towards electrolyte, and formation of passivation layers at anodic surface. Ca and Mg batteries have, though, a role to play and DES electrolytes might be the right playground for their development.

Electroconducting DES-containing polymers. DESs have been combined in various way with polymers to obtain better performing electrochemical materials. The immobilization of a liquid electrolyte in a solid matrix to form a gel (quasi-solid) electrolyte is in principle a strategy to synergistically combine the properties of both limiting their drawbacks. ${ }^{232} \mathrm{~A}$ semisolid DES electrolyte is then a promising approach as this material would practically keep the specific properties of DESs except flowability. ${ }^{232}$ LiTFSI-based DESs were for instance incorporated into polymer backbones, ${ }^{233,234}$ or silica matrices, ${ }^{235}$ obtaining electrolytes with enhanced conductivity and good electrochemical stability, some showing good performances when applied in Li/Li-ion batteries. ${ }^{234,235}$ The gelation of DES electrolytes by functional polymers was also used as a strategy to get non-flammable quasi-solid electrolytes that not only presented improved ionic conductivity and electrochemical stability, but also possessed superior mechanical strength and flexibility, as well as enhanced safety because they avoided leakage risks of toxic or corrosive liquids. ${ }^{142,236,237}$ Tested in LIBs, some of these 
gel electrolytes showed a high potential for safe, robust and high performance devices. ${ }^{142,236}$ Another elegant way to structure DESs into gels relies on the addition of a small gelator that self-assembles into a nanoscale network as a result of intermolecular noncovalent interactions, generating eutectogels with tolerance to ionic salt additives and similar ionic conductivities to the native DESs. ${ }^{238}$ The proper interaction of DESs and flexible polymers, ${ }^{91,92}$ including natural polysaccharides, ${ }^{95,101,239-241}$ was also used to obtain films or ion conductive gels to be used as electrolytes in soft electronics, for instance for flexible supercapacitors for wearable electronics and stretchable power supplies. In these electrolytes, the formation of a genuine DES or a more complex system is questionable and needs further elucidation. However these and other examples demonstrate that the introduction of a DES into a polymer matrix is an interesting approach as it opens up a possibility of combining the physico-chemical properties of DESs with the mechanical properties of polymers in green materials.

Degradation/dissolution at DES-electrode interface. Despite the growing attention given to the use of DESs as electrolytes for secondary batteries, only a handful of studies reported on the electrochemical stability of DESs and very little is known on the metal dissolution and degradation products that can be formed during the electrode-DES interaction. ${ }^{83,242-244}$ Decomposition products such as 2-methyl-1,3-dioxolane and chlorinated products like chloromethane, dichloromethane and chloroform, were detected in ChCl:EG 1:2 over eight days of electrolysis. ${ }^{243}$ Also, the electrochemical corrosion of three metal electrodes (titanium, nickel and iron) and their interactions in two DESs, ChCl:EG and proline:LA, was investigated, indicating that metal dissolution from the electrodes were dependent on the type of applied electrode and DES, with titanium being more stable than nickel and iron. ${ }^{244}$ This is however a very complex subject that should be investigated in greater depth to really boost the concrete application of DES electrolytes in batteries.

As a conclusion, DES-based electrolytes are expected to experience significant breakthroughs in the near future given the increasing scientific interest and the current endeavors to enhance performances keeping their low cost and safety. Their electrochemical properties certainly need to be improved and the investigation of their potentialities should be continued. Nevertheless, considering their merits, they can be successfully introduced in the energy storage applications and can contribute to the design and implementation of safer and environmentally friendly systems. 


\section{Appendix}

\section{List of abbreviations}

\begin{tabular}{|c|c|}
\hline Full name & Abbreviation \\
\hline 1,1,2,2-Tetrafluoroethyl-2,2,3,3-tetrafluoropropyl ether & HFE \\
\hline 1,1,3,3-Tetramethylurea & TMU \\
\hline 1,3-Dimethyl-2-imidazolidinone & DMI \\
\hline 1,3-Dimethylurea & DMU \\
\hline 1-Ethyl-3-methylimidazolium chloride & EMImCl \\
\hline 2,2,2-Trifluoroacetamide & TFAA \\
\hline 2-Imidazolidinone & 1 \\
\hline 4-Ethylpyridine & EP \\
\hline Acetamide & AA \\
\hline Acetonitrile & AN \\
\hline Acetylcholine chloride & $\mathrm{AcChCl}$ \\
\hline Acidic Deep Eutectic Solvent & ADES \\
\hline Activated carbon & $A C$ \\
\hline Allyltrimethylammonium chloride & $\mathrm{AMCl}$ \\
\hline Aluminium ion battery & AlB \\
\hline Aluminium-air battery & $A A B$ \\
\hline Aluminum (III) chloride & $\mathrm{AlCl}_{3}$ \\
\hline Aluminum-selenium batteries & Al-Se batteries \\
\hline Aluminum-sulfur batteries & Al-S batteries \\
\hline Brønsted Acidic Deep Eutectic Solvent & BADES \\
\hline Butyramide & BA \\
\hline Cathode electrolyte interface & CEI \\
\hline Choline bromide & $\mathrm{ChBr}$ \\
\hline Choline chloride & $\mathrm{ChCl}$ \\
\hline Choline iodide & Chl \\
\hline Choline nitrate & $\mathrm{ChNO}_{3}$ \\
\hline Choline perchlorate & $\mathrm{ChClO}_{4}$ \\
\hline Choline tetrafluoroborate & $\mathrm{ChBF}_{4}$ \\
\hline Coulombic efficiency & CE \\
\hline Deep Eutectic & $\mathrm{DE}$ \\
\hline Deep Eutectic Electrolyte & DEE \\
\hline Deep Eutectic Mixture & DEM \\
\hline Deep Eutectic Solvent/System & DES \\
\hline Delta-type manganese oxide & $\delta-\mathrm{MnO}_{2}$ \\
\hline Density functional theory & DFT \\
\hline Dichloromethane & DCM \\
\hline Diethylene glycol dimethyl ether, diglyme & $\mathrm{G} 2$ \\
\hline Dimethyl carbonate & DMC \\
\hline Electrochemical Stability Window & ESW \\
\hline
\end{tabular}




\begin{tabular}{|c|c|}
\hline Ethylene carbonate & EC \\
\hline Ethylene glycol & EG \\
\hline Ethylene glycol dimethyl ether, monoglyme & G1 \\
\hline Ethylurea & EU \\
\hline Fluoroethylenecarbonate & FEC \\
\hline Glycerol & G \\
\hline Graphene nanoplatelets & GNP \\
\hline Hexaethylene glycol dimethyl ether, hexaglyme & G6 \\
\hline Hydrogen Bond Acceptor & HBA \\
\hline Hydrogen Bond Donor & HBD \\
\hline Ionic Liquid & IL \\
\hline Ionic Liquid Analog & ILA \\
\hline Lactic acid & LA \\
\hline Lewis Acidic Deep Eutectic Solvent & LADES \\
\hline Liquid Coordination Complexe & LCC \\
\hline Lithium bis(fluorosulfonyl)imide & LiFSI \\
\hline Lithium bis(pentafluoroethanesulfonyl)imide & LiBETI \\
\hline Lithium bis(trifluoromethanesulfonyl)imide & LiTFSI \\
\hline Lithium bromide & $\mathrm{LiBr}$ \\
\hline Lithium chloride & $\mathrm{LiCl}$ \\
\hline Lithium cobalt oxide & $\mathrm{LiCoO}_{2}, \mathrm{LCO}$ \\
\hline Lithium difluoro(oxalato)borate & LiDFOB \\
\hline Lithium hexafluorophosphate & $\mathrm{LiPF}_{6}$ \\
\hline Lithium iodide & Lil \\
\hline Lithium ion battery & LIB \\
\hline Lithium iron phosphate olivine & $\mathrm{LiFePO}_{4}, \mathrm{LFP}$ \\
\hline Lithium manganese oxide & $\mathrm{LiMn}_{2} \mathrm{O}_{4}, \mathrm{LMO}$ \\
\hline Lithium nickel cobalt aluminium oxide & $\mathrm{LiNi}_{0.8} \mathrm{Co}_{0.15} \mathrm{Al}_{0.05} \mathrm{O}_{2}, \mathrm{NCA}$ \\
\hline Lithium nickel manganese cobalt oxide & $\mathrm{LiNi}_{1 / 3} \mathrm{Mn}_{1 / 3} \mathrm{Co}_{1 / 3} \mathrm{O}_{2}, \mathrm{NMC111}$ \\
\hline Lithium nitrate & $\mathrm{LiNO}_{3}$ \\
\hline Lithium perchlorate & $\mathrm{LiClO}_{4}$ \\
\hline Lithium tetrafluoroborate & $\mathrm{LiBF}_{4}$ \\
\hline Lithium titanate & $\mathrm{Li}_{4} \mathrm{Ti}_{5} \mathrm{O}_{12}, \mathrm{LTO}$ \\
\hline Lithium triflouromethanesulfonate (or triflate) & LiTfO \\
\hline Lithium trifluoroacetate & LiTFA \\
\hline Lithium-sulfur battery & Li-S battery \\
\hline Low-transition-temperature mixtures & LTTM \\
\hline Methanesulfonamide & MSA \\
\hline Methyl acetoacetate & MA \\
\hline Methyl levulinate & $\mathrm{ML}$ \\
\hline Methyl pyruvate & MP \\
\hline Methylsulfonylmethane & MSM \\
\hline Methylurea & $\mathrm{MU}$ \\
\hline
\end{tabular}




\begin{tabular}{|c|c|}
\hline Molecular Dynamics & MD \\
\hline Multiwalled carbon nanotube & MWCNT \\
\hline N,N'-Dimethylpropyleneurea & DMPU \\
\hline $\mathrm{N}, \mathrm{N}$-dimethylacetamide & DMAA \\
\hline N,N-Dimethylmethanesulfonamide & DMMSA \\
\hline Natural Deep Eutectic Solvent & NADES \\
\hline Natural graphite & NG \\
\hline N-methylacetamide & NMAA \\
\hline Nuclear Magnetic Resonance & NMR \\
\hline Oxalic acid & OA \\
\hline Pentaethylene glycol dimethyl ether, pentaglyme & G5 \\
\hline Potassium bis(trifluoromethanesulfonyl)imide & KTFSI \\
\hline Potassium carbonate & $\mathrm{K}_{2} \mathrm{CO}_{3}$ \\
\hline Potassium hexafluorophosphate & $\mathrm{KPF}_{6}$ \\
\hline Potassium ion battery & KIB \\
\hline Propionamide & PA \\
\hline Propylene carbonate & PC \\
\hline Pulsed field gradient & PFG \\
\hline Quasielastic neutron scattering & QENS \\
\hline Room Temperature Molten Salt & RTMS \\
\hline Sodium bis(fluorosulfonyl)imide & $\mathrm{NaFSI}$ \\
\hline Sodium bis(trifluoromethanesulfonyl)imide & NaTFSI \\
\hline Sodium bromide & $\mathrm{NaBr}$ \\
\hline Sodium chloride & $\mathrm{NaCl}$ \\
\hline Sodium hexafluorophosphate & $\mathrm{NaPF}_{6}$ \\
\hline Sodium iodide & Nal \\
\hline Sodium ion battery & NIB \\
\hline Sodium nitrate & $\mathrm{NaNO}_{3}$ \\
\hline Sodium perchlorate & $\mathrm{NaClO}_{4}$ \\
\hline Solid electrolyte interface & SEI \\
\hline Standard hydrogen electrode & SHE \\
\hline Succinonitrile & SN \\
\hline Tetrabutylammonium chloride & $\mathrm{TBCl}$ \\
\hline Tetraethylammonium chloride & $\mathrm{TECl}$ \\
\hline Tetraethylene glycol dimethyl ether, tetraglyme & G4 \\
\hline Tetramethylammonium chloride & $\mathrm{TMCl}$ \\
\hline Thiourea & SU \\
\hline Triethylene glycol dimethyl ether, triglyme & G3 \\
\hline Urea & U \\
\hline Vanadium pentoxide & $\mathrm{V}_{2} \mathrm{O}_{5}$ \\
\hline Zinc acetate & $\mathrm{Zn}\left(\mathrm{CH}_{3} \mathrm{COO}\right)_{2}$ \\
\hline Zinc bis(trifluoromethanesulfonyl)imide & $\mathrm{Zn}(\mathrm{TFSI})_{2}$ \\
\hline Zinc chloride & $\mathrm{ZnCl}_{2}$ \\
\hline
\end{tabular}




\begin{tabular}{|l|l|}
\hline Zinc ion batteries & $\mathrm{ZIB}$ \\
\hline Zinc perchlorate & $\mathrm{Zn}\left(\mathrm{ClO}_{4}\right)_{2}$ \\
\hline Zinc sulfate & $\mathrm{ZnSO}{ }_{4}$ \\
\hline Zinc tetrafluoroborate & $\mathrm{Zn}\left(\mathrm{BF}_{4}\right)_{2}$ \\
\hline Zinc triflouromethanesulfonate (or triflate) & $\mathrm{Zn}(\mathrm{TfO})_{2}$ \\
\hline$Y$-Butyrolactone & $\mathrm{GBL}$ \\
\hline
\end{tabular}


Declaration of competing interest

There are no conflicts to declare.

\section{Acknowledgement}

MEDP thanks Politecnico di Milano for her postdoctoral fellowship in the framework of the "MSCA EF Master Class 2018" funding programme. 


\section{References}

(1) McGavock, W. G.; Bryant, J. M.; Wendlandt, W. W. Urea Complexes of Lithium Chloride. Science (80.). 1956, 123, 897.

(2) Gambino, M.; Gaune, P.; Nabavian, M.; Gaune-Escard, M.; Bros, J. P. Enthalpie de Fusion de l'uree et de Quelques Melanges Eutectiques a Base d'uree. Thermochim. Acta 1987, 111, 37-47.

(3) Abbott, A. P.; Capper, G.; Davies, D. L.; Rasheed, R. K.; Tambyrajah, V. Novel Solvent Properties of Choline Chloride/Urea Mixtures. Chem. Commun. 2003, No. 1, 70-71.

(4) Abbott, A. P.; Boothby, D.; Capper, G.; Davies, D. L.; Rasheed, R. K. Deep Eutectic Solvents Formed between Choline Chloride and Carboxylic Acids: Versatile Alternatives to lonic Liquids. J. Am. Chem. Soc. 2004, 126, 9142-9147.

(5) Hansen, B. B.; Spittle, S.; Chen, B.; Poe, D.; Zhang, Y.; Klein, J. M.; Horton, A.; Adhikari, L.; Zelovich, T.; Doherty, B. W.; et al. Deep Eutectic Solvents: A Review of Fundamentals and Applications. Chem. Rev. 2021.

(6) Abbott, A. P.; Capper, G.; Davies, D. L.; McKenzie, K. J.; Obi, S. U. Solubility of Metal Oxides in Deep Eutectic Solvents Based on Choline Chloride. J. Chem. Eng. Data 2006, 51, 1280-1282.

(7) Cruz, H.; Jordão, N.; Branco, L. C. Deep Eutectic Solvents (DESs) as Low-Cost and Green Electrolytes for Electrochromic Devices. Green Chem. 2017, 19, 1653-1658.

(8) Martins, M. A. R.; Pinho, S. P.; Coutinho, J. A. P. Insights into the Nature of Eutectic and Deep Eutectic Mixtures. J. Solution Chem. 2019, 48, 962-982.

(9) Paiva, A.; Matias, A. A.; Duarte, A. R. C. How Do We Drive Deep Eutectic Systems towards an Industrial Reality? Curr. Opin. Green Sustain. Chem. 2018, 11, 81-85.

(10) Griffin, P. J.; Cosby, T.; Holt, A. P.; Benson, R. S.; Sangoro, J. R. Charge Transport and Structural Dynamics in Carboxylic-Acid-Based Deep Eutectic Mixtures. J. Phys. Chem. B 2014, 118, 9378-9385.

(11) Guchhait, B.; Das, S.; Daschakraborty, S.; Biswas, R. Interaction and Dynamics of (Alkylamide + Electrolyte) Deep Eutectics: Dependence on Alkyl Chain-Length, Temperature, and Anion Identity. J. Chem. Phys. 2014, 140, 104514-104525.

(12) Ogawa, H.; Mori, H. Lithium Salt/Amide-Based Deep Eutectic Electrolytes for Lithium-Ion Batteries: Electrochemical, Thermal and Computational Study. Phys. Chem. Chem. Phys. 2020, 22, 8853-8863.

(13) Angell, M.; Pan, C. J.; Rong, Y.; Yuan, C.; Lin, M. C.; Hwang, B. J.; Dai, H. High Coulombic Efficiency Aluminum-Ion Battery Using an AICl3-Urea Ionic Liquid Analog Electrolyte. Proc. Natl. Acad. Sci. U. S. A. 2017, 114, 834-839.

(14) Wang, Y.; Chen, W.; Zhao, Q.; Jin, G.; Xue, Z.; Wang, Y.; Mu, T. lonicity of Deep Eutectic Solvents by Walden Plot and Pulsed Field Gradient Nuclear Magnetic Resonance (PFG-NMR). Phys. Chem. Chem. Phys. 2020, 22, 25760-25768.

(15) Abbott, A. P.; Barron, J. C.; Ryder, K. S.; Wilson, D. Eutectic-Based lonic Liquids with MetalContaining Anions and Cations. Chem. - A Eur. J. 2007, 13, 6495-6501.

(16) Abbott, A. P.; McKenzie, K. J. Application of lonic Liquids to the Electrodeposition of Metals. Phys. 
Chem. Chem. Phys. 2006, 8, 4265-4279.

(17) Anouti, M. Room-Temperature Molten Salts: Protic lonic Liquids and Deep Eutectic Solvents as Media for Electrochemical Application. In Electrochemistry in lonic Liquids: Volume 1: Fundamentals; Torriero, A. A. J., Ed.; Springer International Publishing, 2015; pp 217-252.

(18) Francisco, M.; Van Den Bruinhorst, A.; Kroon, M. C. Low-Transition-Temperature Mixtures (LTTMs): A New Generation of Designer Solvents. Angew. Chemie - Int. Ed. 2013, 52, 3074-3085.

(19) Coleman, F.; Srinivasan, G.; Swadźba-Kwaśny, M. Liquid Coordination Complexes Formed by the Heterolytic Cleavage of Metal Halides. Angew. Chemie - Int. Ed. 2013, 52, 12582-12586.

(20) Smith, E. L.; Abbott, A. P.; Ryder, K. S. Deep Eutectic Solvents (DESs) and Their Applications. Chem. Rev. 2014, 114, 11060-11082.

(21) Liu, Y.; Friesen, J. B.; McAlpine, J. B.; Lankin, D. C.; Chen, S. N.; Pauli, G. F. Natural Deep Eutectic Solvents: Properties, Applications, and Perspectives. J. Nat. Prod. 2018, 81, 679-690.

(22) Qin, H.; Hu, X.; Wang, J.; Cheng, H.; Chen, L.; Qi, Z. Overview of Acidic Deep Eutectic Solvents on Synthesis, Properties and Applications. Green Energy Environ. 2020, 5, 8-21.

(23) Abranches, D. O.; Martins, M. A. R.; Silva, L. P.; Schaeffer, N.; Pinho, S. P.; Coutinho, J. A. P. Phenolic Hydrogen Bond Donors in the Formation of Non-Ionic Deep Eutectic Solvents: The Quest for Type v Des. Chem. Commun. 2019, 55, 10253-10256.

(24) Nkuku, C. A.; LeSuer, R. J. Electrochemistry in Deep Eutectic Solvents. J. Phys. Chem. B 2007, 111, 13271-13277.

(25) Chakrabarti, M. H.; Mjalli, F. S.; Alnashef, I. M.; Hashim, M. A.; Hussain, M. A.; Bahadori, L.; Low, C. T. J. Prospects of Applying Ionic Liquids and Deep Eutectic Solvents for Renewable Energy Storage by Means of Redox Flow Batteries. Renew. Sustain. Energy Rev. 2014, 30, 254-270.

(26) Kaur, S.; Kumari, M.; Kashyap, H. K. Microstructure of Deep Eutectic Solvents: Current Understanding and Challenges. J. Phys. Chem. B 2020, 124, 10601-10616.

(27) Malik, M.; Ng, K. L.; Azimi, G. Physicochemical Characterization of AICl3-Urea Ionic Liquid Analogs: Speciation, Conductivity, and Electrochemical Stability. Electrochim. Acta 2020, 354, 136708.

(28) Smith, E. L. Deep Eutectic Solvents (DESs) and the Metal Finishing Industry: Where Are They Now? Trans. Inst. Met. Finish. 2013, 91, 241-248.

(29) Ge, X.; Gu, C.; Wang, X.; Tu, J. Deep Eutectic Solvents (DESs)-Derived Advanced Functional Materials for Energy and Environmental Applications: Challenges, Opportunities, and Future Vision. J. Mater. Chem. A 2017, 5, 8209-8229.

(30) Chen, Y.; Yu, D.; Chen, W.; Fu, L.; Mu, T. Water Absorption by Deep Eutectic Solvents. Phys. Chem. Chem. Phys. 2019, 21, 2601-2610.

(31) Hammond, O. S.; Bowron, D. T.; Edler, K. J. The Effect of Water upon Deep Eutectic Solvent Nanostructure: An Unusual Transition from lonic Mixture to Aqueous Solution. Angew. Chemie - Int. Ed. 2017, 56, 9782-9785.

(32) Shah, D.; Mjalli, F. S. Effect of Water on the Thermo-Physical Properties of Reline: An Experimental 
and Molecular Simulation Based Approach. Phys. Chem. Chem. Phys. 2014, 16, 23900-23907.

(33) Meng, X.; Ballerat-Busserolles, K.; Husson, P.; Andanson, J.-M. Impact of Water on the Melting Temperature of Urea + Choline Chloride Deep Eutectic Solvent. New J. Chem. 2016, 40, 4492-4499.

(34) Ma, C.; Laaksonen, A.; Liu, C.; Lu, X.; Ji, X. The Peculiar Effect of Water on Ionic Liquids and Deep Eutectic Solvents. Chem. Soc. Rev. 2018, 47, 8685-8720.

(35) Mernissi Cherigui, E. A.; Sentosun, K.; Bouckenooge, P.; Vanrompay, H.; Bals, S.; Terryn, H.; Ustarroz, J. Comprehensive Study of the Electrodeposition of Nickel Nanostructures from Deep Eutectic Solvents: Self-Limiting Growth by Electrolysis of Residual Water. J. Phys. Chem. C 2017, 121, 93379347.

(36) Al-Murshedi, A. Y. M.; Hartley, J. M.; Abbott, A. P.; Ryder, K. S. Effect of Water on the Electrodeposition of Copper on Nickel in Deep Eutectic Solvents. Trans. Inst. Met. Finish. 2019, 97, 321-329.

(37) Boisset, A.; Menne, S.; Jacquemin, J.; Balducci, A.; Anouti, M. Deep Eutectic Solvents Based on NMethylacetamide and a Lithium Salt as Suitable Electrolytes for Lithium-Ion Batteries. Phys. Chem. Chem. Phys. 2013, 15, 20054-20063.

(38) Lukaczynska, M.; Mernissi Cherigui, E. A.; Ceglia, A.; Van Den Bergh, K.; De Strycker, J.; Terryn, H.; Ustarroz, J. Influence of Water Content and Applied Potential on the Electrodeposition of $\mathrm{Ni}$ Coatings from Deep Eutectic Solvents. Electrochim. Acta 2019, 319, 690-704.

(39) Valverde, P. E.; Green, T. A.; Roy, S. Effect of Water on the Electrodeposition of Copper from a Deep Eutectic Solvent. J. Appl. Electrochem. 2020, 50, 699-712.

(40) Hammond, O. S.; Li, H.; Westermann, C.; Al-Murshedi, A. Y. M.; Endres, F.; Abbott, A. P.; Warr, G. G.; Edler, K. J.; Atkin, R. Nanostructure of the Deep Eutectic Solvent/Platinum Electrode Interface as a Function of Potential and Water Content. Nanoscale Horizons 2019, 4, 158-168.

(41) Lloyd, D.; Vainikka, T.; Murtomäki, L.; Kontturi, K.; Ahlberg, E. The Kinetics of the Cu2+/Cu+ Redox Couple in Deep Eutectic Solvents. Electrochim. Acta 2011, 56, 4942-4948.

(42) Chen, Y.; Yu, D.; Fu, L.; Wang, M.; Feng, D.; Yang, Y.; Xue, X.; Wang, J.; Mu, T. The Dynamic Evaporation Process of the Deep Eutectic Solvent LiTf2N:: N -Methylacetamide at Ambient Temperature. Phys. Chem. Chem. Phys. 2019, 21, 11810-11821.

(43) Abbott, A. P.; Capper, G.; Davies, D. L.; Rasheed, R. K.; Shikotra, P. Selective Extraction of Metals from Mixed Oxide Matrixes Using Choline-Based Ionic Liquids. Inorg. Chem. 2005, 44, 6497-6499.

(44) Abbott, A. A.; Collins, J.; Dalrymple, I.; Harris, R. C.; Mistry, R.; Qiu, F.; Scheirer, J.; Wise, W. R. Processing of Electric Arc Furnace Dust Using Deep Eutectic Solvents. Aust. J. Chem. 2009, 62, 341347.

(45) Goddard, A. J.; Harris, R. C.; Saleem, S.; Azam, M.; Hood, C.; Clark, D.; Satchwell, J.; Ryder, K. S. Electropolishing and Electrolytic Etching of Ni-Based HIP Consolidated Aerospace Forms: A Comparison between Deep Eutectic Solvents and Aqueous Electrolytes. Trans. Inst. Met. Finish. 2017, 95, 137-146.

(46) Kityk, A. A.; Danilov, F. I.; Protsenko, V. S.; Pavlik, V.; Boča, M.; Halahovets, Y. Electropolishing of Two 
Kinds of Bronze in a Deep Eutectic Solvent (Ethaline). Surf. Coatings Technol. 2020, 397, 126060.

(47) Abdel-Fattah, T. M.; Loftis, J. D. Comparison of Electropolishing of Aluminum in a Deep Eutectic Medium and Acidic Electrolyte. Molecules 2020, 25.

(48) Abbott, A. P.; Capper, G.; McKenzie, K. J.; Ryder, K. S. Voltammetric and Impedance Studies of the Electropolishing of Type 316 Stainless Steel in a Choline Chloride Based lonic Liquid. Electrochim. Acta 2006, 51, 4420-4425.

(49) Abbott, A. P.; Capper, G.; McKenzie, K. J.; Glidle, A.; Ryder, K. S. Electropolishing of Stainless Steels in a Choline Chloride Based Ionic Liquid: An Electrochemical Study with Surface Characterisation Using SEM and Atomic Force Microscopy. Phys. Chem. Chem. Phys. 2006, 8, 4214-4221.

(50) Bohlen, B.; Wastl, D.; Radomski, J.; Sieber, V.; Vieira, L. Electrochemical CO2 Reduction to Formate on Indium Catalysts Prepared by Electrodeposition in Deep Eutectic Solvents. Electrochem. commun. 2020, 110, 106597.

(51) Sousa, N. G.; Sousa, C. P.; Campos, O. S.; de Lima-Neto, P.; Correia, A. N. One-Step Preparation of Silver Electrodeposits from Non-Aqueous Solvents. J. Mol. Liq. 2019, 288, 111091.

(52) Abbott, A. P.; Capper, G.; McKenzie, K. J.; Ryder, K. S. Electrodeposition of Zinc-Tin Alloys from Deep Eutectic Solvents Based on Choline Chloride. J. Electroanal. Chem. 2007, 599, 288-294.

(53) Bakkar, A.; Neubert, V. Electrodeposition onto Magnesium in Air and Water Stable lonic Liquids: From Corrosion to Successful Plating. Electrochem. commun. 2007, 9, 2428-2435.

(54) Dale, P. J.; Samantilleke, A. P.; Shivagan, D. D.; Peter, L. M. Synthesis of Cadmium and Zinc Semiconductor Compounds from an lonic Liquid Containing Choline Chloride and Urea. Thin Solid Films 2007, 515, 5751-5754.

(55) Steichen, M.; Thomassey, M.; Siebentritt, S.; Dale, P. J. Controlled Electrodeposition of Cu-Ga from a Deep Eutectic Solvent for Low Cost Fabrication of CuGaSe2 Thin Film Solar Cells. Phys. Chem. Chem. Phys. 2011, 13, 4292-4302.

(56) Abbott, A. P.; Barron, J. C.; Frisch, G.; Ryder, K. S.; Silva, A. F. The Effect of Additives on Zinc Electrodeposition from Deep Eutectic Solvents. Electrochim. Acta 2011, 56, 5272-5279.

(57) Gómez, E.; Cojocaru, P.; Magagnin, L.; Valles, E. Electrodeposition of Co, Sm and SmCo from a Deep Eutectic Solvent. J. Electroanal. Chem. 2011, 658, 18-24.

(58) Rao, S.; Zou, X.; Wang, S.; Shi, T.; Lu, Y.; Ji, L.; Hsu, H.-Y.; Xu, Q.; Lu, X. Electrodeposition of Porous Sn$\mathrm{Ni}-\mathrm{Cu}$ Alloy Anode for Lithium-Ion Batteries from Nickel Matte in Deep Eutectic Solvents. J. Electrochem. Soc. 2019, 166, D427-D434.

(59) Bozzini, B.; Gianoncelli, A.; Kaulich, B.; Mele, C.; Prasciolu, M.; Kiskinova, M. Electrodeposition of Manganese Oxide from Eutectic Urea/Choline Chloride Ionic Liquid: An in Situ Study Based on Soft XRay Spectromicroscopy and Visible Reflectivity. J. Power Sources 2012, 211, 71-76.

(60) Mele, C.; Catalano, M.; Taurino, A.; Bozzini, B. Electrochemical Fabrication of Nanoporous GoldSupported Manganese Oxide Nanowires Based on Electrodeposition from Eutectic Urea/Choline Chloride lonic Liquid. Electrochim. Acta 2013, 87, 918-924.

(61) Bozzini, B.; Busson, B.; Humbert, C.; Mele, C.; Tadjeddine, A. Electrochemical Fabrication of 
Nanoporous Gold Decorated with Manganese Oxide Nanowires from Eutectic Urea/Choline Chloride Ionic Liquid. Part III - Electrodeposition of Au-Mn: A Study Based on in Situ Sum-Frequency Generation and Raman Spectroscopies. Electrochim. Acta 2016, 218, 208-215.

(62) Pereira, N. M.; Salomé, S.; Pereira, C. M.; Silva, A. F. Zn-Sn Electrodeposition from Deep Eutectic Solvents Containing EDTA, HEDTA, and Idranal VII. J. Appl. Electrochem. 2012, 42, 561-571.

(63) Saravanan, G.; Mohan, S. Structure, Composition and Corrosion Resistance Studies of Co-Cr Alloy Electrodeposited from Deep Eutectic Solvent (DES). J. Alloys Compd. 2012, 522, 162-166.

(64) Bernasconi, R.; Magagnin, L. Electrodeposition of Nickel from DES on Aluminium for Corrosion Protection. Surf. Eng. 2017, 33, 131-135.

(65) Ghosh, S.; Roy, S. Electrochemical Copper Deposition from an Ethaline-CuCl2·2H2O DES. Surf. Coatings Technol. 2014, 238, 165-173.

(66) Li, M.; Gao, B.; Liu, C.; Chen, W.; Shi, Z.; Hu, X.; Wang, Z. Electrodeposition of Aluminum from AlCl3/Acetamide Eutectic Solvent. Electrochim. Acta 2015, 180, 811-814.

(67) Starykevich, M.; Salak, A. N.; Ivanou, D. K.; Lisenkov, A. D.; Zheludkevich, M. L.; Ferreira, M. G. S. Electrochemical Deposition of Zinc from Deep Eutectic Solvent on Barrier Alumina Layers. Electrochim. Acta 2015, 170, 284-291.

(68) Sebastian, P.; Giannotti, M. I.; Gómez, E.; Feliu, J. M. Surface Sensitive Nickel Electrodeposition in Deep Eutectic Solvent. ACS Appl. Energy Mater. 2018, 1, 1016-1028.

(69) Yang, H.; Reddy, R. G. Electrochemical Deposition of Zinc from Zinc Oxide in 2:1 Urea/Choline Chloride Ionic Liquid. Electrochim. Acta 2014, 147, 513-519.

(70) Ru, J.; Hua, Y.; Wang, D.; Xu, C.; Li, J.; Li, Y.; Zhou, Z.; Gong, K. Mechanistic Insight of in Situ Electrochemical Reduction of Solid PbO to Lead in ChCl-EG Deep Eutectic Solvent. Electrochim. Acta 2015, 186, 455-464.

(71) Maniam, K. K.; Paul, S. Progress in Electrodeposition of Zinc and Zinc Nickel Alloys Using lonic Liquids. Appl. Sci. 2020, 10, 1-20.

(72) Zhang, Q.; Wang, Q.; Zhang, S.; Lu, X.; Zhang, X. Electrodeposition in lonic Liquids. ChemPhysChem 2016, 17, 335-351.

(73) Yavuz, A.; Ozdemir, N.; Erdogan, P. Y.; Zengin, H.; Zengin, G.; Bedir, M. Nickel-Based Materials Electrodeposited from a Deep Eutectic Solvent on Steel for Energy Storage Devices. Appl. Phys. A Mater. Sci. Process. 2019, 125, 1-10.

(74) Manolova, M.; Böck, R.; Scharf, I.; Mehner, T.; Lampke, T. Electrodeposition of Pd Alloys from Choline Chloride/Urea Deep Eutectic Solvents. J. Alloys Compd. 2021, 855.

(75) Sides, W.; Kassouf, N.; Huang, Q. Electrodeposition of Ferromagnetic FeCo and FeCoMn Alloy from Choline Chloride Based Deep Eutectic Solvent. J. Electrochem. Soc. 2019, 166, D77-D85.

(76) Bahadori, L.; Abdul Manan, N. S.; Chakrabarti, M. H.; Hashim, M. A.; Mjalli, F. S.; Alnashef, I. M.; Hussain, M. A.; Low, C. T. J. The Electrochemical Behaviour of Ferrocene in Deep Eutectic Solvents Based on Quaternary Ammonium and Phosphonium Salts. Phys. Chem. Chem. Phys. 2013, 15, 17071714. 
(77) Chakrabarti, M. H.; Brandon, N. P.; Hashim, M. A.; Mjalli, F. S.; Al Nashef, I. M.; Bahadori, L.; Abdul Manan, N. S.; Hussain, M. A.; Yufit, V. Cyclic Voltammetry of Metallic Acetylacetonate Salts in Quaternary Ammonium and Phosphonium Based Deep Eutectic Solvents. Int. J. Electrochem. Sci. 2013, 8, 9652-9676.

(78) Abbott, A. P.; Frisch, G.; Gurman, S. J.; Hillman, A. R.; Hartley, J.; Holyoak, F.; Ryder, K. S. Ionometallurgy: Designer Redox Properties for Metal Processing. Chem. Commun. 2011, 47, 1003110033.

(79) Nasir, S. N. S.; Sidek, N.; Kadir, M. F. Z.; Manan, N. S. A. Electrochemical Behavior of NH4VO3 in Glyceline DES Studied by Cyclic Voltammetry Method. Ionics (Kiel). 2019, 25, 4981-4990.

(80) Xu, J.; Ma, Q.; Su, H.; Qiao, F.; Leung, P.; Shah, A.; Xu, Q. Redox Characteristics of Iron Ions in Different Deep Eutectic Solvents. Ionics (Kiel). 2020, 26, 483-492.

(81) Xu, Q.; Zhao, T. S.; Wei, L.; Zhang, C.; Zhou, X. L. Electrochemical Characteristics and Transport Properties of Fe(II)/Fe(III) Redox Couple in a Non-Aqueous Reline Deep Eutectic Solvent. Electrochim. Acta 2015, 154, 462-467.

(82) Figueiredo, M.; Gomes, C.; Costa, R.; Martins, A.; Pereira, C. M.; Silva, F. Differential Capacity of a Deep Eutectic Solvent Based on Choline Chloride and Glycerol on Solid Electrodes. Electrochim. Acta 2009, 54, 2630-2634.

(83) Fuchs, D.; Bayer, B. C.; Gupta, T.; Szabo, G. L.; Wilhelm, R. A.; Eder, D.; Meyer, J. C.; Steiner, S.; Gollas, B. Electrochemical Behavior of Graphene in a Deep Eutectic Solvent. ACS Appl. Mater. Interfaces 2020, 12, 40937-40948.

(84) Tan, Z.; Peng, Y.; Liu, J.; Yang, Y.; Zhang, Z.; Chen, Z.; Mao, B.; Yan, J. An In Situ Scanning Tunneling Microscopy Study on the Electrochemical Interface between $\mathrm{Au}(111)$ and Ethaline Deep Eutectic Solvent. ChemElectroChem 2020, 7, 4601-4605.

(85) Mamme, M. H.; Moors, S. L. C.; Terryn, H.; Deconinck, J.; Ustarroz, J.; De Proft, F. Atomistic Insight into the Electrochemical Double Layer of Choline Chloride-Urea Deep Eutectic Solvents: Clustered Interfacial Structuring. J. Phys. Chem. Lett. 2018, 9, 6296-6304.

(86) Vieira, L.; Schennach, R.; Gollas, B. In Situ PM-IRRAS of a Glassy Carbon Electrode/Deep Eutectic Solvent Interface. Phys. Chem. Chem. Phys. 2015, 17, 12870-12880.

(87) Tran, M. K.; Rodrigues, M. T. F.; Kato, K.; Babu, G.; Ajayan, P. M. Deep Eutectic Solvents for Cathode Recycling of Li-Ion Batteries. Nat. Energy 2019, 4, 339-345.

(88) Wang, M.; Tan, Q.; Liu, L.; Li, J. A Low-Toxicity and High-Efficiency Deep Eutectic Solvent for the Separation of Aluminum Foil and Cathode Materials from Spent Lithium-Ion Batteries. J. Hazard. Mater. 2019, 380.

(89) Albler, F. J.; Bica, K.; Foreman, M. R. S. J.; Holgersson, S.; Tyumentsev, M. S. A Comparison of Two Methods of Recovering Cobalt from a Deep Eutectic Solvent: Implications for Battery Recycling. J. Clean. Prod. 2017, 167, 806-814.

(90) Sánchez-Ortiz, W.; Aldana-Gonzalez, J. I.; Manh, T. Le; Romero-Romo, M.; Mejia-Caballero, I.; Ramirez-Silva, M. T.; Arce-Estrada, E. M.; Mugica-Álvarez, V.; Palomar-Pardavé, M. A Deep Eutectic Solvent as Leaching Agent and Electrolytic Bath for Silver Recovery from Spent Silver Oxide 
Batteries. J. Electrochem. Soc. 2021.

(91) Qin, H.; Panzer, M. J. Chemically Cross-Linked Poly(2-Hydroxyethyl Methacrylate)-Supported Deep Eutectic Solvent Gel Electrolytes for Eco-Friendly Supercapacitors. ChemElectroChem 2017, 4, 25562562.

(92) Deng, M. J.; Chou, T. H.; Yeh, L. H.; Chen, J. M.; Lu, K. T. 4.2 V Wearable Asymmetric Supercapacitor Devices Based on a VOx//MnOx Paper Electrode and an Eco-Friendly Deep Eutectic Solvent-Based Gel Electrolyte. J. Mater. Chem. A 2018, 6, 20686-20694.

(93) Lien, C. W.; Vedhanarayanan, B.; Chen, J. H.; Lin, J. Y.; Tsai, H. H.; Shao, L. D.; Lin, T. W. Optimization of Acetonitrile/Water Content in Hybrid Deep Eutectic Solvent for Graphene/MoS2 Hydrogel-Based Supercapacitors. Chem. Eng. J. 2021, 405, 126706.

(94) Sathyamoorthi, S.; Phattharasupakun, N.; Sawangphruk, M. Environmentally Benign Non-Fluoro Deep Eutectic Solvent and Free-Standing Rice Husk-Derived Bio-Carbon Based High-Temperature Supercapacitors. Electrochim. Acta 2018, 286, 148-157.

(95) Hong, S.; Yuan, Y.; Liu, C.; Chen, W.; Chen, L.; Lian, H.; Liimatainen, H. A Stretchable and Compressible Ion Gel Based on a Deep Eutectic Solvent Applied as a Strain Sensor and Electrolyte for Supercapacitors. J. Mater. Chem. C 2020, 8, 550-560.

(96) Yilmaz Erdogan, P.; Zengin, H.; Yavuz, A. Growth and Cycling of Polyaniline Electrode in a Deep Eutectic Solvent: A New Electrolyte for Supercapacitor Applications. Solid State Ionics 2020, 352, 115362.

(97) Zhong, M.; Tang, Q. F.; Zhu, Y. W.; Chen, X. Y.; Zhang, Z. J. An Alternative Electrolyte of Deep Eutectic Solvent by Choline Chloride and Ethylene Glycol for Wide Temperature Range Supercapacitors. J. Power Sources 2020, 452, 227847.

(98) Zaidi, W.; Timperman, L.; Anouti, M. Deep Eutectic Solvent Based on Sodium Cations as an Electrolyte for Supercapacitor Application. RSC Adv. 2014, 4, 45647-45652.

(99) Zaidi, W.; Boisset, A.; Jacquemin, J.; Timperman, L.; Anouti, M. Deep Eutectic Solvents Based on NMethylacetamide and a Lithium Salt as Electrolytes at Elevated Temperature for Activated CarbonBased Supercapacitors. J. Phys. Chem. C 2014, 118, 4033-4042.

(100) Zhong, M.; Tang, Q. F.; Qiu, Z. G.; Wang, W. P.; Chen, X. Y.; Zhang, Z. J. A Novel Electrolyte of Ternary Deep Eutectic Solvent for Wide Temperature Region Supercapacitor with Superior Performance. J. Energy Storage 2020, 32, 101904.

(101) Vorobiov, V. K.; Smirnov, M. A.; Bobrova, N. V.; Sokolova, M. P. Chitosan-Supported Deep Eutectic Solvent as Bio-Based Electrolyte for Flexible Supercapacitor. Mater. Lett. 2021, 283, 128889.

(102) Nguyen, P. T.; Nguyen, T. D. T.; Nguyen, V. S.; Dang, D. T. X.; Le, H. M.; Wei, T. C.; Tran, P. H. Application of Deep Eutectic Solvent from Phenol and Choline Chloride in Electrolyte to Improve Stability Performance in Dye-Sensitized Solar Cells. J. Mol. Liq. 2019, 277, 157-162.

(103) Boldrini, C. L.; Manfredi, N.; Perna, F. M.; Trifiletti, V.; Capriati, V.; Abbotto, A. Dye-Sensitized Solar Cells That Use an Aqueous Choline Chloride-Based Deep Eutectic Solvent as Effective Electrolyte Solution. Energy Technol. 2017, 5, 345-353. 
(104) Boldrini, C. L.; Manfredi, N.; Perna, F. M.; Capriati, V.; Abbotto, A. Designing Eco-Sustainable DyeSensitized Solar Cells by the Use of a Menthol-Based Hydrophobic Eutectic Solvent as an Effective Electrolyte Medium. Chem. - A Eur. J. 2018, 24, 17656-17659.

(105) Boldrini, C. L.; Manfredi, N.; Perna, F. M.; Capriati, V.; Abbotto, A. Eco-Friendly Sugar-Based Natural Deep Eutectic Solvents as Effective Electrolyte Solutions for Dye-Sensitized Solar Cells. ChemElectroChem 2020, 7, 1707-1712.

(106) Jhong, H. R.; Wong, D. S. H.; Wan, C. C.; Wang, Y. Y.; Wei, T. C. A Novel Deep Eutectic Solvent-Based Ionic Liquid Used as Electrolyte for Dye-Sensitized Solar Cells. Electrochem. commun. 2009, 11, 209211.

(107) Lloyd, D.; Vainikka, T.; Kontturi, K. The Development of an All Copper Hybrid Redox Flow Battery Using Deep Eutectic Solvents. Electrochim. Acta 2013, 100, 18-23.

(108) Malik, R. Flow Battery Solvents: Looking Deeper. Joule 2017, 1, 425-427.

(109) Xu, Q.; Qin, L. Y.; Ji, Y. N.; Leung, P. K.; Su, H. N.; Qiao, F.; Yang, W. W.; Shah, A. A.; Li, H. M. A Deep Eutectic Solvent (DES) Electrolyte-Based Vanadium-Iron Redox Flow Battery Enabling Higher Specific Capacity and Improved Thermal Stability. Electrochim. Acta 2019, 293, 426-431.

(110) Lloyd, D.; Vainikka, T.; Ronkainen, M.; Kontturi, K. Characterisation and Application of the $\mathrm{Fe}(\mathrm{II}) / \mathrm{Fe}(\mathrm{III})$ Redox Reaction in an Ionic Liquid Analogue. Electrochim. Acta 2013, 109, 843-851.

(111) Wang, Y.; Zhou, H. A Green and Cost-Effective Rechargeable Battery with High Energy Density Based on a Deep Eutectic Catholyte. Energy Environ. Sci. 2016, 9, 2267-2272.

(112) Zhang, C.; Ding, Y.; Zhang, L.; Wang, X.; Zhao, Y.; Zhang, X.; Yu, G. A Sustainable Redox-Flow Battery with an Aluminum-Based, Deep-Eutectic-Solvent Anolyte. Angew. Chemie 2017, 129, 7562-7567.

(113) Zhang, L.; Zhang, C.; Ding, Y.; Ramirez-Meyers, K.; Yu, G. A Low-Cost and High-Energy Hybrid IronAluminum Liquid Battery Achieved by Deep Eutectic Solvents. Joule 2017, 1, 623-633.

(114) Wang, Y.; Niu, Z.; Zheng, Q.; Zhang, C.; Ye, J.; Dai, G.; Zhao, Y.; Zhang, X. Zn-Based Eutectic Mixture as Anolyte for Hybrid Redox Flow Batteries. Sci. Rep. 2018, 8, 8-15.

(115) Cheng, R.; Xu, J.; Zhang, J.; Leung, P.; Ma, Q.; Su, H.; Yang, W.; Xu, Q. Facile Segmented Graphite Felt Electrode for Iron-Vanadium Redox Flow Batteries with Deep Eutectic Solvent (DES) Electrolyte. J. Power Sources 2021, 483.

(116) Chakrabarti, B.; Rubio-Garcia, J.; Kalamaras, E.; Yufit, V.; Tariq, F.; Low, C. T. J.; Kucernak, A.; Brandon, N. Evaluation of a Non-Aqueous Vanadium Redox Flow Battery Using a Deep Eutectic Solvent and Graphene-Modified Carbon Electrodes via Electrophoretic Deposition. Batteries 2020, 6, 1-20.

(117) Ma, Q.; Zhao, L.; Xu, J.; Su, H.; Zhang, W.; Yang, W.; Xu, Q. Pore-Scale Investigation of Reactive Transfer Process in a Deep Eutectic Solvent (DES) Electrolyte-Based Vanadium-Iron Redox Flow Battery. Electrochim. Acta 2020, 353, 136486.

(118) Armand, M.; Axmann, P.; Bresser, D.; Copley, M.; Edström, K.; Ekberg, C.; Guyomard, D.; Lestriez, B.; Novák, P.; Petranikova, M.; et al. Lithium-Ion Batteries - Current State of the Art and Anticipated Developments. J. Power Sources 2020, 479. 
(119) Jaumaux, P.; Wu, J.; Shanmukaraj, D.; Wang, Y.; Zhou, D.; Sun, B.; Kang, F.; Li, B.; Armand, M.; Wang, G. Non-Flammable Liquid and Quasi-Solid Electrolytes toward Highly-Safe Alkali Metal-Based Batteries. Adv. Funct. Mater. 2020, 2008644, 1-28.

(120) Geiculescu, O. E.; Desmarteau, D. D.; Creager, S. E.; Haik, O.; Hirshberg, D.; Shilina, Y.; Zinigrad, E.; Levi, M. D.; Aurbach, D.; Halalay, I. C. Novel Binary Deep Eutectic Electrolytes for Rechargeable Li-lon Batteries Based on Mixtures of Alkyl Sulfonamides and Lithium Perfluoroalkylsulfonimide Salts. J. Power Sources 2016, 307, 519-525.

(121) Pauric, A. D.; Halalay, I. C.; Goward, G. R. Combined NMR and Molecular Dynamics Modeling Study of Transport Properties in Sulfonamide Based Deep Eutectic Lithium Electrolytes: LiTFSI Based Binary Systems. Phys. Chem. Chem. Phys. 2016, 18, 6657-6667.

(122) Lesch, V.; Heuer, A.; Rad, B. R.; Winter, M.; Smiatek, J. Atomistic Insights into Deep Eutectic Electrolytes: The Influence of Urea on the Electrolyte Salt LiTFSI in View of Electrochemical Applications. Phys. Chem. Chem. Phys. 2016, 18, 28403-28408.

(123) Liang, H.; Li, H.; Wang, Z.; Wu, F.; Chen, L.; Huang, X. New Binary Room-Temperature Molten Salt Electrolyte Based on Urea and LiTFSI. J. Phys. Chem. B 2001, 105, 9966-9969.

(124) Nandy, A.; Smiatek, J. Mixtures of LiTFSI and Urea: Ideal Thermodynamic Behavior as Key to the Formation of Deep Eutectic Solvents? Phys. Chem. Chem. Phys. 2019, 21, 12279-12287.

(125) Hu, Y.; Li, H.; Huang, X.; Chen, L. Novel Room Temperature Molten Salt Electrolyte Based on LiTFSI and Acetamide for Lithium Batteries. Electrochem. commun. 2004, 6, 28-32.

(126) Hu, Y.; Wang, Z.; Li, H.; Huang, X.; Chen, L. Ionic Conductivity and Association Studies of Novel RTMS Electrolyte Based on LiTFSI and Acetamide. J. Electrochem. Soc. 2004, 151, A1424.

(127) Chen, R.; Wu, F.; Liang, H.; Li, L.; Xu, B. Novel Binary Room-Temperature Complex Electrolytes Based on LiTFSI and Organic Compounds with Acylamino Group. J. Electrochem. Soc. 2005, 152, A1979.

(128) Xu, B.; Wu, F.; Chen, R.; Cao, G.; Chen, S.; Wang, G.; Yang, Y. Room Temperature Molten Salt as Electrolyte for Carbon Nanotube-Based Electric Double Layer Capacitors. J. Power Sources 2006, $158,773-778$.

(129) Chen, R.; Wu, F.; Li, L.; Qiu, X.; Chen, L.; Chen, S. The Structure-Activity Relationship Studies of Binary Room Temperature Complex Electrolytes Based on LiTFSI and Organic Compounds with Acylamino Group. Vib. Spectrosc. 2007, 44, 297-307.

(130) Guchhait, B.; Daschakraborty, S.; Biswas, R. Medium Decoupling of Dynamics at Temperatures 100 K above Glass-Transition Temperature: A Case Study with (Acetamide + Lithium Bromidenitrate) Melts. J. Chem. Phys. 2012, 136.

(131) Das, S.; Biswas, R.; Mukherjee, B. Orientational Jumps in (Acetamide + Electrolyte) Deep Eutectics: Anion Dependence. J. Phys. Chem. B 2015, 119, 11157-11168.

(132) Kerridge, D. H. The Chemistry of Molten Acetamide and Acetamide Complexes. Chem. Soc. Rev. $1988,17,181-227$.

(133) Chen, R.; Wu, F.; Xu, B.; Li, L.; Qiu, X.; Chen, S. Binary Complex Electrolytes Based on LiX[X=N(SO[Sub 2] CF[Sub 3])[Sub 2][Sup -], CF[Sub 3]SO[Sub 3][Sup -], ClO[Sub 4][Sup -]]-Acetamide for Electric 
Double Layer Capacitors. J. Electrochem. Soc. 2007, 154, A703.

(134) Srinivasan, H.; Sharma, V. K.; Mitra, S.; Biswas, R.; Mukhopadhyay, R. Dynamics in Acetamide+LiNO 3 Deep Eutectic Solvents. Phys. B Condens. Matter 2019, 562, 13-16.

(135) Srinivasan, H.; Sharma, V. K.; Sakai, V. G.; Embs, J. P.; Mukhopadhyay, R.; Mitra, S. Transport Mechanism of Acetamide in Deep Eutectic Solvents. J. Phys. Chem. B 2020, 124, 1509-1520.

(136) Srinivasan, H.; Sharma, V. K.; Mukhopadhyay, R.; Mitra, S. Solvation and Transport of Lithium lons in Deep Eutectic Solvents. J. Chem. Phys. 2020, 153.

(137) Biswas, R.; Das, A.; Shirota, H. Low-Frequency Collective Dynamics in Deep Eutectic Solvents of Acetamide and Electrolytes: A Femtosecond Raman-Induced Kerr Effect Spectroscopic Study. J. Chem. Phys. 2014, 141, 134506-134516.

(138) Das, A.; Das, S.; Biswas, R. Fast Fluctuations in Deep Eutectic Melts: Multi-Probe Fluorescence Measurements and All-Atom Molecular Dynamics Simulation Study. Chem. Phys. Lett. 2013, 581, 47-51.

(139) Subba, N.; Tarif, E.; Sen, P.; Biswas, R. Subpicosecond Solvation Response and Partial Viscosity Decoupling of Solute Diffusion in Ionic Acetamide Deep Eutectic Solvents: Fluorescence UpConversion and Fluorescence Correlation Spectroscopic Measurements. J. Phys. Chem. B 2020, 124, 1995-2005.

(140) Das, S.; Mukherjee, B.; Biswas, R. Microstructures and Their Lifetimes in Acetamide/Electrolyte Deep Eutectics: Anion Dependence. J. Chem. Sci. 2017, 129, 939-951.

(141) Boisset, A.; Jacquemin, J.; Anouti, M. Physical Properties of a New Deep Eutectic Solvent Based on Lithium Bis[(Trifluoromethyl)Sulfonyl]Imide and N-Methylacetamide as Superionic Suitable Electrolyte for Lithium Ion Batteries and Electric Double Layer Capacitors. Electrochim. Acta 2013, $102,120-126$.

(142) Jaumaux, P.; Liu, Q.; Zhou, D.; Xu, X.; Wang, T.; Wang, Y.; Kang, F.; Li, B.; Wang, G. Deep-EutecticSolvent-Based Self-Healing Polymer Electrolyte for Safe and Long-Life Lithium-Metal Batteries. Angew. Chemie - Int. Ed. 2020, 59, 9134-9142.

(143) Hu, Z.; Xian, F.; Guo, Z.; Lu, C.; Du, X.; Cheng, X.; Zhang, S.; Dong, S.; Cui, G.; Chen, L. Nonflammable Nitrile Deep Eutectic Electrolyte Enables High-Voltage Lithium Metal Batteries. Chem. Mater. 2020, $32,3405-3413$.

(144) Dinh, T. T. A.; Huynh, T. T. K.; Le, L. T. M.; Truong, T. T. T.; Nguyen, O. H.; Tran, K. T. T.; Tran, M. V.; Tran, P. H.; Kaveevivitchai, W.; Le, P. M. L. Deep Eutectic Solvent Based on Lithium Bis[(Trifluoromethyl)Sulfonyl] Imide (LiTFSI) and 2,2,2-Trifluoroacetamide (TFA) as a Promising Electrolyte for a High Voltage Lithium-Ion Battery with a LiMn2O4Cathode. ACS Omega 2020, 5 , 23843-23853.

(145) Jiang, P.; Chen, L.; Shao, H.; Huang, S.; Wang, Q.; Su, Y.; Yan, X.; Liang, X.; Zhang, J.; Feng, J.; et al. Methylsulfonylmethane-Based Deep Eutectic Solvent as a New Type of Green Electrolyte for a HighEnergy-Density Aqueous Lithium-Ion Battery. ACS Energy Lett. 2019, 4, 1419-1426.

(146) Tran, K. T. T.; Le, L. T. M.; Phan, A. L. B.; Tran, P. H.; Vo, T. D.; Truong, T. T. T.; Nguyen, N. T. B.; Garg, A.; Le, P. M. L.; Tran, M. V. New Deep Eutectic Solvents Based on Ethylene Glycol - LiTFSI and Their 
Application as an Electrolyte in Electrochemical Double Layer Capacitor (EDLC). J. Mol. Liq. 2020, 320, 114495.

(147) Dokko, K.; Tachikawa, N.; Yamauchi, K.; Tsuchiya, M.; Yamazaki, A.; Takashima, E.; Park, J.-W.; Ueno, K.; Seki, S.; Serizawa, N.; et al. Solvate Ionic Liquid Electrolyte for Li-S Batteries. J. Electrochem. Soc. 2013, 160, A1304-A1310.

(148) Kondou, S.; Thomas, M. L.; Mandai, T.; Ueno, K.; Dokko, K.; Watanabe, M. lonic Transport in Highly Concentrated Lithium Bis(Fluorosulfonyl)Amide Electrolytes with Keto Ester Solvents: Structural Implications for Ion Hopping Conduction in Liquid Electrolytes. Phys. Chem. Chem. Phys. 2019, 21, 5097-5105.

(149) Gafurov, M. M.; Rabadanov, K. S.; Prisyazhnyi, V. D.; Tret'Yakov, D. O.; Gorobets, M. I.; Kirillov, S. A.; Ataev, M. B.; Kakagasanov, M. M. Phase Equilibriums, Ion Association, and Mechanisms of Solvation in the LiN(CF3SO2)2-(CH3) 2SO2 System. Russ. J. Phys. Chem. A 2011, 85, 1499-1504.

(150) Tretyakov, D. O.; Prisiazhnyi, V. D.; Gafurov, M. M.; Rabadanov, K. S.; Kirillov, S. A. Formation of Contact Ion Pairs and Solvation of Li+ Ion in Sulfones: Phase Diagrams, Conductivity, Raman Spectra, and Dynamics. J. Chem. Eng. Data 2010, 55, 1958-1964.

(151) Xian, F.; Li, J.; Hu, Z.; Zhou, Q.; Wang, C.; Lu, C.; Zhang, Z.; Dong, S.; Mou, C.; Cui, G. Investigation of the Cathodic Interfacial Stability of a Nitrile Electrolyte and Its Performance with a High-Voltage LiCoO2cathode. Chem. Commun. 2020, 56, 4998-5001.

(152) Cruz, H.; Jordão, N.; Amorim, P.; Dionísio, M.; Branco, L. C. Deep Eutectic Solvents as Suitable Electrolytes for Electrochromic Devices. ACS Sustain. Chem. Eng. 2018, 6, 2240-2249.

(153) Cruz, H.; Jordao, N.; Pinto, A. L.; Dionisio, M.; Neves, L. A.; Branco, L. C. Alkaline lodide-Based Deep Eutectic Solvents for Electrochemical Applications. ACS Sustain. Chem. Eng. 2020, 8, 10653-10663.

(154) Tamura, T.; Yoshida, K.; Hachida, T.; Tsuchiya, M.; Nakamura, M.; Kazue, Y.; Tachikawa, N.; Dokko, K.; Watanabe, M. Physicochemical Properties of Glyme-Li Salt Complexes as a New Family of RoomTemperature Ionic Liquids. Chem. Lett. 2010, 39, 753-755.

(155) Tamura, T.; Hachida, T.; Yoshida, K.; Tachikawa, N.; Dokko, K.; Watanabe, M. New Glyme-Cyclic Imide Lithium Salt Complexes as Thermally Stable Electrolytes for Lithium Batteries. J. Power Sources 2010, 195, 6095-6100.

(156) Yoshida, K.; Nakamura, M.; Kazue, Y.; Tachikawa, N.; Tsuzuki, S.; Seki, S.; Dokko, K.; Watanabe, M. Oxidative-Stability Enhancement and Charge Transport Mechanism in Glyme-Lithium Salt Equimolar Complexes. J. Am. Chem. Soc. 2011, 133, 13121-13129.

(157) Ueno, K.; Yoshida, K.; Tsuchiya, M.; Tachikawa, N.; Dokko, K.; Watanabe, M. Glyme-Lithium Salt Equimolar Molten Mixtures: Concentrated Solutions or Solvate lonic Liquids? J. Phys. Chem. B 2012, $116,11323-11331$.

(158) Austen Angell, C.; Ansari, Y.; Zhao, Z. Ionic Liquids: Past, Present and Future. Faraday Discuss. 2012, 154, 9-27.

(159) Ueno, K.; Tatara, R.; Tsuzuki, S.; Saito, S.; Doi, H.; Yoshida, K.; Mandai, T.; Matsugami, M.; Umebayashi, Y.; Dokko, K.; et al. Li+ Solvation in Glyme-Li Salt Solvate lonic Liquids. Phys. Chem. Chem. Phys. 2015, 17, 8248-8257. 
(160) Mandai, T.; Yoshida, K.; Ueno, K.; Dokko, K.; Watanabe, M. Criteria for Solvate Ionic Liquids. Phys. Chem. Chem. Phys. 2014, 16, 8761-8772.

(161) Shinoda, W.; Hatanaka, Y.; Hirakawa, M.; Okazaki, S.; Tsuzuki, S.; Ueno, K.; Watanabe, M. Molecular Dynamics Study of Thermodynamic Stability and Dynamics of [Li(Glyme)]+ Complex in LithiumGlyme Solvate Ionic Liquids. J. Chem. Phys. 2018, 148.

(162) Seki, S.; Takei, K.; Miyashiro, H.; Watanabe, M. Physicochemical and Electrochemical Properties of Glyme-LiN(SO2F)2 Complex for Safe Lithium-Ion Secondary Battery Electrolyte. J. Electrochem. Soc. 2011, 158, A769.

(163) Orita, A.; Kamijima, K.; Yoshida, M.; Dokko, K.; Watanabe, M. Favorable Combination of Positive and Negative Electrode Materials with Glyme-Li Salt Complex Electrolytes in Lithium Ion Batteries. J. Power Sources 2011, 196, 3874-3880.

(164) Tachikawa, N.; Yamauchi, K.; Takashima, E.; Park, J. W.; Dokko, K.; Watanabe, M. Reversibility of Electrochemical Reactions of Sulfur Supported on Inverse Opal Carbon in Glyme-Li Salt Molten Complex Electrolytes. Chem. Commun. 2011, 47, 8157-8159.

(165) Seki, S.; Serizawa, N.; Takei, K.; Dokko, K.; Watanabe, M. Charge/Discharge Performances of GlymeLithium Salt Equimolar Complex Electrolyte for Lithium Secondary Batteries. J. Power Sources 2013, 243, 323-327.

(166) Seki, S.; Serizawa, N.; Takei, K.; Tsuzuki, S.; Umebayashi, Y.; Katayama, Y.; Miura, T.; Dokko, K.; Watanabe, M. Effects of Non-Equimolar Lithium Salt Glyme Solvate lonic Liquid on the Control of Interfacial Degradation in Lithium Secondary Batteries. RSC Adv. 2016, 6, 33043-33047.

(167) Pan, Y.; Li, S.; Yin, M.; Li, J. Electrolyte Evolution Propelling the Development of Nonlithium MetalSulfur Batteries. Energy Technol. 2019, 7, 1-16.

(168) Wu, S. C.; Ai, Y.; Chen, Y. Z.; Wang, K.; Yang, T. Y.; Liao, H. J.; Su, T. Y.; Tang, S. Y.; Chen, C. W.; Wu, D. C.; et al. High-Performance Rechargeable Aluminum-Selenium Battery with a New Deep Eutectic Solvent Electrolyte: Thiourea-AICI3. ACS Appl. Mater. Interfaces 2020, 12, 27064-27073.

(169) Reuter, D.; Binder, C.; Lunkenheimer, P.; Loidl, A. Ionic Conductivity of Deep Eutectic Solvents: The Role of Orientational Dynamics and Glassy Freezing. Phys. Chem. Chem. Phys. 2019, 21, 6801-6809.

(170) Gadilohar, B. L.; Shankarling, G. S. Choline Based Ionic Liquids and Their Applications in Organic Transformation. J. Mol. Liq. 2017, 227, 234-261.

(171) Xu, L. H.; Wu, D.; Zhong, M.; Wang, G. B.; Chen, X. Y.; Zhang, Z. J. The Construction of a New Deep Eutectic Solvents System Based on Choline Chloride and Butanediol: The Influence of the Hydroxyl Position of Butanediol on the Structure of Deep Eutectic Solvent and Supercapacitor Performance. J. Power Sources 2021, 490.

(172) Li, Q.; Jiang, J.; Li, G.; Zhao, W.; Zhao, X.; Mu, T. The Electrochemical Stability of Ionic Liquids and Deep Eutectic Solvents. Sci. China Chem. 2016, 59, 571-577.

(173) Dhingra, D.; Bhawna; Pandey, S. Effect of Lithium Chloride on the Density and Dynamic Viscosity of Choline Chloride/Urea Deep Eutectic Solvent in the Temperature Range (303.15-358.15) K. J. Chem. Thermodyn. 2019, 130, 166-172. 
(174) Dhingra, D.; Bhawna, B.; Pandey, A.; Pandey, S. Pyrene Fluorescence to Probe a Lithium ChlorideAdded (Choline Chloride + Urea) Deep Eutectic Solvent. J. Phys. Chem. B 2019, 123, 3103-3111.

(175) Barik, S.; Chakraborty, M.; Sarkar, M. How Does Addition of Lithium Salt Influence the Structure and Dynamics of Choline Chloride-Based Deep Eutectic Solvents? J. Phys. Chem. B 2020, 124, 2864-2878.

(176) Millia, L.; Dall'Asta, V.; Ferrara, C.; Berbenni, V.; Quartarone, E.; Perna, F. M.; Capriati, V.; Mustarelli, P. Bio-Inspired Choline Chloride-Based Deep Eutectic Solvents as Electrolytes for Lithium-Ion Batteries. Solid State Ionics 2018, 323, 44-48.

(177) Mokhtarpour, M.; Shekaari, H.; Zafarani-Moattar, M. T.; Golgoun, S. Solubility and Solvation Behavior of Some Drugs in Choline Based Deep Eutectic Solvents at Different Temperatures. J. Mol. Liq. 2020, 297.

(178) Kharbachi, A. El; Zavorotynska, O.; Latroche, M.; Cuevas, F.; Yartys, V.; Fichtner, M. Exploits, Advances and Challenges Benefiting beyond Li-Ion Battery Technologies. J. Alloys Compd. 2020, 817, 153261-153286.

(179) Hasa, I.; Mariyappan, S.; Saurel, D.; Adelhelm, P.; Koposov, A. Y.; Masquelier, C.; Croguennec, L.; Casas-Cabanas, M. Challenges of Today for Na-Based Batteries of the Future: From Materials to Cell Metrics. J. Power Sources 2021, 482, 228872.

(180) Zhang, J.; Yao, X.; Misra, R. K.; Cai, Q.; Zhao, Y. Progress in Electrolytes for Beyond-Lithium-lon Batteries. J. Mater. Sci. Technol. 2020, 44, 237-257.

(181) Ponrouch, A.; Monti, D.; Boschin, A.; Steen, B.; Johansson, P.; Palacín, M. R. Non-Aqueous Electrolytes for Sodium-Ion Batteries. J. Mater. Chem. A 2015, 3, 22-42.

(182) Zhao, Q.; Hu, Y.; Zhang, K.; Chen, J. Potassium-Sulfur Batteries: A New Member of RoomTemperature Rechargeable Metal-Sulfur Batteries. Inorg. Chem. 2014, 53, 9000-9005.

(183) Karimi, M. B.; Mohammadi, F.; Hooshyari, K. Potential Use of Deep Eutectic Solvents (DESs) to Enhance Anhydrous Proton Conductivity of Nafion $115^{\circledR}$ Membrane for Fuel Cell Applications. J. Memb. Sci. 2020, 611.

(184) Sedghamiz, M. A.; Raeissi, S. Physical Properties of Deep Eutectic Solvents Formed by the Sodium Halide Salts and Ethylene Glycol, and Their Mixtures with Water. J. Mol. Liq. 2018, 269, 694-702.

(185) Karimi, M. B.; Mohammadi, F.; Hooshyari, K. Non-Humidified Fuel Cells Using a Deep Eutectic Solvent (DES) as the Electrolyte within a Polymer Electrolyte Membrane (PEM): The Effect of Water and Counterions. Phys. Chem. Chem. Phys. 2020, 22, 2917-2929.

(186) Mjalli, F. S.; Naser, J.; Jibril, B.; Al-Hatmi, S. S.; Gano, Z. S. Ionic Liquids Analogues Based on Potassium Carbonate. Thermochim. Acta 2014, 575, 135-143.

(187) Mandai, T.; Nozawa, R.; Tsuzuki, S.; Yoshida, K.; Ueno, K.; Dokko, K.; Watanabe, M. Phase Diagrams and Solvate Structures of Binary Mixtures of Glymes and Na Salts. J. Phys. Chem. B 2013, 117, 15072-15085.

(188) Terada, S.; Mandai, T.; Nozawa, R.; Yoshida, K.; Ueno, K.; Tsuzuki, S.; Dokko, K.; Watanabe, M. Physicochemical Properties of Pentaglyme-Sodium Bis(Trifluoromethanesulfonyl)Amide Solvate Ionic Liquid. Phys. Chem. Chem. Phys. 2014, 16, 11737-11746. 
(189) Mandai, T.; Yoshida, K.; Tsuzuki, S.; Nozawa, R.; Masu, H.; Ueno, K.; Dokko, K.; Watanabe, M. Effect of Ionic Size on Solvate Stability of Glyme-Based Solvate lonic Liquids. J. Phys. Chem. B 2015, 119, $1523-1534$.

(190) Das, S. K.; Mahapatra, S.; Lahan, H. Aluminium-Ion Batteries: Developments and Challenges. J. Mater. Chem. A 2017, 5, 6347-6367.

(191) Jiao, H.; Wang, C.; Tu, J.; Tian, D.; Jiao, S. A Rechargeable Al-Ion Battery: Al/Molten AlCl3Urea/Graphite. Chem. Commun. 2017, 53, 2331-2334.

(192) Lampkin, J.; Li, H.; Furness, L.; Raccichini, R.; Garcia-Araez, N. A Critical Evaluation of the Effect of Electrode Thickness and Side Reactions on Electrolytes for Aluminum-Sulfur Batteries. ChemSusChem 2020, 13, 3514-3523.

(193) Elia, G. A.; Kravchyk, K. V.; Kovalenko, M. V.; Chacón, J.; Holland, A.; Wills, R. G. A. An Overview and Prospective on Al and Al-Ion Battery Technologies. J. Power Sources 2021, 481.

(194) Zhang, Y.; Liu, S.; Ji, Y.; Ma, J.; Yu, H. Emerging Nonaqueous Aluminum-Ion Batteries: Challenges, Status, and Perspectives. Adv. Mater. 2018, 30.

(195) Yuan, D.; Zhao, J.; Manalastas, W.; Kumar, S.; Srinivasan, M. Emerging Rechargeable Aqueous Aluminum Ion Battery: Status, Challenges, and Outlooks. Nano Mater. Sci. 2020, 2, 248-263.

(196) Abood, H. M. A.; Abbott, A. P.; Ballantyne, A. D.; Ryder, K. S. Do All lonic Liquids Need Organic Cations? Characterisation of [AlCl2·nAmide]+ $\mathrm{AlCl} 4$ - and Comparison with Imidazolium Based Systems. Chem. Commun. 2011, 47, 3523-3525.

(197) Hu, P.; Zhang, R.; Meng, X.; Liu, H.; Xu, C.; Liu, Z. Structural and Spectroscopic Characterizations of Amide-AICl3-Based Ionic Liquid Analogues. Inorg. Chem. 2016, 55, 2374-2380.

(198) Wang, C.; Li, J.; Jiao, H.; Tu, J.; Jiao, S. The Electrochemical Behavior of an Aluminum Alloy Anode for Rechargeable Al-Ion Batteries Using an AICl3-Urea Liquid Electrolyte. RSC Adv. 2017, 7, 3228832293.

(199) Ng, K. L.; Malik, M.; Buch, E.; Glossmann, T.; Hintennach, A.; Azimi, G. A Low-Cost Rechargeable Aluminum/Natural Graphite Battery Utilizing Urea-Based Ionic Liquid Analog. Electrochim. Acta 2019, 327, 135031.

(200) Canever, N.; Bertrand, N.; Nann, T. Acetamide: A Low-Cost Alternative to Alkyl Imidazolium Chlorides for Aluminium-Ion Batteries. Chem. Commun. 2018, 54, 11725-11728.

(201) Paterno, D.; Rock, E.; Forbes, A.; Iqbal, R.; Mohammad, N.; Suarez, S. Aluminum lons Speciation and Transport in Acidic Deep Eutectic AICl3 Amide Electrolytes. J. Mol. Liq. 2020, 319.

(202) Liu, C.; Chen, W.; Wu, Z.; Gao, B.; Hu, X.; Shi, Z.; Wang, Z. Density, Viscosity and Electrical Conductivity of AICl3-Amide Ionic Liquid Analogues. J. Mol. Liq. 2017, 247, 57-63.

(203) Angell, M.; Zhu, G.; Lin, M. C.; Rong, Y.; Dai, H. Ionic Liquid Analogs of AlCl3 with Urea Derivatives as Electrolytes for Aluminum Batteries. Adv. Funct. Mater. 2020, 30.

(204) Li, C.; Patra, J.; Li, J.; Rath, P. C.; Lin, M. H.; Chang, J. K. A Novel Moisture-Insensitive and LowCorrosivity lonic Liquid Electrolyte for Rechargeable Aluminum Batteries. Adv. Funct. Mater. 2020, 30. 
(205) Kitada, A.; Nakamura, K.; Fukami, K.; Murase, K. AlCl3-Dissolved Diglyme as Electrolyte for RoomTemperature Aluminum Electrodeposition. Electrochemistry 2014, 82, 946-948.

(206) Kitada, A.; Nakamura, K.; Fukami, K.; Murase, K. Electrochemically Active Species in Aluminum Electrodeposition Baths of AICl3/Glyme Solutions. Electrochim. Acta 2016, 211, 561-567.

(207) Kravchyk, K. V.; Kovalenko, M. V. Aluminum Electrolytes for Al Dual-Ion Batteries. Commun. Chem. 2020, 3, 1-9.

(208) Zhang, Z.; Kitada, A.; Gao, S.; Fukami, K.; Tsuji, N.; Yao, Z.; Murase, K. A Concentrated AlCl3-Diglyme Electrolyte for Hard and Corrosion-Resistant Aluminum Electrodeposits. ACS Appl. Mater. Interfaces 2020, 12, 43289-43298.

(209) Wen, X.; Liu, Y.; Xu, D.; Zhao, Y.; Lake, R. K.; Guo, J. Room-Temperature Electrodeposition of Aluminum via Manipulating Coordination Structure in AlCl3 Solutions. J. Phys. Chem. Lett. 2020, 11, 1589-1593.

(210) Bogolowski, N.; Drillet, J. F. Activity of Different AICl3-Based Electrolytes for the Electrically Rechargeable Aluminium-Air Battery. Electrochim. Acta 2018, 274, 353-358.

(211) Mori, R. Recent Developments for Aluminum - Air Batteries. 2020, 344-369.

(212) Chu, W.; Zhang, X.; Wang, J.; Zhao, S.; Liu, S.; Yu, H. A Low-Cost Deep Eutectic Solvent Electrolyte for Rechargeable Aluminum-Sulfur Battery. Energy Storage Mater. 2019, 22, 418-423.

(213) Bian, Y.; Li, Y.; Yu, Z.; Chen, H.; Du, K.; Qiu, C.; Zhang, G.; Lv, Z.; Lin, M. C. Using an AICl3/Urea lonic Liquid Analog Electrolyte for Improving the Lifetime of Aluminum-Sulfur Batteries. ChemElectroChem 2018, 5, 3607-3611.

(214) Zhao, J.; Zhang, J.; Yang, W.; Chen, B.; Zhao, Z.; Qiu, H.; Dong, S.; Zhou, X.; Cui, G.; Chen, L. "Waterin-Deep Eutectic Solvent" Electrolytes Enable Zinc Metal Anodes for Rechargeable Aqueous Batteries. Nano Energy 2019, 57, 625-634.

(215) Wan, F.; Zhou, X.; Lu, Y.; Niu, Z.; Chen, J. Energy Storage Chemistry in Aqueous Zinc Metal Batteries. ACS Energy Lett. 2020, 5, 3569-3590.

(216) Kao-ian, W.; Pornprasertsuk, R.; Thamyongkit, P.; Maiyalagan, T.; Kheawhom, S. Rechargeable ZincIon Battery Based on Choline Chloride-Urea Deep Eutectic Solvent. J. Electrochem. Soc. 2019, 166, A1063-A1069.

(217) Bozzini, B.; Kazemian, M.; Kiskinova, M.; Kourousias, G.; Mele, C.; Gianoncelli, A. Operando Soft XRay Microscope Study of Rechargeable Zn-Air Battery Anodes in Deep Eutectic Solvent Electrolyte. $X$-Ray Spectrom. 2019, 48, 527-535.

(218) Ghareh Bagh, F. S.; Shahbaz, K.; Mjalli, F. S.; Hashim, M. A.; Alnashef, I. M. Zinc (II) Chloride-Based Deep Eutectic Solvents for Application as Electrolytes: Preparation and Characterization. J. Mol. Liq. 2015, 204, 76-83.

(219) Qiu, H.; Du, X.; Zhao, J.; Wang, Y.; Ju, J.; Chen, Z.; Hu, Z.; Yan, D.; Zhou, X.; Cui, G. Zinc AnodeCompatible in-Situ Solid Electrolyte Interphase via Cation Solvation Modulation. Nat. Commun. 2019, 10.

(220) Zhang, J.; Zhao, J.; Du, H.; Zhang, Z.; Wang, S.; Cui, G. Amide-Based Molten Electrolyte with Hybrid 
Active lons for Rechargeable Zn Batteries. Electrochim. Acta 2018, 280, 108-113.

(221) Gan, F.; Chen, K.; Li, N.; Wang, Y.; Shuai, Y.; He, X. Low Cost lonic Liquid Electrolytes for Rechargeable Aluminum/Graphite Batteries. Ionics (Kiel). 2019, 25, 4243-4249.

(222) Xu, H.; Bai, T.; Chen, H.; Guo, F.; Xi, J.; Huang, T.; Cai, S.; Chu, X.; Ling, J.; Gao, W.; et al. Low-Cost $\mathrm{AlCl} 3 / \mathrm{Et} 3 \mathrm{NHCl}$ Electrolyte for High-Performance Aluminum-Ion Battery. Energy Storage Mater. 2019, $17,38-45$.

(223) Guo, Q.; Kim, K.-I.; Li, S.; Scida, A. M.; Yu, P.; Sandstrom, S. K.; Zhang, L.; Sun, S.; Jiang, H.; Ni, Q.; et al. Reversible Insertion of I-Cl Interhalogen in a Graphite Cathode for Aqueous Dual-Ion Batteries. ACS Energy Lett. 2021, 459-467.

(224) Hayyan, M.; Hashim, M. A.; Hayyan, A.; Al-Saadi, M. A.; AlNashef, I. M.; Mirghani, M. E. S.; Saheed, O. K. Are Deep Eutectic Solvents Benign or Toxic? Chemosphere 2013, 90, 2193-2195.

(225) Wen, Q.; Chen, J. X.; Tang, Y. L.; Wang, J.; Yang, Z. Assessing the Toxicity and Biodegradability of Deep Eutectic Solvents. Chemosphere 2015, 132, 63-69.

(226) De Morais, P.; Gonçalves, F.; Coutinho, J. A. P.; Ventura, S. P. M. Ecotoxicity of Cholinium-Based Deep Eutectic Solvents. ACS Sustain. Chem. Eng. 2015, 3, 3398-3404.

(227) Mbous, Y. P.; Hayyan, M.; Wong, W. F.; Looi, C. Y.; Hashim, M. A. Unraveling the Cytotoxicity and Metabolic Pathways of Binary Natural Deep Eutectic Solvent Systems. Sci. Rep. 2017, 7, 1-14.

(228) Kudłak, B.; Owczarek, K.; Namieśnik, J. Selected Issues Related to the Toxicity of lonic Liquids and Deep Eutectic Solvents-a Review. Environ. Sci. Pollut. Res. 2015, 22, 11975-11992.

(229) Dominko, R.; Bitenc, J.; Berthelot, R.; Gauthier, M.; Pagot, G.; Di Noto, V. Magnesium Batteries: Current Picture and Missing Pieces of the Puzzle. J. Power Sources 2020, 478.

(230) Stievano, L.; de Meatza, I.; Bitenc, J.; Cavallo, C.; Brutti, S.; Navarra, M. A. Emerging Calcium Batteries. J. Power Sources 2021, 482.

(231) Arroyo-De Dompablo, M. E.; Ponrouch, A.; Johansson, P.; Palacín, M. R. Achievements, Challenges, and Prospects of Calcium Batteries. Chem. Rev. 2020, 120, 6331-6357.

(232) Navarro-Suárez, A. M.; Johansson, P. Perspective-Semi-Solid Electrolytes Based on Deep Eutectic Solvents: Opportunities and Future Directions. J. Electrochem. Soc. 2020, 167, 070511.

(233) Sim, L. N.; Yahya, R.; Arof, A. K. Infrared Studies of Polyacrylonitrile-Based Polymer Electrolytes Incorporated with Lithium Bis(Trifluoromethane)Sulfonimide and Urea as Deep Eutectic Solvent. Opt. Mater. (Amst). 2016, 56, 140-144.

(234) Joos, B.; Volders, J.; Da Cruz, R. R.; Baeten, E.; Safari, M.; Van Bael, M. K.; Hardy, A. T. Polymeric Backbone Eutectogels as a New Generation of Hybrid Solid-State Electrolytes. Chem. Mater. 2020, 32, 3783-3793.

(235) Joos, B.; Vranken, T.; Marchal, W.; Safari, M.; Van Bael, M. K.; Hardy, A. T. Eutectogels: A New Class of Solid Composite Electrolytes for Li/Li-Ion Batteries. Chem. Mater. 2018, 30, 655-662.

(236) Logan, M. W.; Langevin, S.; Tan, B.; Freeman, A. W.; Hoffman, C.; Trigg, D. B.; Gerasopoulos, K. UVCured Eutectic Gel Polymer Electrolytes for Safe and Robust Li-lon Batteries. J. Mater. Chem. A 2020, 
8, 8485-8495.

(237) Miguel, Á.; García, N.; Gregorio, V.; López-Cudero, A.; Tiemblo, P. Tough Polymer Gel Electrolytes for Aluminum Secondary Batteries Based on Urea: $\mathrm{AlCl} 3$, Prepared by a New Solvent-Free and Scalable Procedure. Polymers (Basel). 2020, 12.

(238) Ruiz-Olles, J.; Slavik, P.; Whitelaw, N. K.; Smith, D. K. Self-Assembled Gels Formed in Deep Eutectic Solvents: Supramolecular Eutectogels with High lonic Conductivity. Angew. Chemie - Int. Ed. 2019, $58,4173-4178$.

(239) Smirnov, M. A.; Nikolaeva, A. L.; Vorobiov, V. K.; Bobrova, N. V.; Abalov, I. V.; Smirnov, A. V.; Sokolova, M. P. Ionic Conductivity and Structure of Chitosan Films Modified with Lactic Acid-Choline Chloride NADES. Polymers (Basel). 2020, 12.

(240) Selvanathan, V.; Azzahari, A. D.; Adyani, A. A.; Yahya, R. Ternary Natural Deep Eutectic Solvent (NADES) Infused Phthaloyl Starch as Cost Efficient Quasi-Solid Gel Polymer Electrolyte. Carbohydr. Polym. 2017, 167, 210-218.

(241) Gachuz, E. J.; Castillo-Santillán, M.; Juarez-Moreno, K.; Maya-Cornejo, J.; Martinez-Richa, A.; Andrio, A.; Compañ, V.; Mota-Morales, J. D. Electrical Conductivity of an All-Natural and Biocompatible Semi-Interpenetrating Polymer Network Containing a Deep Eutectic Solvent. Green Chem. 2020, 22, 5785-5797.

(242) Abbott, A. P.; Frisch, G.; Hartley, J.; Karim, W. O.; Ryder, K. S. Anodic Dissolution of Metals in lonic Liquids. Prog. Nat. Sci. Mater. Int. 2015, 25, 595-602.

(243) Haerens, K.; Matthijs, E.; Binnemans, K.; Van der Bruggen, B. Electrochemical Decomposition of Choline Chloride Based Ionic Liquid Analogues. Green Chem. 2009, 11, 1357-1365.

(244) Di Marino, D.; Shalaby, M.; Kriescher, S.; Wessling, M. Corrosion of Metal Electrodes in Deep Eutectic Solvents. Electrochem. commun. 2018, 90, 101-105. 